UN IRP Assessment of Resource Efficiency and Climate Change Mitigation (RECC) for G7, India, and China

\title{
Documentation of part IV of the RECC model framework: Open Dynamic Material Systems Model for the Resource Efficiency-Climate Change Nexus (ODYM-RECC), v2.2
}

\author{
Stefan Pauliuk* \\ with input from the entire RECC modelling team, in particular: Niko \\ Heeren, Tomer Fishman, Qingshi Tu, Paul Wolfram, Peter Berrill, and \\ Edgar Hertwich \\ Freiburg (Breisgau), Germany, January 21 $1^{\text {st }}, 2020$
}

This report contains the documentation of the ODYM-RECC model version 2.2, used to generate the RECC scenarios for the IRP report "Resource Efficiency and Climate Change - Material Efficiency Strategies for a Low-Carbon Future"

\footnotetext{
*) stefan.pauliuk@indecol.uni-freiburg.de

Faculty of Environment and Natural Resources, University of Freiburg

Tennenbacher Strasse 4

D-79106 Freiburg, Germany.
}

Link to UNEP-IRP Report:

https://www.resourcepanel.org/reports/resource-efficiency-and-climate-change 


\section{Table of Contents}

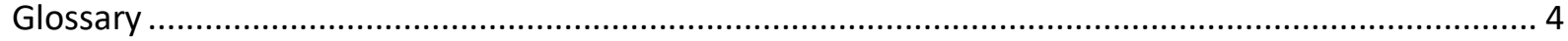

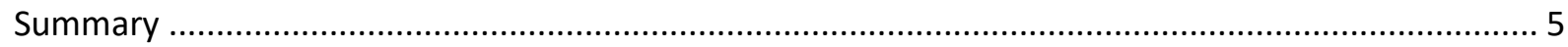

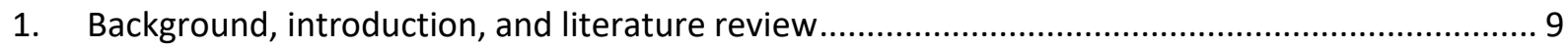

1.1. Literature review: Previous approaches to modelling material efficiency on the large scale 9

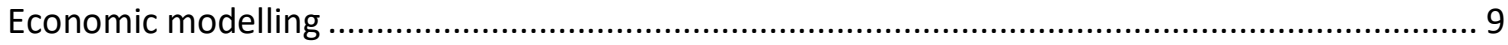

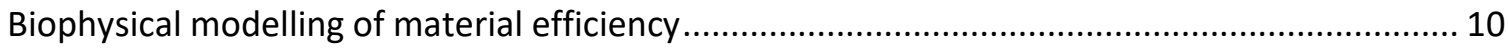

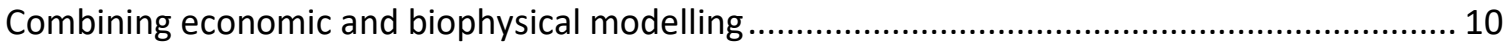

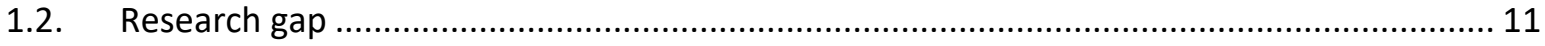

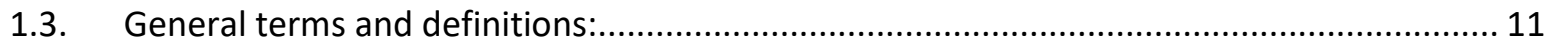

1.3.1. Our scoping of the term resource efficiency........................................................... 11

1.3.2. Our scoping of the term material efficiency ............................................................ 12

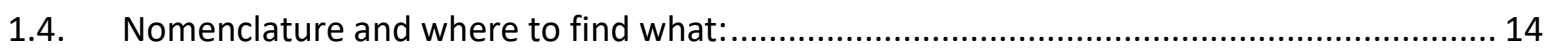

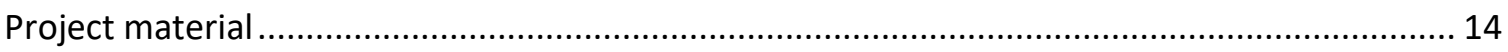

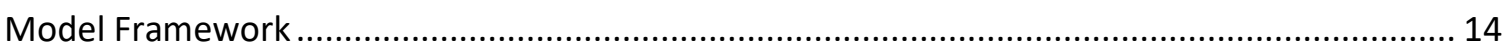

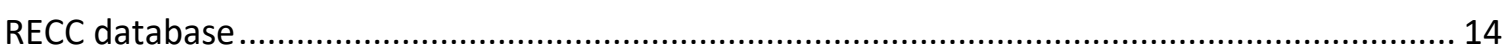

2. Research questions, and project structure ....................................................................... 15

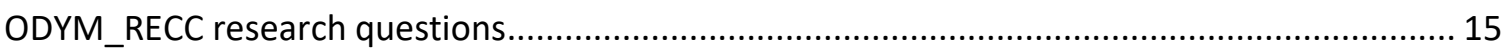

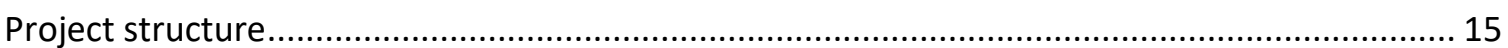

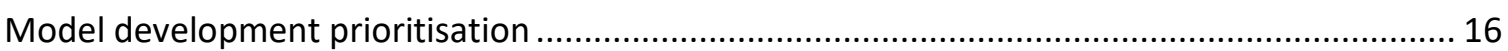

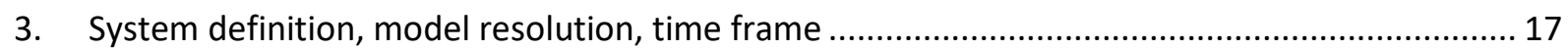

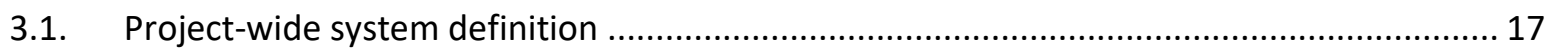

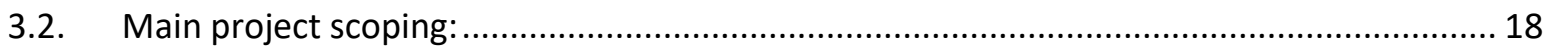

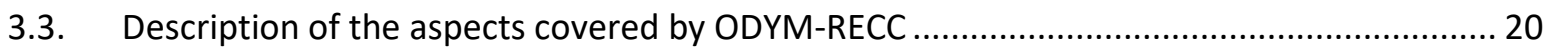

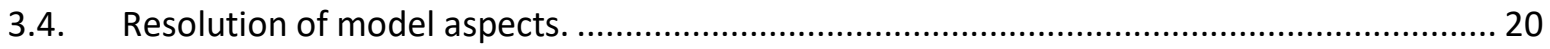

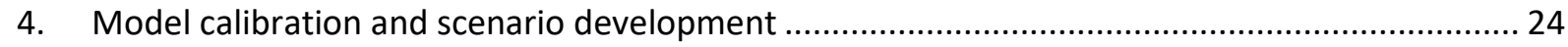

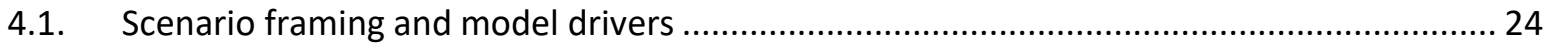

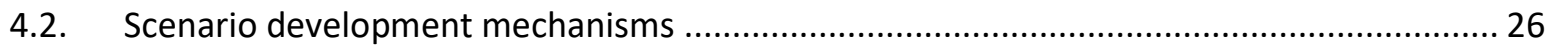

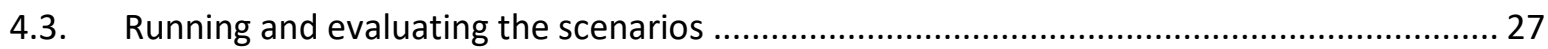

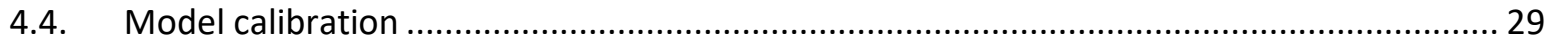

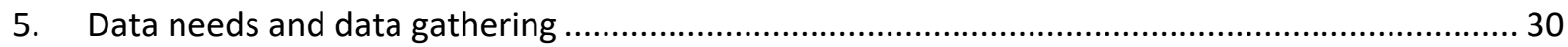

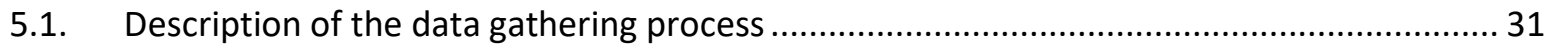

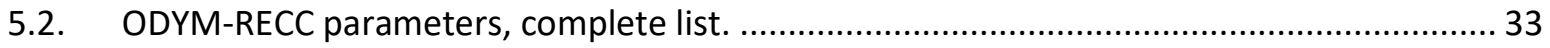

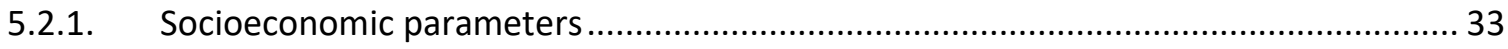

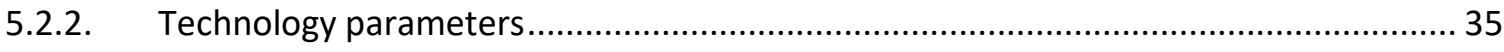

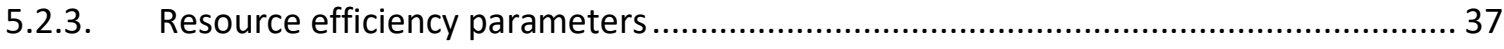

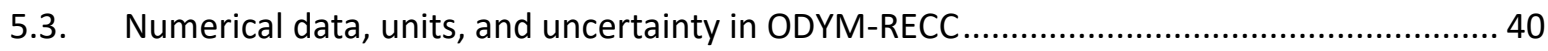


5.4. ODYM-RECC parameter list and rationales ...................................................... 41

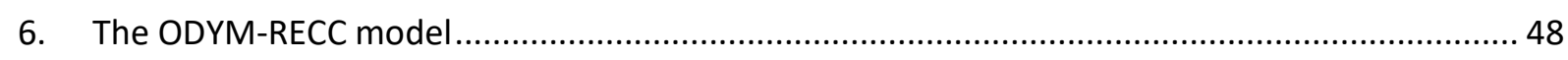

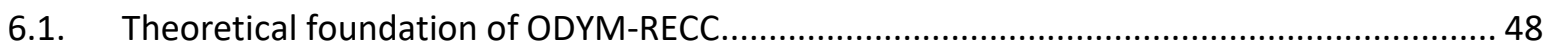

6.2. Reference to methods and software used.............................................................. 49

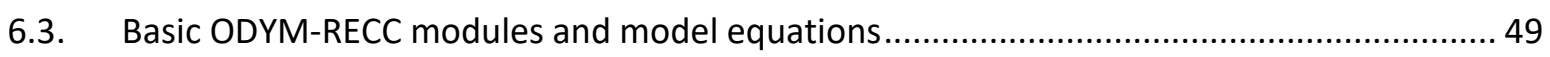

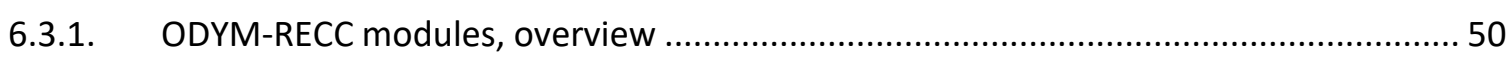

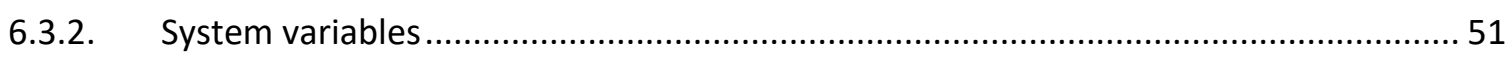

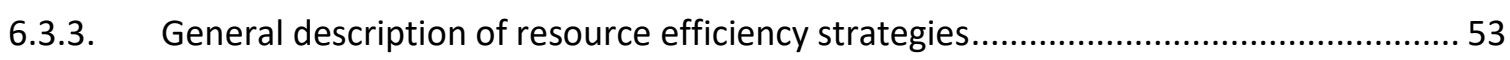

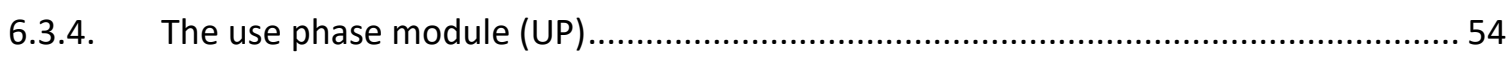

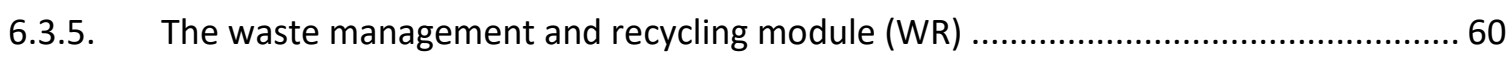

6.3.6. Link to service provision and energy consumption (module EX) .............................61

6.3.7. Manufacturing (MF module) and the closure of the recycling loop ..........................62

6.3.8. Link to material composition of products and materials (ME module) .....................63

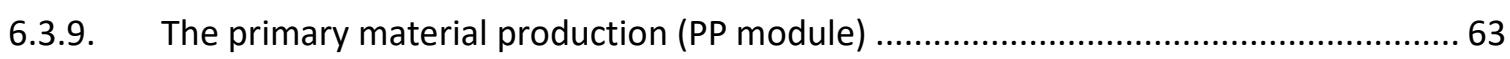

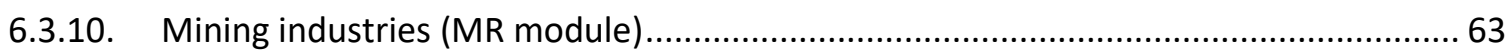

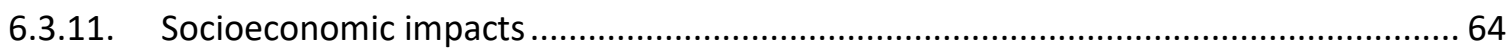

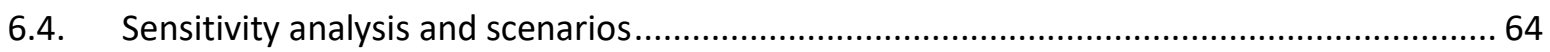

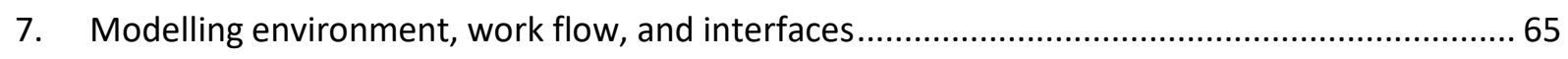

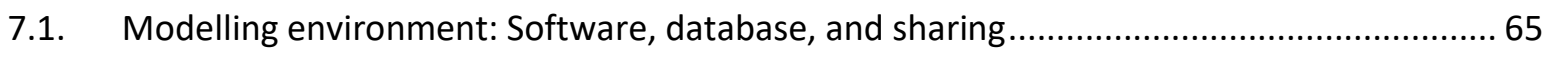

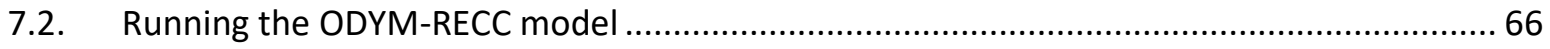

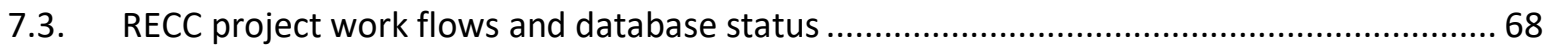

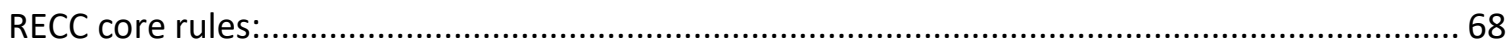

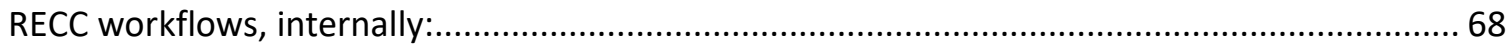

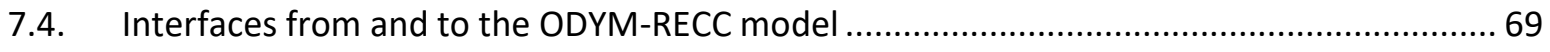

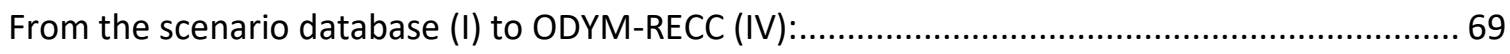

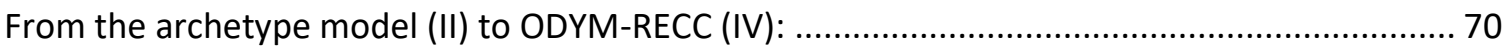

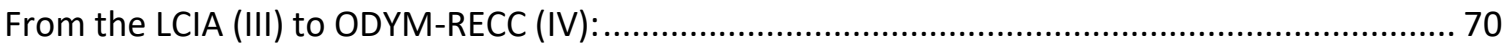

8. Outlook, future model expansion and development ..................................................... 71

8.1. Expanding the scope of the ODYM-RECC model ..................................................... 71

8.2. Expanding the capabilities of the ODYM-RECC model .............................................. 71

8.3. Interface to other modelling frameworks ............................................................. 71

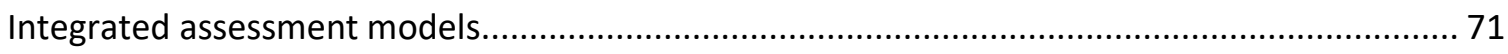

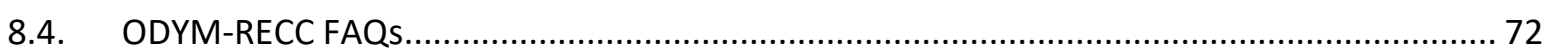

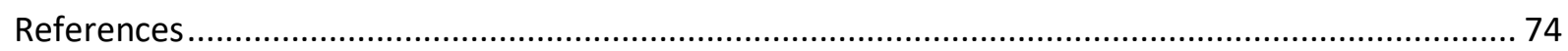




\section{Glossary}

BAU Business-as-usual (scenario baseline)

EoL End-of-life, referring to a product after the end of its useful life: end-of-life product

LED Low energy demand, a scenario for low energy demand for decent living standards published by Grubler et al. (2018).

ME Material efficiency, increasing the ratio of useful output/service by material input

ODYM Open Dynamic material systems model, a Python toolbox for dynamic material flow analysis (Pauliuk and Heeren, 2019)

Primary material, primary production: Material produced from virgin (mineral) resources

RE Resource efficiency, increasing the ratio of useful output/service by resource input

RECC Resource efficiency and climate change mitigation

RES Resource efficiency strategy

Secondary material, secondary production: Material produced from scrap, both fabrication and postconsumer scrap

SSP Shared socioeconomic pathway, a comprehensive scenario storyline for future human and societal development, developed and used mostly by the climate change mitigation / integrated assessment modelling community. 


\section{Summary}

\section{ODYM-RECC model}

The ODYM-RECC model (open dynamic material systems model for the resource efficiency and climate change mitigation project) is a modular depiction of major end-use sectors and the material cycles for the climate-relevant bulk materials (Pauliuk and Heeren, 2019) (https://github.com/YaleCIE/RECCODYM). Its system definition [Fig. 0.1] comprises the use phase of materials (in products) and the material cycle stages mining, primary production, manufacturing, waste management and scrap recovery, and remelting/recycling as well as an energy supply scenario.

ODYM-RECC generates a set of what-if scenarios (Börjeson et al., 2006) for the climate-relevant enduse sectors and bulk material cycles against different socioeconomic, technology deployment, and climate policy backgrounds. It does so by applying a mass-balanced framework for the material cycles (Brunner and Rechberger, 2016). It allows us to study the impacts of a broad spectrum of sustainable development strategies on the material cycles and identify trade-offs and constraints. It does not assess the likelihood of realisation of any of the scenarios studied but checks if mass balance constraints (e.g. by long product lifetimes or limited scrap supply) render some scenarios unfeasible from a material cycle point of view.

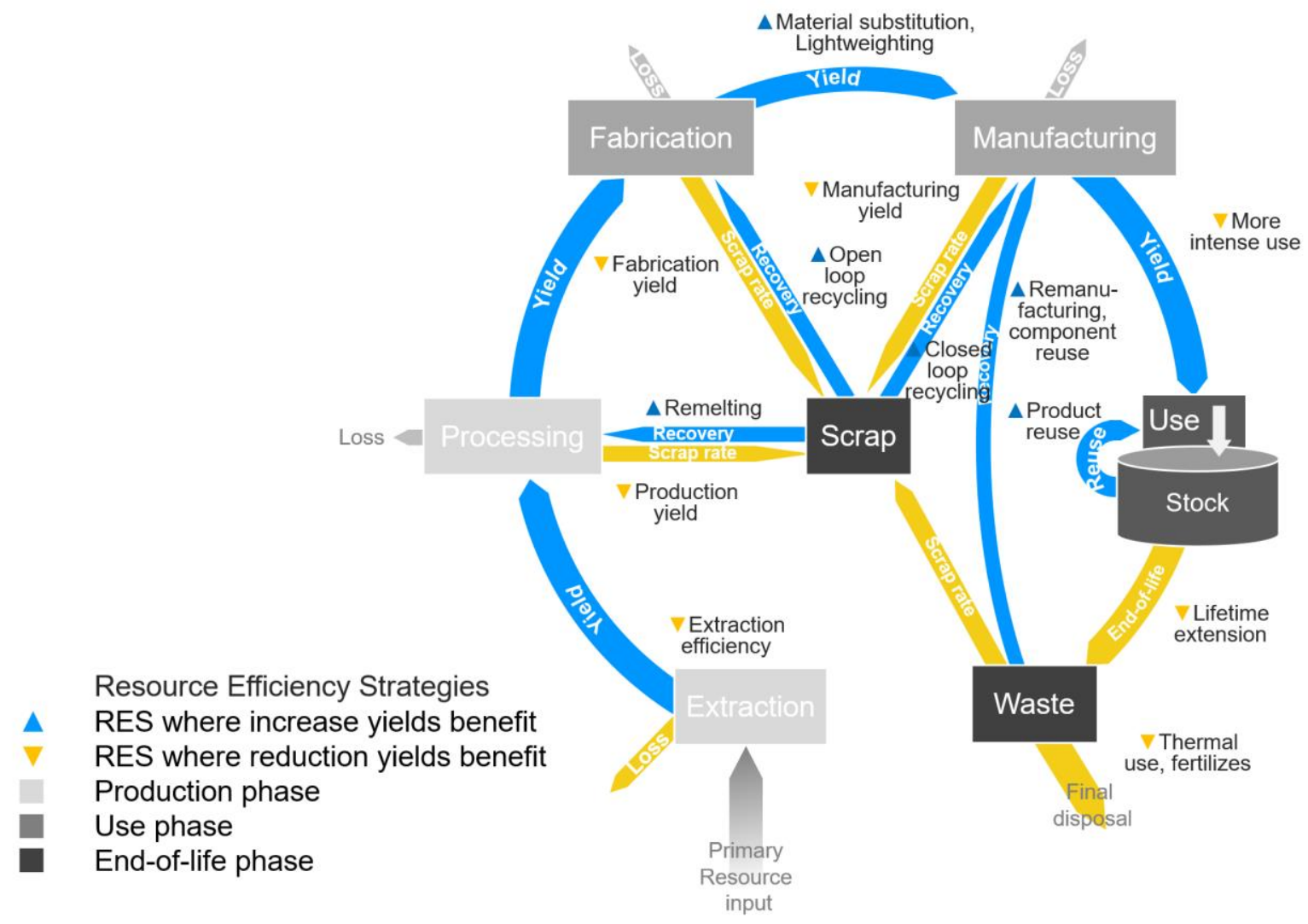

Figure 0.1: System definition of ODYM-RECC assessment with processes and flows studied, resource efficiency strategies, and the modelling approaches taken for the computation of the material cycle response to resource efficiency. Inspired by Allwood et al. (Allwood et al., 2012) and Reck and Graedel (Reck and Graedel, 2012). Figure drawn by Tomer Fishman for the RECC project.

ODYM-RECC is a multi-layer model depicting products, materials, chemical elements, energy flows, and emissions, with mass balance across all processes down to the individual chemical element. 
ODYM-RECC has six modules that quantify the system in Fig. 0.1 by translating a given service scenario into product stocks, inflows and outflows (module 'use phase UP', using stock-driven modelling (Müller, 2006), product outflows into scrap and recycled materials (module 'waste management and recycling $W^{\prime}$ ', using parameter equations), product inflows into material demand and fabrication scrap (module 'manufacturing MF' using parameter equations), material demand into primary production and related impacts (module 'primary production PP', using environmental extension factors), and by determining the chemical element composition of al stocks and flows (module 'material-element composition $\mathrm{ME}^{\prime}$, using mass balance). Finally, the energy consumption and environmental pressure and impact indicators are calculated (module 'energy and extensions EX').

For the RECC project, 20 data aspects (time, age-cohort, process, material, chemical element, waste/scrap, environmental extension, socioeconomic scenario...) were defined and each of the 40 model parameters has a specific data model that links it to the data aspects. For example, the parameter for the product lifetime extension potential has the three aspects 'product', 'region', and 'scenario. The parameter for the future stock levels needed has the four aspects 'scenario', 'product', 'region', and 'time'. The resolution of each data aspect is defined in the model config file, a summary is given in Table 0.1 .

Table 0.1: ODYM-RECC model and data resolution.

\begin{tabular}{|l|l|}
\hline Model and data aspect & Resolution \\
\hline Time & 2016-2060 in steps of 1 year \\
\hline Age-cohorts/Vintages & Vehicles: 1980-2060, residential buildings: 1900-2060 \\
\hline Regions & All G7 countries, individual and as an ensemble, India, China \\
\hline Products & 6 passenger vehicle types and 9 residential building types \\
\hline Engineering materials & $\begin{array}{l}\text { construction grade steel, automotive steel, stainless steel, cast } \\
\text { iron, wrought Al, cast Al, copper electric grade, plastics, wood } \\
\text { and wood products, zinc, concrete }\end{array}$ \\
\hline Waste and scrap types & $\begin{array}{l}\text { heavy melt, plate, and structural steel scrap; steel shred; Al } \\
\text { extrusion scrap, auto rims, clean; Al old sheet and construction } \\
\text { waste; Al old cast; copper wire scrap; construction waste, } \\
\text { concrete, bricks, tiles, ceramics }\end{array}$ \\
\hline Chemical elements & C, Al, Cr, Fe, Cu, Zn, 'other' \\
\hline Energy carriers & $\begin{array}{l}\text { Electricity, coal, hard coal, diesel, gasoline, natural gas, } \\
\text { hydrogen, fuel wood }\end{array}$ \\
\hline Service categories & $\begin{array}{l}\text { Driving (vehicles), heating, cooling, domestic hot water } \\
\text { (residential buildings) }\end{array}$ \\
\hline Scenarios & $\begin{array}{l}\text { Socioeconomic: Low energy demand (LED), SSP1, SSP2 } \\
\text { Climate policy: No policy after 2020 (reference scenario), 2 } \\
\text { degrees Celsius (66\%), corrs. to RCP2.6 forcing pathway. }\end{array}$ \\
\hline
\end{tabular}

The model parameters are linked to the system variables (stocks and flows shown in Fig. 0.1) via the model equations, which are grouped into the five ODYM-RECC modules. The parameters are divided into three groups: socioeconomic parameters such as future population, service demand, or intensity of operation of stocks (e.g. vehicle-km per year), technology parameters like energy efficiency of stock operation of the future emissions intensity of energy supply, and resource efficiency parameters describing both the potential for resource efficiency at the different stages of the system (green boxes in Fig. 0.1), and the speed of implementation of these potentials under different socioeconomic and climate policy scenarios. 
Each RE strategy can be implemented separately or as part of a cascade of strategies. The model allows for calculating the impact of one strategy at a time (sensitivity analysis) or a bundle of strategies in different orders of implementation, each for different socioeconomic and climate policy scenarios.

Once the first results are mature the model and the corresponding database (barring confidential data) will be released under a permissive license on https://github.com/YaleCIE/RECC-ODYM and on Zenodo:

UNEP-IRP Report input database: https://zenodo.org/record/3566865, DOI 10.5281/zenodo.3566865 UNEP-IRP Report results: https://zenodo.org/record/3566859, DOI 10.5281/zenodo.3566859

\section{The ODYM-RECC Database}

The ODYM-RECC v2.2 database contains 56 model parameters of two to six dimensions each. Parameters range from static values (direct emissions of combustion by MJ of energy carrier) to highly detailed highly uncertain datasets (e.g., the future energy carrier split of buildings by region, time, and operation mode (heating/cooling/hot water).

The ODYM-RECC database was compiled as a community effort involving a large number of experts. Its scope is unprecedented in the industrial ecology community. Data templates and project wide classifications were used to facilitate the compilation of the various types of information.

Depending on data availability, we applied several pathways of data compilation, which are listed and described in detail below.

- Extract mostly socioeconomic parameters from existing scenario models (scenario reference)

- Compile own plausible scenario estimates for socioeconomic parameters in line with the different scenario narratives where established model framework results are not available (group consensus scenarios)

- Extract process-, product, and material-specific data from the engineering and industrial ecology literature (bottom-up data)

- Extract quantitative estimates of resource efficiency strategy potentials, mostly related to prototypes and case studies, from the literature (strategy potentials)

- Simulate energy consumption and material composition of a number of building and vehicle archetypes with specialised software, which are then used as bottom-up product descriptions with and without implementation of RE strategies (archetype descriptions)

Scenario reference: For the socioeconomic parameters the Shared Socioeconomic Pathways (SSP) database and model results as well as available data from the World Energy Outlook and Energy Technology Perspectives models were used wherever possible, e.g., for future population, future GHG intensity of energy supply, or the drive technology mix for vehicles (IEA, 2015a; O'Neill et al., 2014; OECD/IEA, 2017, 2010a; Riahi et al., 2017a). The data were extracted from available databases (like the SSP scenario database hosted at IIASA:

https://www.iiasa.ac.at/web/home/research/researchPrograms/Energy/SSP Scenario Database.ht $\mathrm{ml}$ ) or shared by colleagues, then parsed and reviewed by the RECC team, then aggregated, disaggregated, and interpolated to fit the ODYM-RECC project-wide classification. For each parameter file the data gathering process is documented both in the respective template files in the RECC database (if only Excel was used), in custom scripts (for more comprehensive datasets) and in the data log files archived under https://github.com/YaleCIE/RECC-data.

Group consensus scenarios: For some parameters like the future stock levels or the split of residential buildings into different types no detailed SSP-consistent scenario calculation was available that we could refer to. Hence we assumed a set of plausible target values for a number of socioeconomic 
parameters in line with the storylines of the individual socioeconomic scenarios. This process is commonly used when translating broad storylines into high product and regional resolution and sector-specific parameters, cf. Riahi et al. (2017a) and Grübler et al. (2018). The target values for 2020, 2030, and 2050 chosen and the rationale for their choice are documented in scenario target tables, one for each parameter. From there, the target values are read, interpolated, smoothed with a moving average, and exported in ODYM format to be directly used in the ODYM-RECC model. The documentation for the individual parameters is archived in https://github.com/YaleCIE/RECC-data.

The open model and data framework allow for third parties to modify the scenario assumptions and to run calculations with custom parameters and storylines.

Bottom-up data: For the energy intensity, emissions intensity, and material composition of products and processes detailed but representative product or process descriptions were compiled from the literature and available databases. These data include the material composition and specific energy consumption of vehicles and buildings, e.g., (Hawkins et al., 2013; Marcellus-Zamora et al., 2016; Reyna and Chester, 2014), the loss and recovery rates for the manufacturing and waste management industries e.g., (Liu et al., 2012; Pauliuk et al., 2013), and the specific energy consumption and process emissions for the manufacturing, waste management, and primary material production industries (IEA, 2015a; OECD/IEA, 2017, 2010b; Wernet et al., 2016). While the data can be regarded as representative of current average global technology, their main limitation is that they are static and no information on their change under different socioeconomic and climate policy scenarios, in particular, is given. To become more realistic a scenario reference was made wherever possible (cf. above), e.g., for the changing GHG intensity of the supply of different energy carriers, for which a combination of MESSAGE IAM results and IEA Energy Technology Perspective results was used. Also, for the average GHG intensity of primary metal production a scenario analysis based on ecoinvent was calculated to take into account scenario-dependent changes of the GHG intensity of electricity generation.

Resource efficiency Strategy potentials: For some parameters, including the improvement potentials for fabrication scrap, end-of-life recovery efficiency of scrap, re-use of steel components in buildings, or product lifetime extension, previous estimates can be used (Milford et al., 2013). For the more intense use of products, the in-use stock curves for the scenario with the next smallest mitigation challenge were used, i.e., SSP1 values in the SSP2 scenario and LED values in the SSP1 scenario.

Archetype descriptions: For the final product categories residential buildings and vehicles, the product-specific simulation tools BuildME and FASTSim were used to derive model estimates for both the material composition and energy intensity of operation for different building and vehicle archetypes. For each of the nine building and six vehicle types four archetypes, representing maximal potential for change, were simulated: a standard product without special consideration of material efficiency, downsizing, or material substitution, a downsized product, a product with ambitious material substitution, and a downsized material-substituted product.

For a detailed description and definition of all model aspects, the classifications used for them, the system variables and parameters, the model equation and their division into modules and the data compilation, (dis)aggregation and formatting process, we refer to the ODYM-RECC model documentation.

The ODYM-RECC database is formatted in standardised spreadsheets and archived on Zenodo (dataset DOIs 10.5281/zenodo.3566865 and 10.5281/zenodo.3566859), barring the confidential and licensed input data, which are available on request. 


\section{Background, introduction, and literature review}

Global human extraction of biomass, minerals, and fossil fuels has risen to more than $90 \mathrm{Gt} / \mathrm{yr}$ and is directly associated with $50 \%$ of all human impact on the climate and $90 \%$ of all biodiversity loss and water stress (UNEP-IRP, 2019).

Due to the sheer magnitude and ubiquity of human resource extraction and processing (OECD, 2019; UNEP-IRP, 2019), their future environmental impacts and mitigation options need to be studied from a systems perspective (Liu et al., 2015). Ambitious global dematerialization scenarios need to be formulated, their system-wide consequences explored, their political feasibility studied, and their impact mitigation opportunities lined out in detail.

Such assessments are already underway. For example, the 2015 World Energy Outlook by the IEA contains a material efficiency scenario (IEA, 2015b), with the following central findings. First, on P26: "Changing product design, re-use and recycling ("material efficiency") also offers huge potential for energy saving; for energy-intensive products such as steel, cement, plastics or aluminium, efficient use and re-use of materials can save more than twice as much energy as can be saved by efficiency measures in the production process to 2040." And on P387: "Achieving greater efficiency in the use of materials through light-weighting, longer life products, re-use and recycling, is an important complementary strategy to energy efficiency in energy-intensive industries, as the potential for energy savings is about twice as large."

To be able to study the system-wide impacts of material use and material efficiency and to robustly quantify the potential of the different mitigation options, the scientific community needs a push in dynamic material cycle modelling. The different resource efficiency, sufficiency, and circular economy strategies and their impact on material cycles, energy use, and environmental damage needs to be understood better, and prospective scenario modelling can make a central contribution to generate such knowledge (Pauliuk and Hertwich, 2016). Current established socioeconomic scenario models, in particular integrated assessment models, do not capture material cycles at the level of detail necessary to answer research question related to the linkage of resource efficiency and climate change (Pauliuk et al., 2017a). The concurrent IRP assessment team states that there is "no known global forwardlooking [built asset] model available" (Hatfield-Dodds et al., 2017a). A recent OECD report comes to a similar conclusion: More detail and better connection between technology-detail ('bottom-up') and aggregated macroeconomic ('top-down') representations is needed (McCarthy et al., 2018).

\subsection{Literature review: Previous approaches to modelling material efficiency on the large scale}

\section{Economic modelling}

Global system wide repercussions of resource efficiency have been captured by a number of general equilibrium approaches. A list and review of recent approaches is given in Wining et al. (2017). It includes the work with computable general equilibrium models (CGE) of Böhringer and Rutherford (Böhringer and Rutherford, 2008), the EllenMcArthur Foundation and McKinsey, EXIOMOD, and GINFORS as approaches to assess resource efficiency in a GCE framework, as well as the econometric model E3ME and the mixed model framework GIAM/GTEM-C. Recent major additions to the literature are the Global Resource Outlooks by the OEDC and the UN IRP, both published in 2019 and built upon a CGE framework (OECD, 2019; UNEP-IRP, 2019). For such works, CGE-based macro-economic models, such as GTEM-C are combined with physical accounts or physical sectoral models (Hatfield-Dodds et al., 2017b, 2015; Schandl et al., 2016), including MEFISTO stock and flow framework (Lennox et al., 2005).

A recent model review by the OECD (McCarthy et al., 2018) found that the material cycle processes relevant for quantifying the economy-wide impacts of material efficiency in a detailed manner are not 
described by these models, hence, such assessments can only give a rough estimate of future material use. They can neither be checked for physical correctness (do the service-providing products actually need that many materials for their production?), nor can the savings potential of the many different material efficiency strategies and policy options be assessed. Clearly, improvements are needed.

Physical detail needs to be added to macro-economic models. Wining et al. (2017) and Schuhmacher and Sands (Schumacher and Sands, 2006) amend CGE models by adding detail about steelmaking, e.g., by disaggregating the steel sector into the primary and secondary production route. (Cooper et al., 2017) use an MRIO approach to study the linkage between circular economy strategies, energy use, and emissions. They do not capture material flows and cycles themselves, as these are not covered by monetary 10 models.

\section{Biophysical modelling of material efficiency}

The biophysical modelling approach uses engineering models as common in industrial ecology, such as prospective life cycle assessments or dynamic material flow analysis, to create a physical linkage between service provision and material flows (the so-called material stock-flow-service nexus) (Haberl et al., 2017). These approaches include much technological detail and estimations of the impact of a number of material efficiency strategies ('bottom-up'). While the number of product-level life cycle assessments that include some kind of material efficiency or other circular economy strategies abounds (e.g., for material substitution in vehicles as reviewed by Kim and Wallington (2013)), there are only some examples of detailed technology-based assessments of material efficiency at the large scale. These include a detailed assessment of material efficiency in the global steel cycle (Milford et al., 2013), a case study for reducing cement demand in the UK (Shanks et al., 2019), and a study on the material efficiency-climate change mitigation link for the climate-relevant bulk materials in the EU (Enkvist and Klevnäs, 2018). Hertwich et al. (2019) provide a comprehensive review of these studies and their findings. The high level of detail of such work allows for a robust estimation of the technical potential of the different strategies in the different sectors, taking into account system effects such as a changing quality of postconsumer scrap or export of excess secondary material to other sectors. Still, it is not clear what the economy-wide potential of such strategies would be, as costs are often not considered. More importantly, the economy-wide consequences of ambitious material efficiency, such as material-related rebound effects (Hertwich, 2005; Zink and Geyer, 2017), are ignored, even by the studies that include costs, leading to potentially flawed (over-optimistic) policy recommendations.

Material efficiency was pushed (again) on the policy agenda (Allwood et al., 2011) and later (Allwood et al., 2012) defined six core material efficiency strategies: more intense use, light-weighting, lifetime extension, re-use, fabrication scrap reduction, and fabrication scrap diversion.

A first global assessment of these six material efficiency strategies was undertaken for the steel cycle (Milford et al., 2013). Material efficiency in the steel cycle could reduce emissions from the steel sector by $50 \%$ in the future compared to present levels, and thus complements the spectrum of emissions mitigation potential with gigaton potential.

Future metal and material demand has been projected and studied from the perspective of different macro-level scenarios (Deetman et al., 2019, 2018; Elshkaki et al., 2018, 2016; Elshkaki and Graedel, 2013; Hatayama et al., 2010; Schipper et al., 2018; van der Voet et al., 2018; Watari et al., 2019), but those assessments are not linked to resource efficiency, but represent a very important starting point for our work, as we can link our scenarios and data to these studies.

\section{Combining economic and biophysical modelling}

The MATTER project, which ran in the Netherlands between 1995 and 1999, aimed at establishing a link between material cycles and energy use and GHG scenarios produced by the MARKAL energy system model (Gielen, 1999; Gielen et al., 1998; Groenendaal and Gielen, 1999; Kram et al., 2001). The 
main finding is that a material-related GHG emissions savings potential of up to $1 \mathrm{Gt}$ exists for Western Europe, including strategies in waste management, material efficiency, and material substitution.

The scope of MATTER was limited to Western Europe, but for an assessment of global climate targets a global scope is needed. MATTER also ignored the coupling between material cycles. Back in the 90ies, the recent development in China, which produces now about half of many bulk metals globally, could not have been anticipated. Technology (dismantling and sorting) and policy (Paris Agreement, circular economy) have advanced significantly since then, and a refined modelling approach is needed now to incorporate the recent progress in resource policy and material flow analysis.

A GDP-driven steel cycle model is now part of the IMAGE integrated assessment framework (Stehfest et al., 2014; van Ruijven et al., 2016), which contains all major steel-related technologies but which is not connected to the rest of the IMAGE scenarios, where buildings, vehicles, and consumer appliances are depicted in detail, thus lacking internal consistency.

Finally, there are some recent attempts to link material consumption to economy-wide models more directly. First, by converting sectoral output of CGE models into material flows by applying product material composition and prices (Cao et al., 2018; Winning et al., 2017), and second, by converting end-user demand for new products provided by energy system models into material flows by applying product material composition data (Deetman et al., 2018; Watari et al., 2019). These attempts are a step in the right direction, but the CGE approaches focus on single economic sectors only and do not consider material cycles and the mitigation potentials therein, and the energy system-based approaches only estimate final demand and currently do not consider the material cycle response.

\subsection{Research gap}

The research described above has led to ad-hoc models describing material systems in a partial and incomplete manner only. A holistic prospective assessment framework for metal cycles is currently lacking. The importance of metals for sustainable development was studied from different angles (cf. above), but these studies were all done in isolation, using only parts of the available data, too narrow system boundaries, and simplified scenario drivers.

Due to the scattered modelling approaches, the field of prospective metal cycle studies is severely underdeveloped (Pauliuk and Hertwich, 2016). The link between prospective material cycle studies and climate policy assessments, especially by integrated assessment models, is almost completely lacking (Pauliuk et al., 2017). The impact of the circular economy on the different material cycles, the very subject of the circular economy, cannot be quantified with the available tools. That lack of modelling capability is problematic as the system-wide benefits of material-specific strategies such as recycling and material efficiency cannot be correctly assessed. The spectrum of GHG mitigation options is artificially (for practical and not for scientific reasons) narrowed down to technologies described by the incumbent integrated assessment models.

It is the job of the modelling team of ODYM-RECC to contribute to filling that gap and to provide to the industrial ecology community a powerful scenario tool for the assessment of resource efficiency and other industrial ecology strategies from a systems perspective.

\subsection{General terms and definitions:}

\subsubsection{Our scoping of the term resource efficiency}

Resource efficiency is a very broad concept, roughly defined as "using the Earth's limited resources in a sustainable manner while minimising impacts on the environment. It allows us to create more with less and to deliver greater value with less input."

(http://ec.europa.eu/environment/resource efficiency/, accessed 2018-01-16) 
In a wider meaning, resources include materials, biomass, and energy across the entire economy, including technical raw materials and primary energy, but also refined materials, products, and refined (secondary) energy. Sometimes, water is also included. That definition includes food and food products. It is understood as material and energy efficiency applied across all economic processes and consumption stages. Exergy is sometimes proposed as a common measure for this type of resource efficiency (Ayres et al., 2006; Gutowski et al., 2009; Wu et al., 2016), but especially for materials quality in terms of physical properties is the desired outcome of the industry, and this objective cannot be captured by exergy efficiency.

In a more narrow sense, resources include material resources across all economic processes and consumption stages, but not water, food, and energy carriers. That means engineering materials, including metals, construction materials and minerals, wood/timber, and man-made materials such as plastics. In this context, resource efficiency is then understood as economy-wide material efficiency (Allwood et al., 2011; Worrell et al., 2016) (Box 1).

Box 1: RE strategy scope.

For the ODYM-RECC assessment resource efficiency is understood as economy-wide (engineering) material efficiency (ME), that means material efficiency across all industries and consumption stages. We also include energy efficiency and the impacts of material efficiency on energy use, as the link between materials and energy is particularly important when assessing the system-wide impacts of $M E$ strategies from a life cycle perspective.

The System boundary of ODYM-RECC spans the entire industrial system from the environmenttechnosphere boundary to the services provided to final consumers, which is identical to the system scope of the life cycle inventory of products and services (service level described as functional unit to elementary flows). This overlap of system boundaries is crucial to the combination of the material cycle and product life cycle perspectives.

The resource efficiency scope ME includes all the $3 R$ (reduce, reuse, recycle), $6 R, 9 R$ (rethink, reduce, reuse, repair, refurbish, remanufacture, repurpose, recycle, and recover) and other circular economy strategies.

\subsubsection{Our scoping of the term material efficiency}

The RECC project will investigate core material efficiency strategies in the use phase of products and the material cycles of bulk materials (cement, steel, plastics, ...) (Allwood et al., 2012). The list of strategies considered and their definitions and implementations for residential buildings and vehicles is listed below in Table 1.1. 
Table 1.1: The ten material efficiency strategies considered in ODYM-RECC V2.2.

\begin{tabular}{|c|c|c|}
\hline Strategy & Buildings & Vehicles \\
\hline $\begin{array}{l}\text { Using less material by light- } \\
\text { weighting through improved } \\
\text { design and/or downsizing, } \\
\text { ULD }\end{array}$ & $\begin{array}{l}\text { Optimized Design: Using less material } \\
\text { by better design and engineering } \\
\text { without loss in functionality }\end{array}$ & $\begin{array}{l}\text { Segment shift from large vehicles } \\
\text { (light trucks, sports utility vehicles) to } \\
\text { smaller ones (passenger cars). }\end{array}$ \\
\hline \multirow[t]{2}{*}{$\begin{array}{l}\text { Less material through light- } \\
\text { weighting by material } \\
\text { substitution, MSu }\end{array}$} & \multicolumn{2}{|c|}{$\begin{array}{l}\text { Implementation differs for the two models. For buildings, materials with } \\
\text { lower life-cycle emissions are being used. For vehicles, material is substituted } \\
\text { to achieve less operational energy demand. }\end{array}$} \\
\hline & $\begin{array}{l}\text { Wooden buildings have less life-cycle } \\
\text { emissions than concrete or brick } \\
\text { buildings. While other material } \\
\text { options exist, wood is particularly } \\
\text { effective because of the carbon } \\
\text { sequestration. Regional limits to } \\
\text { wood supply are taken into account. }\end{array}$ & $\begin{array}{l}\text { Replacing steel with aluminum or } \\
\text { high-strength steel (not considered } \\
\text { here) reduces life-cycle emissions } \\
\text { due to weight reduction and } \\
\text { subsequent fuel savings in the use } \\
\text { phase }\end{array}$ \\
\hline $\begin{array}{l}\text { Fabrication yield } \\
\text { improvement, FYI }\end{array}$ & \multicolumn{2}{|c|}{$\begin{array}{l}\text { Fabrication yield improvements }(\mathrm{FYI}) \text { reduces the amount of material scrap in } \\
\text { the fabrication and manufacturing process, thereby lessening the demand for } \\
\text { material input to the manufacturing sector. }\end{array}$} \\
\hline $\begin{array}{l}\text { End-of-life recovery rate } \\
\text { improvement, EoL }\end{array}$ & \multicolumn{2}{|c|}{$\begin{array}{l}\text { End-of-life recovery rate improvement (EoL) increases the share of materials } \\
\text { salvaged as scrap from end-of-life products }\end{array}$} \\
\hline $\begin{array}{l}\text { Fabrication scrap diversion, } \\
\text { FSD }\end{array}$ & \multicolumn{2}{|c|}{$\begin{array}{l}\text { Large pieces of manufacturing scrap, like trimmings or cuttings, can be } \\
\text { diverted into other manufacturing units for manufacturing smaller } \\
\text { components from them. This avoids the remelting step and potentially } \\
\text { reduces costs. }\end{array}$} \\
\hline Car-sharing, CaS & \multicolumn{2}{|c|}{ Shift away from the personal car to the use of cars from a shared fleet } \\
\hline Ride-sharing, RiS & \multicolumn{2}{|c|}{$\begin{array}{l}\text { Driving patterns where people with same or similar driving destinations share } \\
\text { a ride. Different from ride-hailing, which is a modified taxi service. }\end{array}$} \\
\hline More intensive use, MIU & \multicolumn{2}{|c|}{$\begin{array}{l}\text { MIU implies that fewer products are required to provide the same basic } \\
\text { service. For buildings, peer-to-peer lodging is a potential strategy, in addition } \\
\text { to steps such as increased household size/cohabitation, and a reduction of } \\
\text { second homes. }\end{array}$} \\
\hline $\begin{array}{l}\text { Product lifetime extension, } \\
\text { LTE }\end{array}$ & \multicolumn{2}{|c|}{ Better design, increased repair, enhanced secondary markets. } \\
\hline $\begin{array}{l}\text { Recovery, remanufacturing, } \\
\text { and reuse of components, } \\
\text { ReU }\end{array}$ & \multicolumn{2}{|c|}{ Replacing the production of spare parts or even primary products. } \\
\hline
\end{tabular}


A detailed description of the implementation of the different strategies can be found in the model and data description chapters below.

\subsection{Nomenclature and where to find what:}

\section{Project material}

A general publicly available project description can be found here:

https://cie.research.yale.edu/project main/resource-efficiency-climate-change

There are three public repositories for the project material:

1. A GitHub public page (https://github.com/YaleCIE/RECC-public) to share publicly available material like publications, documentation, posters, talks, and other.

2. The GitHub repository with the ODYM-RECC model code: https://github.com/YaleCIE/RECC-ODYM

3. The database of the project, archived on Zenodo (dataset DOIs 10.5281/zenodo.3566865 and 10.5281/zenodo.3566859).

Internally (for project team members), there is another repo mainly used for data documenation: https://github.com/YaleCIE/RECC-data as well as an internal shared folder \Dropbox〉G7 RECC〉, where the data, all project documents, and the main results are stored.

\section{Model Framework}

We distinguish between the model framework, which is general for dynamic MFA, and its application for this project.

The name of the general model framework is

\section{ODYM - Open Dynamic Material Systems Model}

The public repository on GitHub (https://github.com/indecol/odym/) hosts the software framework ODYM. A publication on ODYM is also available (Pauliuk and Heeren, 2019).

For our common project we use the acronym

\section{RECC - Resource efficiency and Climate Change Mitigation}

The service-material cycle-climate model used for this project is then

\section{ODYM-RECC}

The ODYM-RECC model is hosted on GitHub in an open repository: https://github.com/YaleCIE/RECCODYM

\section{RECC database}

All 56 ODYM-RECC v2.2 parameters are formatted into the same general data model (Pauliuk et al., 2019) and are available as Excel templates, through which they are parsed by the model. The current ODYM-RECC database is stored on the common Dropbox folder \Dropbox\G7 RECC\Data. The database of the model version 2.2 is archived on Zenodo (dataset DOIs 10.5281/zenodo.3566865 and 10.5281/zenodo.3566859). 


\section{Research questions, and project structure}

The ODYM-RECC research questions are listed below in Box 2.

Box 2: Research questions for ODYM-RECC, part IV of the model framework.

\section{ODYM_RECC research questions}

The following research questions are guiding model development, data gathering, and scenario analysis for ODYM-RECC:

RQ1) What is the impact of the different material efficiency strategies on material cycles, energy use, and GHG emissions for different socioeconomic scenarios until 2060?

RQ2) How large are the trade-offs and co-benefits of the different material efficiency strategies when implemented together?

RQ3) What socioeconomic or lifestyle changes translate directly into lower material use and what are the possible GHG savings until 2060?

RQ4) How big is the impact of material efficiency strategies on burden shifting across economic sectors and on the life cycle performance indicators of products and services?

\section{Project structure}

The RECC model framework and database consist of four modules, whose interaction is depicted in Figure 2.1:

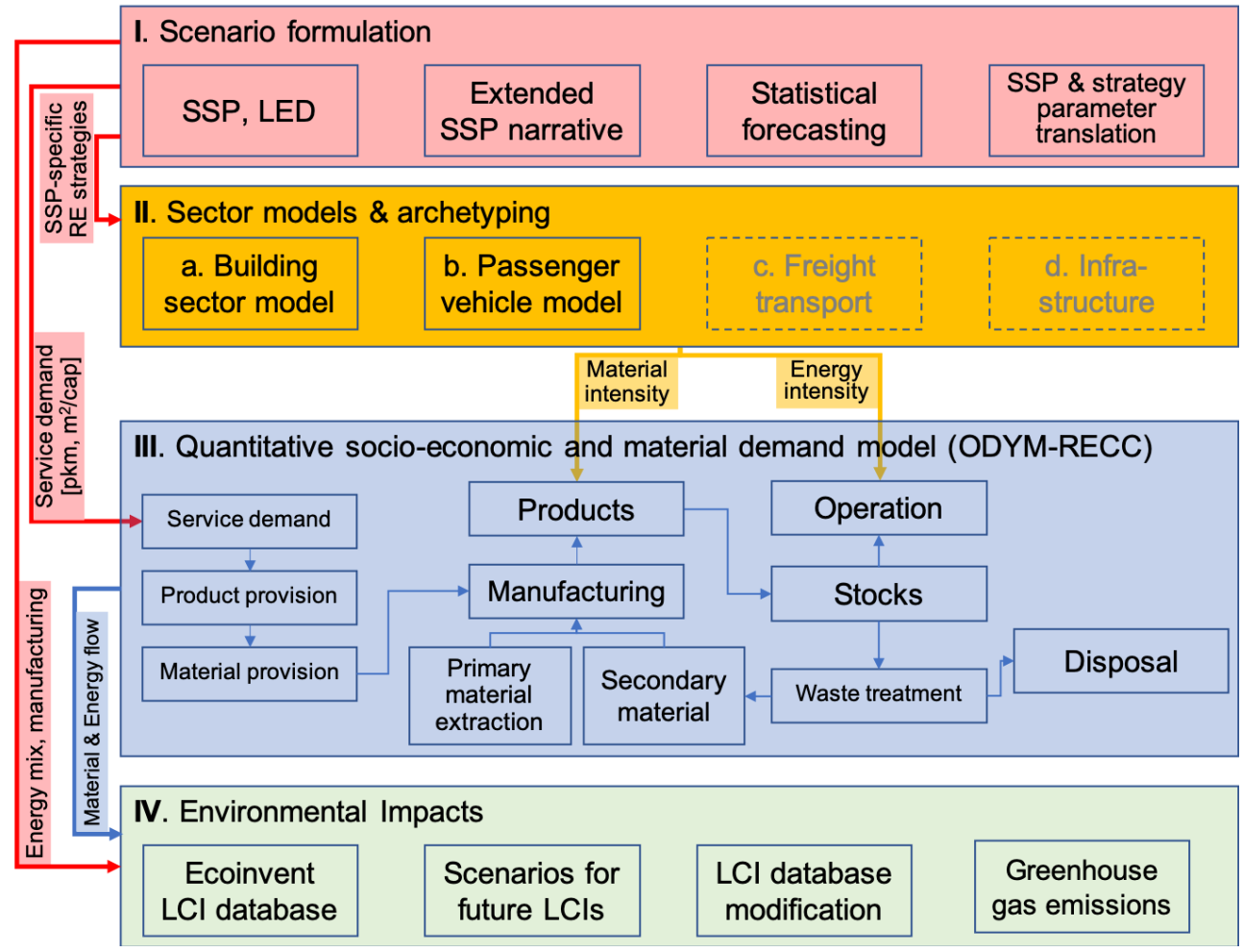

Figure 2.1: RECC model framework and database, overall structure. Figure drawn by Niko Heeren. The overall model consists of four key elements: I. Scenario formulation, II. Sector models and archetype description, III. Environmental impact assessment factors and IV. Quantitative socio-economic material demand model (ODYMRECC). [Note: The numbering of parts III and IV has changed, the numbering listed in this caption is the correct one.] Module I contains the data from the Shared-Socioeconomic Pathways (SSP) (Riahi et al., 2017b; van Vuuren et al., 2017). The interfaces between the ODYM-RECC model and the other parts are described in section 7.3. 
The overall RECC project workflow follows the structure outlined in Figure 2.2:

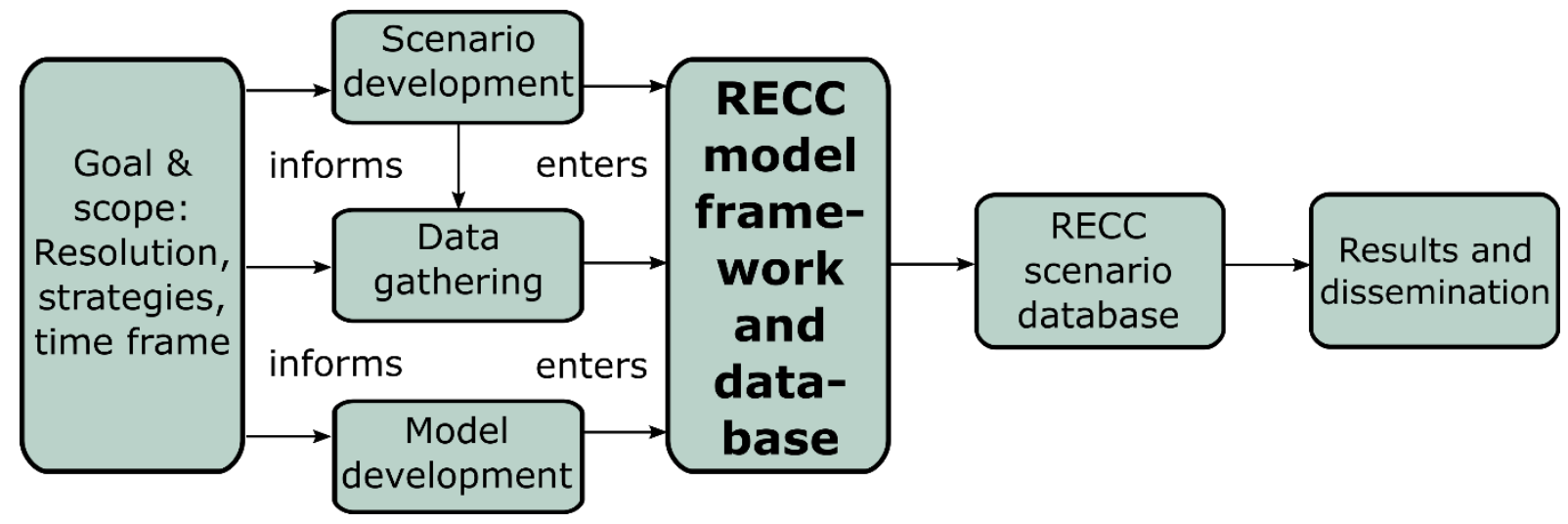

Figure 2.2: ODYM-RECC workflow, aggregated. The ODYM-RECC model (part IV) of the project's model framework is where all raw, refined, and product-based data enter the large-scale scenario model and where the main results are calculated and exported to the different formats.

The main body of the ODYM-RECC documentation is structured as listed in box 3 below:

Box 3: Chapter structure of this report.

In the subsequent chapters the model framework is explained in detail.

Section 3: System definition, assessment resolution, and time frame

Section 4: Model calibration, scenario description and development

Section 5: Data description and data gathering

Section 6: ODYM-RECC model description and development

Section 7: Working environment and work flow, interfaces between modules

Section 8: Outlook

\section{Appendix}

\section{Model development prioritisation}

With the given time frame and available resources, the following priorities/steps were chosen:

P1) Implement a generic description of future passenger vehicles and residential buildings for the US until 2060 and calculate material cycle response to material efficiency strategies across system, cover climate-relevant bulk materials.

P2) Expand scope to all G7 countries

P3) Provide a detailed and consistent scenario description for the multiple model parameters

P4) Developed a detailed inventory of archetypes for vehicles and buildings to be scaled up

P6) Expand scope to China and India

P7) Refine model and database, consider timber supply constraints, recycling limits, etc.

For the current model version 2.2, which was used for the IRP report, all steps above could be implemented. 


\section{System definition, model resolution, time frame}

\subsection{Project-wide system definition}

The system definition of a general material cycle is shown in Fig. 3.1. The more detailed ODYM-RECC system definition with process group numbers is shown in Fig.3.2.

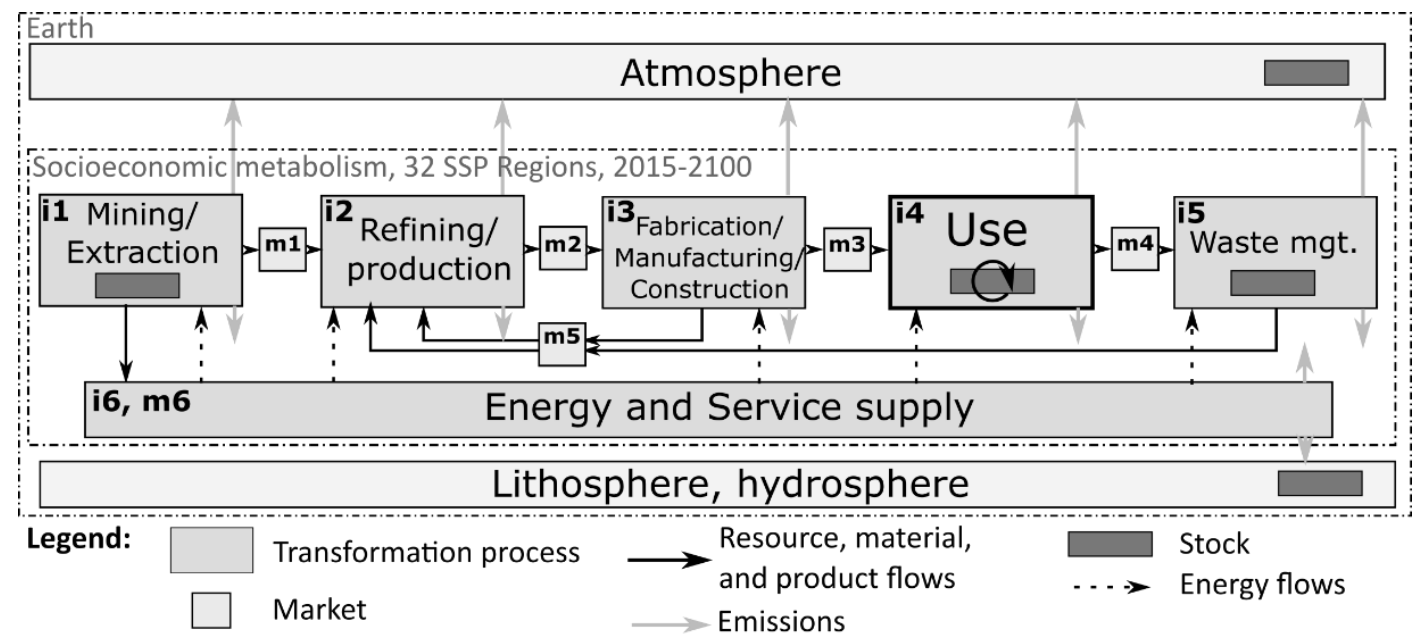

Not all flows are shown. Energy supply and markets are aggregated (i6, m6).

Figure 3.1: Generic system definition of a material cycle with process group numbers. The process groups can have sub-indices, allowing us to distinguish between different product groups (m3), waste types (m4, m5), etc.

Based on the generic system definition, Fig. 3.2 provides an overview of the resource efficiency strategies covered for ODYM-RECC.

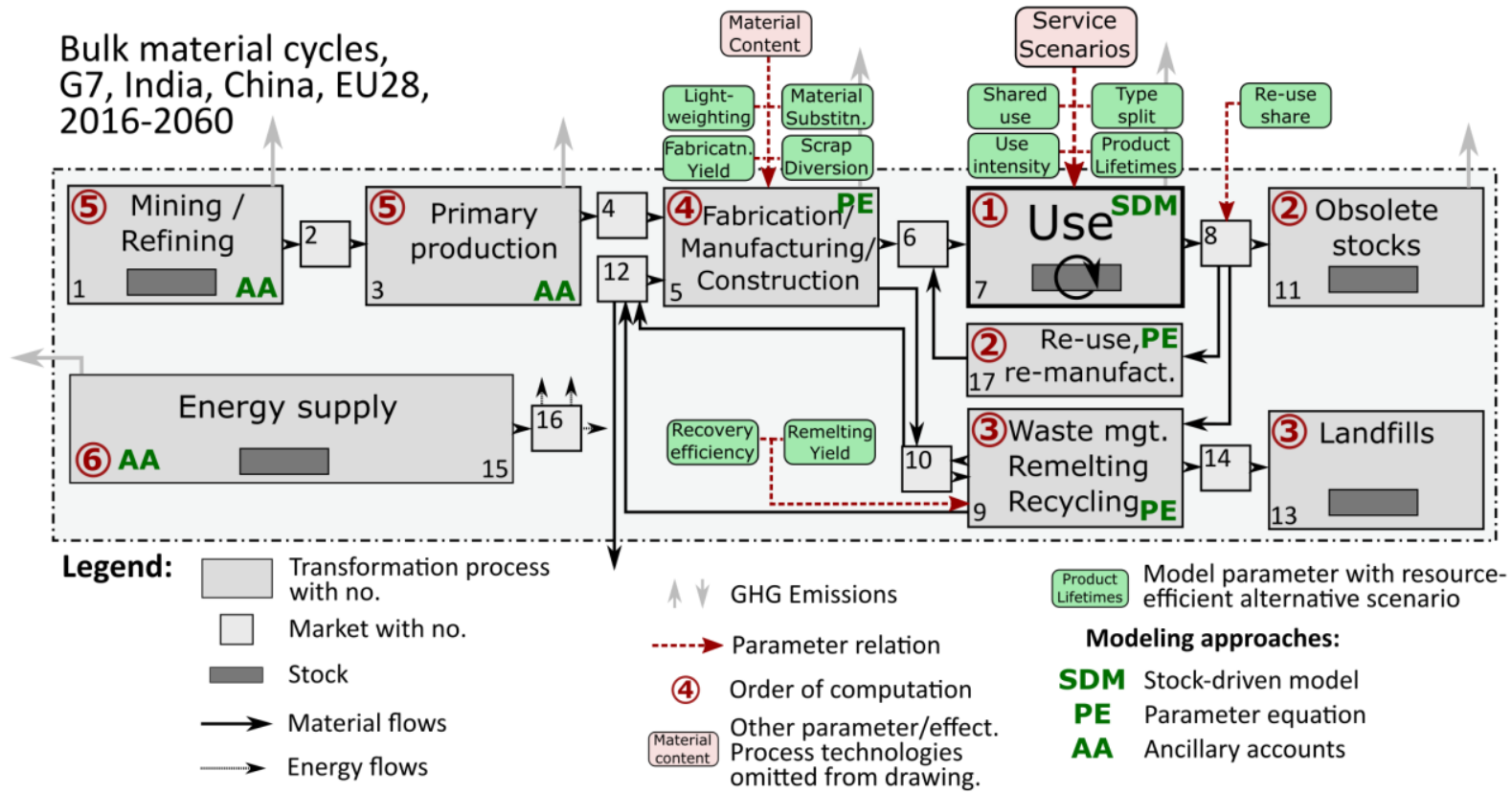

Figure 3.2: System definition of ODYM-RECC assessment with model parameters, resource efficiency strategies, and the modelling approaches taken for the computation of the material cycle response to resource efficiency.

The mathematical representation of the different RE strategies is introduced in the model description chapter. 


\subsection{Main project scoping:}

Starting point of the RECC assessment is the physical service level: $\mathrm{m}^{2}$ of dwelling space and mobility in terms of passenger-km/yr. The GHG emissions associated with these two services are major contributors to the GHG balance in high income countries, next to industry (e.g. for Germany: $190 \mathrm{Mt}$ for residential buildings and $150 \mathrm{Mt}$ for passenger vehicles out of the country's total emissions of ca. $900 \mathrm{Mt} / \mathrm{yr}$, https://www.umweltbundesamt.de/en/indicator-greenhouse-gasemissions) (Fig. 3.3).

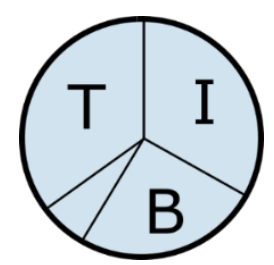

Figure 3.3: The three major energy and material using sectors Transport (T), Buildings (B), and Industry (I). Infrastructure is part of the transport sector, together with vehicles. Industrial buildings are part of the industrial sector, but are currently not captured by the RECC assessment.

For the IRP RECC assessment the following services and service-providing stocks were considered:

\section{RECC project, services and their links to stocks:}

i) Shelter and thermal comfort, provided by residential buildings, measured in $\mathbf{~ m}^{2}$.

ii) Mobility, provided by vehicles and traffic infrastructure, measured in vehicles, passenger-km and infrastructure-km. The focus here lies on passenger vehicle transportation, measured in km driven per year.

Not included are:

iii) Social services, education, commerce, etc., provided by public and commercial buildings measured in $\mathrm{m}^{2}$.

iv) Energy conversion, material production, manufacturing, and waste handling capacity, provided by industrial assets, measured in $\mathrm{GWh} / \mathrm{yr}, \mathrm{Mt} / \mathrm{yr}$, etc.

v) Infrastructure

vi) Vehicles and transport modes other than passenger cars.

Services are linked to material cycles via the stock-flow-service nexus (Haberl et al., 2017) (Fig. 3.4). The scheme starts with the energy service cascade to relate values to services to functions to products (and their operation) (Kalt et al., 2019), stock-driven modelling to translate product in-use stock demand into production of new and recycling of old products (Müller, 2006), new and old products to material flows via dynamic material flow analysis (MFA) (Brunner and Rechberger, 2016), and the material flows to the energy demand and related GHG emissions via environmental extensions as done in previous work (Milford et al., 2013; Modaresi et al., 2014).

Fig. 3.4 (next page): Calculation scheme for the use phase (here shown as 'product stocks'). Stock levels are determined from historic stocks and scenarios following different storylines. The stock-driven model then determines the age-cohort decomposition of the in-use stock as well as product inflows and outflows and the associated material content. With the total stock broken down into different age-cohorts by the stock-driven model, the service and energy flows of the use phase can then be determined (cf. below) by applying the following parameters in turn: intensity of operation and intensity of use (for service flows) and energy intensity and energy carrier split (for energy use of the use phase). The indices are as follows (cf. RECC config table and RECC index table 3.1): t: time, c: age-cohort, $r$ : region, g: good/commodity/product, S: scenario (SSP, RCP, and/or $\mathrm{RE}), \mathrm{V}$ : service category, $\mathrm{n}$ : energy carrier, to: starting time of prospective assessment (2015). See also Tables 5.25.4 for an explanation of the different parameters. 


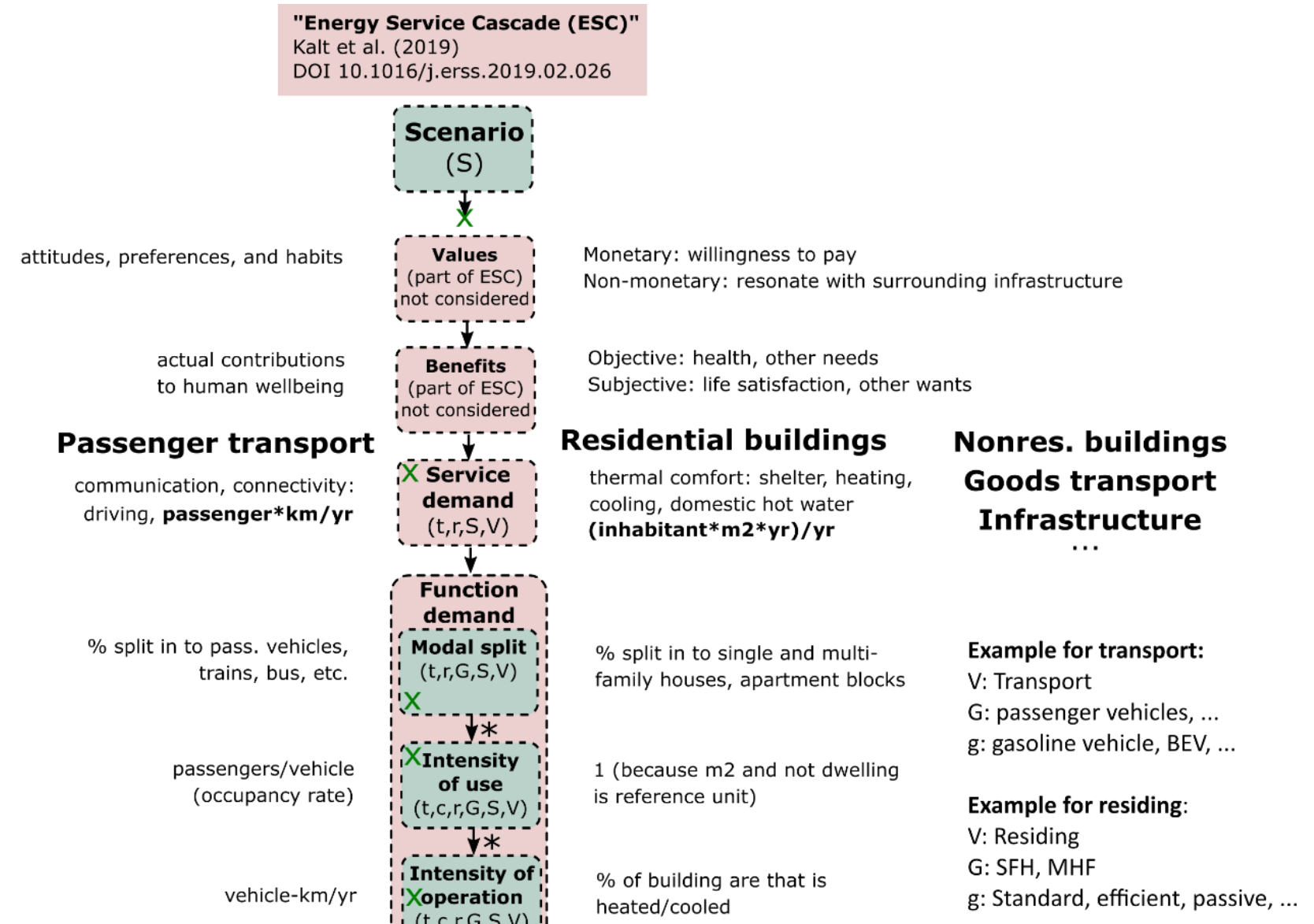

Indices/aspects: t: time,

c: age-cohort,

$r$ : region,

G: commodity group

g: good/commodity/product,

$\mathrm{S}$ : scenario(SSP, RE),

$\mathrm{V}$ : service category,

$\mathrm{n}$ : energy carrier,

m: material

$t_{0}$ : starting time of

prospective assessment (2015)

$(*, 1 /)$ : Parameters combined

by multiplication/division.

$\mathrm{TJ} / \mathrm{yr}$, to energy balance/

GHG emissions

\begin{tabular}{c}
$\begin{array}{c}\text { Product } \\
\text { stocks } \\
(t, c, r, g, S)\end{array}$ \\
\hline
\end{tabular}

duct heated/cooled

g: Standard, efficient, passive, ...

\section{oods transport}

V: Transport

G: passenger vehicles, ...

Example for residing:

$\mathrm{V}$ : Residing 


\subsection{Description of the aspects covered by ODYM-RECC}

The elements of the system (processes with stocks, and flows) can be described along different aspects, such as time, age-cohort, regions, processes, materials, etc. (Pauliuk et al., 2019). First, all relevant aspects need to be introduced and then their resolution for the first assessment round is stated.

The ODYM-RECC index table (Pauliuk and Heeren, 2019) is part of the ODYM-RECC configuration excel file RECC_Config_V2_2.xlsx. The ODYM-RECC model framework covers the following aspects as specified in its index table (Table 3.1).

Table 3.1: Index table of ODYM-RECC, model version 2.2.

\begin{tabular}{|c|c|c|c|}
\hline Aspect & Description & Dimension & Index letter \\
\hline Time & Model time & Time & $\mathbf{t}$ \\
\hline Cohort & age-cohorts & Time & c \\
\hline Element & chemical elements & Element & e \\
\hline Unity & trivial classification, 1 entry only & Unity & $\mathbf{u}$ \\
\hline Region32 & region of process or stock, region of origin (flow) & Region & $\mathbf{r}$ \\
\hline Region11 & region of process or stock, region of origin (flow) & Region & I \\
\hline Region5 & region of process or stock, region of origin (flow) & Region & f \\
\hline Region1 & region of process or stock, region of origin (flow) & Region & o \\
\hline MaterialProductionProcess & Engineering material production processes & Process & $\mathbf{P}$ \\
\hline Engineering materials & Engineering materials considered & Material & m \\
\hline ManufacturingProcess & Manufacturing processes & Process & $\mathbf{F}$ \\
\hline Sectors & Aggregated product groups: buildings, vehicles, ... & Good_Product & G \\
\hline Good & List of ALL goods and products considered & Good_Product & g \\
\hline Cars & List of car types considered & Good_Product & $\mathbf{p}$ \\
\hline OtherVehicles & List of other vehicles considered & Good_Product & $\mathbf{v}$ \\
\hline ResidentialBuildings & List of residential building types considered & Good_Product & B \\
\hline NonresidentialBuildings & List of nonresidential building types considered & Good_Product & $\mathbf{N}$ \\
\hline Infrastructure & List of infrastructure considered & Good_Product & $\mathbf{i}$ \\
\hline Industry & List of industry considered & Good_Product & $\mathbf{I}$ \\
\hline Appliances & List of appliances considered & Good_Product & a \\
\hline WasteManagementIndustries & Waste management industries & Process & $\mathbf{w}$ \\
\hline Waste_Scrap & waste and scrap types considered & Material & $\mathbf{w}$ \\
\hline Energy & Energy consumed & Energy carriers & $\mathbf{n}$ \\
\hline Scenario & Scenerios considered (e.g., SSP) & Scenario & $\mathbf{S}$ \\
\hline Extensions & Costs, emissions factors, social impacts & Extensions & $\mathbf{x}$ \\
\hline Scenario_RCP & RCP scenarios & Scenario & $\mathbf{R}$ \\
\hline SSP_Population_model & Population model used for SSP scenarios & Scenario & M \\
\hline ServiceType & Different uses of building energy: heating, cooling, ... & Extensions & $\mathbf{v}$ \\
\hline Archetype & Product archetypes & Good_Product & A \\
\hline Custom & Custom aspect, for calibration parameter & Unity & C \\
\hline Car_segments & Segments of passenger vehicles & Good_Product & $\mathbf{s}$ \\
\hline
\end{tabular}

\subsection{Resolution of model aspects.}

For each of the model aspects defined in the aspect table a common classification that defines a certain resolution is used. The resolution of the most central aspects are listed here. 
The information presented here is a summary only. The full info about the resolution of the RECC project is documented in the Master classification file, which is part of the project's database:

\section{RECC_Classifications_Master_V2.0.xlsx}

\section{Time and age-cohort, dimension: Time:}

- The time frame is 1900-2060, as some historic data reach back to 1900 and before. The Actual modelling period is 2016 to 2060, where usually, results until 2050 are extracted for reporting and publication.

Regions, dimension: Region:

- The 32 SSP regions are chosen (O'Neill et al., 2014) as reference, with focus on G7 (the six largest EU countries are depicted separately), 3 remaining EU regions, India, and China:

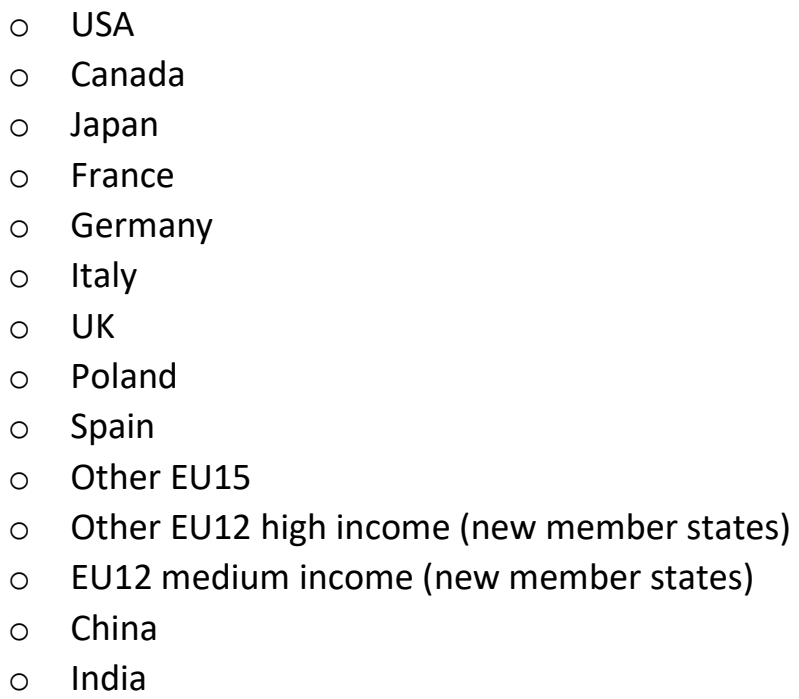

\section{Eningering_Materials, dimension: Material:}

- Construction grade steel

- Automotive steel

- stainless steel

- Cast iron

- Wrought Al

- Cast Al

- Copper electric grade

- Plastics

- Cement

- Wood and wood products

- Zinc

- Concrete

- Concrete aggregates

UsePhase, dimension: Process:

- Cf. Products resolution

Products, dimension: Good_Product:

- Passenger vehicles:

Internal Combustion Engine, gasoline (ICEG)

Internal Combustion Engine, diesel (ICED)

Hybrid Electric Vehicles (HEV) 
Plugin Hybrid Electric Vehicles (PHEV)

Battery Electric Vehicles (BEV)

Fuel Cell Vehicles (FCV)

- Residential buildings (SFH = single family house, $\mathrm{MFH}=$ multi-family house):

SFH_non-standard

SFH_standard

SFH_efficient

SFH_ZEB (zero energy building)

MFH_non-standard

MFH_standard

MFH_efficient

MFH_ZEB

informal_non-standard

EoL goods, dimension: Good_Product:

- Cf. Products resolution

Energy, dimension: Energy carriers:

- Electricity

- Coal, hard coal

- Diesel

- Gasoline

- Natural gas

- Hydrogen

- Fuel wood

SSP_Scenarios, dimension: Scenario:

- LED (low energy demand)

- SSP1

- SSP2

RCP_Scenarios, dimension: Scenario:

- $\mathrm{RCP} 2.6$

- Baseline (no new climate policy after 2020)

Extensions, dimension: Extensions:

- $\mathrm{CO}_{2}$-equivalents per main output, GWP 100

Chemical Elements, dimension: Element:

- $\mathrm{C}$

- Al

- $\mathrm{Cr}$

- $\mathrm{Fe}$

- $\mathrm{Cu}$

- $\mathrm{Zn}$

- 'Other'

MaterialProductionProcess, dimension: Process:

- One (average) primary production process for each material. 
ManufacturingProcess, dimension: Process:

- One average manufacturing process for each product/good

Waste management process, dimension: Process:

- One waste mgt. (dismantling, shredding, sorting) process to convert each of the 15 products into waste/scrap at the end of life, one re-melting process for each scrap category

Waste/scrap, dimension: Material:

- Heavy melt, plate, and structural steel scrap

- Steel shred

- Al extrusion scrap, auto rims, clean

- Al old sheet and construction waste

- Al old cast

- Copper wire scrap

- Construction waste, concrete, bricks, tiles, ceramics

- Thermoplastic waste

- Used wood

Car segments, Good_Product:

- microcar

- passenger car

- minivan_SUV

- light truck 


\section{Model calibration and scenario development}

About half of the ODYM-RECC parameters (29 out of 56) is scenario-dependent, meaning, that their values need to be linked to an exogenous socioeconomic or climate policy storyline.

\subsection{Scenario framing and model drivers}

During the time frame of the RECC project we will not be able to establish a close connection to technology-rich IAMs or other comprehensive bottom-up models of the passenger vehicle and residential building sector to obtain detailed and authoritative drivers for material cycles. Moreover, the parameters needed here are often not considered by such models. We will hence need to implement a standalone but SSP-compatible assessment, and it was the task of the scenario team to add the relevant detail to the SSP and LED storyline. The scenario relevant aspects/parameter groups and the individual parameters are listed in Table 4.1 below.

Table 4.1: Broad scenario model parameter categories in the ODYM-RECC framework.

\begin{tabular}{|l|l|}
\hline \multicolumn{1}{|c|}{ Group } & \multicolumn{1}{c|}{ Parameter } \\
\hline $\begin{array}{l}\text { D0) Present stock levels } \\
\text { [no scenario] }\end{array}$ & $\begin{array}{l}\text { Current levels of in-use stocks and breakdown into age-cohorts } \\
\text { EXOGENOUS }\end{array}$ \\
\hline D1) Future service level & $\begin{array}{l}\text { Total service need by category: m2 of buildings, vehicles, production } \\
\text { capacity, km of infrastructure, EXOGENOUS }\end{array}$ \\
\hline $\begin{array}{l}\text { D2) Future technology } \\
\text { level }\end{array}$ & $\begin{array}{l}\text { Type of products that supply the services: vehicle types, building } \\
\text { types, ... EXOGENOUS }\end{array}$ \\
\hline $\begin{array}{l}\text { D3) Future material stock } \\
\text { level }\end{array}$ & $\begin{array}{l}\text { In-use stock of material by application, region, and scenario, } \\
\text { EXOGENOUS }\end{array}$ \\
\hline $\begin{array}{l}\text { D4) Future material } \\
\text { demand and EoL material } \\
\text { supply }\end{array}$ & $\begin{array}{l}\text { Final material demand (in products) by region and scenario, supply } \\
\text { of materials in EoL products by region and scenario., ENDOGENOUS }\end{array}$ \\
\hline $\begin{array}{l}\text { D5) Resource efficiency } \\
\text { strategies }\end{array}$ & Cf. Figure 3.2, EXOGENOUS \\
\hline $\begin{array}{l}\text { D6) Material industry } \\
\text { response }\end{array}$ & $\begin{array}{l}\text { Technology setup and decision making in the mining, refining, } \\
\text { manufacturing, and waste management sectors, ENDOGENOUS }\end{array}$ \\
\hline $\begin{array}{l}\text { D7) Industry background } \\
\text { response }\end{array}$ & Electricity mix, carbon intensity of service, EXOGENOUS \\
\hline $\begin{array}{l}\text { D8) Mining industry } \\
\text { scenarios }\end{array}$ & $\begin{array}{l}\text { Bulk and companion metal production scenarios, extraction capacity } \\
\text { development, brownfield exploration, greenfield exploration, and } \\
\text { social and environmental impacts of future mining operations. NOT } \\
\text { PART OF ODYM-RECC }\end{array}$ \\
\hline
\end{tabular}

\section{DO) Present stock levels, EXOGENOUS}

All model parameters with time series start at their present levels for the reference year 2015, the latest year where complete historic data were available. The 2015 in-use stocks represent a lock-in that partly determines future outflows and thus the potential for recycling and for the introduction of new technologies, especially for the vehicle fleet until 2030 and the building stock all throughout 2060. One therefore needs to know the current levels of in-use stocks, their lifetimes, and breakdown into age-cohorts.

\section{D1) Future service levels and use phase parameters, EXOGENOUS}

Starting point of the scenario modelling is the use phase, where services and the related in-use stocks are described as a function of time. Future per capita stock levels can be derived from

- The literature, both from the IE and the IAM communities 
- a regression model using population, GDP, and urbanisation (only suitable for interpolation due to non-stationarity of time series)

- a detailed descriptive scenario for future service levels (approach taken here)

Irrespective of their origin, the future stock curves enter the stock-driven model as simple functions of the independent variable time and the aspects product group, region, and scenario. That approach increases the transparency of the approach, as we display those functions, explain how they were derived, and invite others to create their own functions.

In addition, the use phase parameters product lifetime and obsolete stock formation need to be quantified.

\section{D2) Future technology levels, EXOGENOUS}

Future technologies, e.g., the share of electric vehicle in transportation, can be derived as above from

- The literature, both from the Energy system modelling and the IAM communities [approach taken for passenger vehicles]

- a regression model using population, GDP, and urbanisation

- a detailed descriptive scenario for future service levels [approach taken here for residential buildings]

\section{D3) Future material stock levels, EXOGENOUS}

Future material stock levels describe the material content of the products required to deliver services to end users, such as residential buildings and passenger vehicles.

Stock levels for individual buildings are determined by multiplying the product stock size with the respective material content.

The material composition is determined from available data for historic age-cohorts up to 2015 and from an archetype representation and mixing of different archetypes into average products for a given future years, region, and scenario.

\section{D4) Future material demand and EOL material supply, ENDOGENOUS}

The future final consumption of materials in products and the supply of materials for recovery in EoL products is the link between the use phase and the rest of the material cycle. It is determined endogenously in ODYM-RECC by solving a stock-driven model (Müller, 2006) (future stock curve and lifetime distribution determine product inflows and outflows to/from use phase), and multiplying those flows with the age-cohort and region-specific material composition of products yields the material demand (final consumption) and the available material in EoL products.

Since the sectors captured in ODYM-RECC do not comprise the entire economy but just a part of it (currently, only residential buildings and passenger vehicles are covered), this approach does not give the total future material demand, which is needed to determine global mining and production levels and the total extent of recycling.

\section{D5) Resource efficiency strategies: Potentials and implementation patterns, EXOGENOUS}

Ten resource efficiency strategies are within the scope of the rapid assessment for the G7, India, and China. They are defined in terms of model equations (section 6), then implemented in the software, and then quantified by scaling up reference/prototype implementation cases using implementation curves that indicate how quickly and to which extent the different prototypes will be used in the future. 


\section{D6) Material and waste mgt. industry response, ENDOGENOUS}

Using process parameters, the ODYM-RECC model calculates the levels of re-use/remanufacturing and recycling/remelting. The potentials for reuse and recycling improvement enter this calculation, they are scenario-dependent.

\section{D7) Industry background response (Energy mix etc.), EXOGENOUS}

Changes in the future energy mix and carbon intensity of services determines the future life cycle impacts of products consumed. To estimate the climate impact of the different RE strategies we need to account for changes in the future energy mix, and we were able to obtain scenario results for the GHG intensity of energy supply for the different SSP scenarios from the MESSAGE team.

\section{D8) Mining industry scenarios NOT PART OF ODYM-RECC}

Based on future lifestyles, consumption patterns, and technology choices a certain amount of primary materials will be needed. Given estimates of the future extent of recycling one can then infer the amount of primary production needed, and develop mining exploration, extraction capacity development, and production scenarios for both bulk and companion/minor metals to advice mining developers and resource policy makers on which types of deposits are likely to be needed most in the future. This extension is outside the system boundary of the RECC project and not part of the assessment. Instead, the GHG emissions of primary production is modelled with a static mining process description.

\subsection{Scenario development mechanisms}

Starting point of RE implementation is the socioeconomic background provided by the shared socioeconomic pathways (SSP) scenario family, Fig 4.1 (O'Neill et al., 2014; van Vuuren et al., 2017).

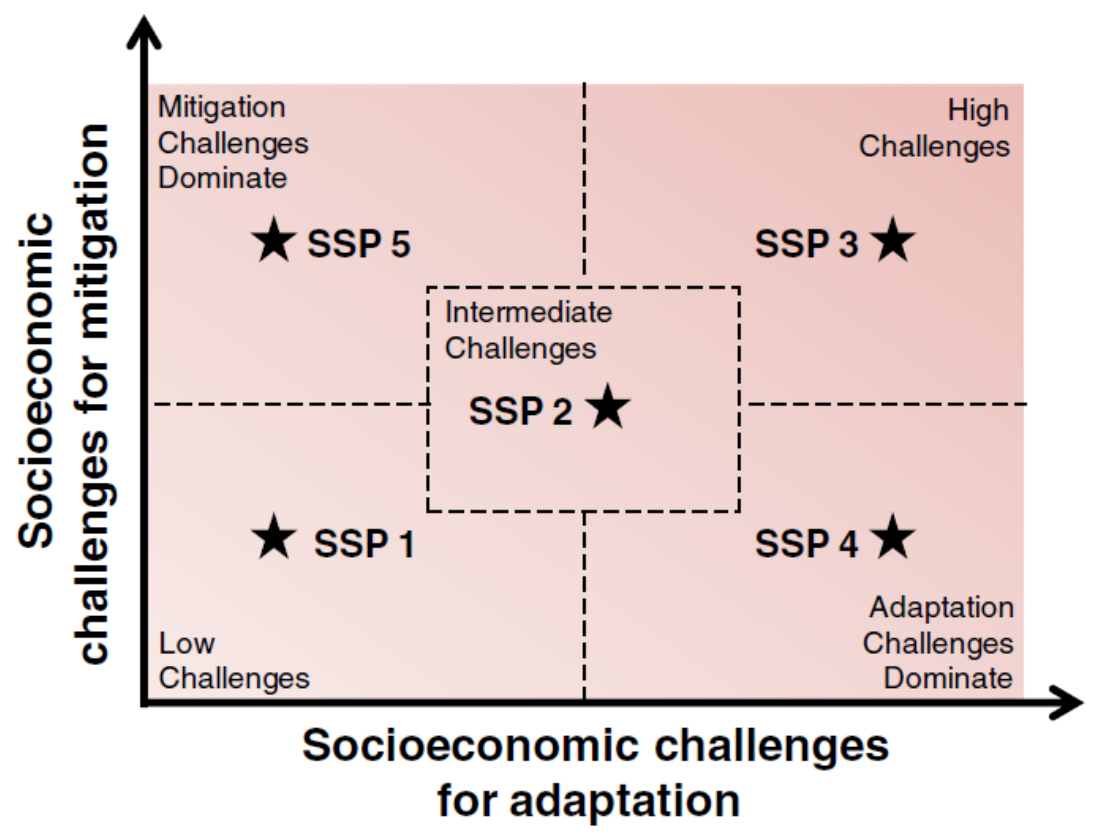

Fig. 4.1.: Space of challenges for mitigation of and adaptation to climate change. The challenge space is divided into five "domains" with one SSP located within each domain, represented by a star. Image source: O'Neill et al. (2014).

The core SSP scenario drivers include: Population, urbanisation, and GDP (Fig. 4.2), and these are available from the IIASA scenario database for the 32 SSP regions.

https://tntcat.iiasa.ac.at/SspDb/dsd?Action=htmlpage\&page=about 

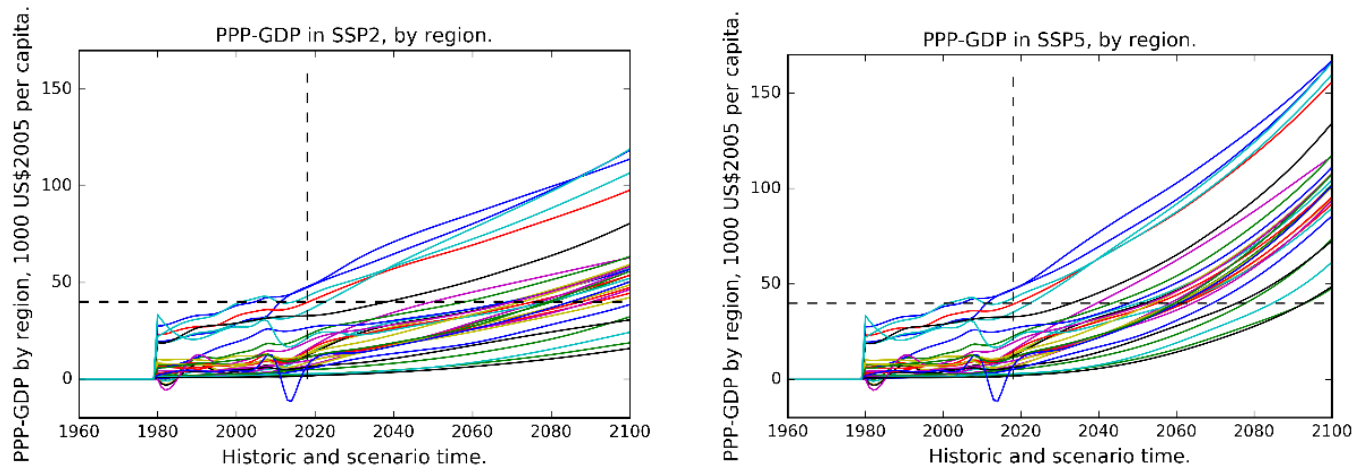

Fig. 4.2.: PPP GDP per capita in SSP2 (left) and SSP5 (right), by region. Vertical dashed line: 2018, horizontal dashed line: 40000 US\$2005 per capita. Negative values are contained in SSP database.

Within the RECC team, scenario development focusses on three parameter domains with the relevant parameters, which are defined and described in the data section below, and the different ways to obtain the relevant parameters and to add detail to the scenario storylines.

1. Socioeconomic parameters (population, future service levels, building types split, intensity of operation of vehicles)

a. From existing databases, such as the SSP scenario database or scenario work of the International Energy Agency IEA

b. Expert consensus in line with the SSP storylines within the project team to identify plausible target values for the individual parameters for 2040, 2050, and 2060. These values are then inserted into a scenario target table and interpolated to produce time series from 2015 to 2060.

2. Technology parameters (Energy carrier split of buildings, GHG intensity of energy supply)

a. From existing model rungs, e.g., results from the MESSAGE model and work by the International Energy Agency IEA

b. Scenario target table approach (cf. above, internal expert consensus)

c. Own modelling effort (for the future GHG intensity of primary material production)

d. Archetype descriptions for products and processes (detailed description of individual products to be scaled up) from own modelling efforts to describe vehicle and building prototypes with established engineering planning tools

3. Resource and material efficiency parameters (Reuse share, recovery rate improvements)

a. From case studies and prototypes described in the literature

\subsection{Running and evaluating the scenarios}

A large number of different scenario settings is possible, which allow the model user to answer a wide array of different research questions. The different sectors can be run together or separate, the same holds for different countries. The larger the scope of a model run, the higher the change that the secondary material available from the scrap supply will find a market inside the system boundary and doesn't have to be exported.

For each model run, the following information needs to be supplied in the ODYM-RECC config file:

- Which region(s) are included

- Which sector(s) are included

- Which material efficiency strategies are included (any combination is possible).

For each model configuration, the model script then computes six socioeconomic-climate policy scenarios: 
Socioeconomic:

- LED / SSP1 / SSP2

Climate policy:

- No new climate policy after 2020 / RCP2.6

For each material efficiency strategy we define two implementation cases: One where the strategy is absent and one where it is implemented to an extent specified by the scenario target table or by the so-called implementation curve (parameter 3_SHA_RECC_REStrategyScaleUp_V3.3), that describes the ramp-up over time.

To facilitate the interpretation of the results, the different material efficiency strategies are either considered one by one in a single-strategy sensitivity analysis or in a cascade. Table 4.2 defines the sequence of ME strategies for which the scenarios are run in ODYM-RECC (ME strategies implementation cascade).

Table 4.2. Material efficiency cascades and their breakdown into individual strategies. ${ }^{*}$ ) vehicles only. \#) residential buildings only. The cascade is a sequence of model runs where additional strategies are added in each step as indicated below. For passenger vehicles, there are six, for residential buildings five steps in the material efficiency cascade

\begin{tabular}{|c|c|c|c|c|c|c|c|}
\hline & \multicolumn{7}{|c|}{ ME strategies implementation cascade } \\
\hline & $\begin{array}{l}0 \text { (Current } \\
\text { ME levels) }\end{array}$ & 1 & 2 & 3 & 4 & $\mathbf{5}$ & $\begin{array}{c}6 \\
\text { (cars only) }\end{array}$ \\
\hline $\begin{array}{l}\text { End-of-life recovery } \\
\text { rate improvement }\end{array}$ & & $\mathrm{x}$ & $\mathrm{x}$ & $\mathrm{x}$ & $\mathrm{x}$ & $\mathrm{x}$ & $\mathrm{x}$ \\
\hline $\begin{array}{l}\text { Fabrication yield } \\
\text { improvement }\end{array}$ & & $\mathrm{x}$ & $\mathrm{x}$ & $\mathrm{x}$ & $\mathrm{x}$ & $\mathrm{x}$ & $\mathrm{x}$ \\
\hline $\begin{array}{l}\text { Fabrication scrap } \\
\text { diversion }\end{array}$ & & $\mathrm{x}$ & $\mathrm{x}$ & $\mathrm{x}$ & $\mathrm{x}$ & $\mathrm{x}$ & $\mathrm{x}$ \\
\hline Reuse & & & $x$ & $x$ & $x$ & $x$ & $x$ \\
\hline Lifetime extension & & & $\mathrm{x}$ & $\mathrm{x}$ & $\mathrm{x}$ & $\mathrm{x}$ & $x$ \\
\hline Material substitution & & & & $\mathrm{x}$ & $\mathrm{x}$ & $\mathrm{x}$ & $\mathrm{x}$ \\
\hline $\begin{array}{l}\text { Using less material by } \\
\text { design / down-sizing }\end{array}$ & & & & & $\mathrm{x}$ & $\mathrm{x}$ & $\mathrm{x}$ \\
\hline Car-sharing * & & & & & & $x$ & $x$ \\
\hline Ride-sharing for cars * & & & & & & & $x$ \\
\hline $\begin{array}{l}\text { More intensive use of } \\
\text { floor space \# }\end{array}$ & & & & & & $\mathrm{x}$ & $n / a$ \\
\hline
\end{tabular}




\subsection{Model calibration}

The different parameters based on partly inconsistent historical data need to lead to correct results. They also need to fit the future scenario times series. To achieve both goals, the database needs to be calibrated, which is done by changing the most uncertain parameters from their literature values to values that will lead to correct model results for selected reference values. Results from noncalibrated model runs show a typical peak in the model year 2016 (Fig. 4.3), because the gap in stock resulting from the difference between actual data and scenarios is filled in that year.
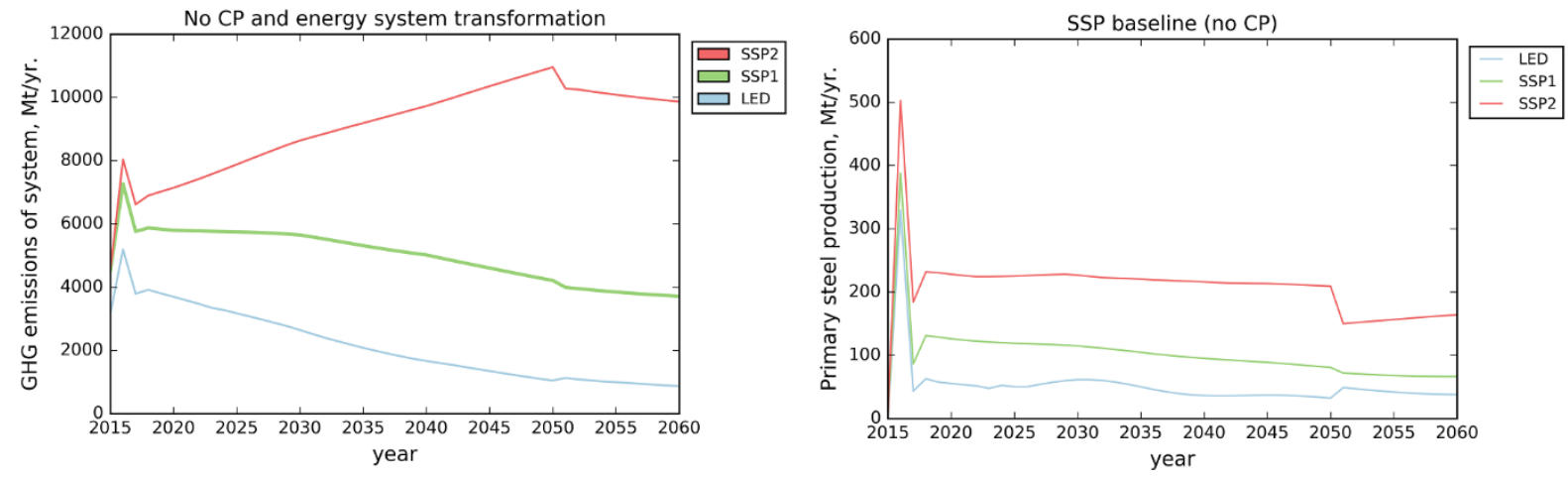

Fig. 4.3.: Model result for non-calibrated historical data, with the characteristic 2016 peak in total emissions and material production.

The model calibration has two steps:

\section{1) Stock calibration:}

The 2015 stock per capita stock levels, which can be calculated from the stock parameter 2_S_RECC_FinalProducts_2015 and the population 2_P_RECC_Population_SSP_32R, need to be the starting points of the scenario curves. They need to be entered as 2015 values in the scenario target tables to make sure that the future stock curves have the right starting point.

\section{2) Energy consumption calibration}

Some of the 2015 statistical data in the RECC database need to be recalibrated to fit the reported energy demand. This procedure is documented in the parameter file 6_PR_Calibration_V2.2. The calibration affects the use phase parameter kilometrage 3_IO_Vehicles_UsePhase_V2.2 and the use phase energy intensity of operation 3_EI_Products_UsePhase_passvehicles_V1.1. For some regions, for example, the reported kilometrage and energy consumption $(\mathrm{MJ} / \mathrm{km})$ are too low to match the reported energy consumption. These regions include: Poland, Oth_R32EU12-H, and R32EU12-M (calibration results in an increase of the annual vehicle kilometrage by 25\%), and Oth_R32EU15 (increase by $10 \%$ ). Both the vehicle kilometrage as well as the vehicle and building energy intensity of operation are changed for most countries to reproduce the reported values for sectoral energy consumption, which is closely related to the GHG emissions statistics and therefore serves as reference for the calibration.

For details cf. the documentation in the ODYM-RECC parameter file 6_PR_Calibration_V2.2.xIsx. 


\section{Data needs and data gathering}

In this section, the 56 ODYM-RECC model parameters are defined and the main data sources and assumptions are listed. In section 6 , all parameters are connected to the system variables (stocks and flows in the model's system definition, Fig. 3.2), and formally defined via the ODYM-RECC model equations.

All parameters are defined in tuple format (Pauliuk et al., 2019):

$$
\text { parameter_value = function (aspect1, aspect2, aspect3, ...) }
$$

The different aspects and their symbols are defined in the aspect table 3.1.

The parameter symbols are listed in the parameter definition tables below.

Each ODYM-RECC model parameter has a dataset ID, which consists of the following parts:

$$
\text { ParameterGroup_ParameterType_DescriptiveName_DataSetVersion }
$$

The general data model based on tuples or multi-dimensional arrays (data cubes), the six general parameter groups (table 5.1), and the assigned data types are adapted from the general data model for industrial ecology (Pauliuk et al., 2019), which is documented as part of the industrial ecology data inventory under https://github.com/IndEcol/IE data commons

\begin{tabular}{|c|c|c|c|}
\hline ID & Name & Symbol & Description \\
\hline 1 & Flow & $F$ & Objects flowing between processes \\
\hline 2 & \begin{tabular}{|cc} 
Stock & \\
& Stock \\
& In-use stock \\
& Population \\
\end{tabular} & $\begin{array}{c}\text { S } \\
\text { IUS } \\
P\end{array}$ & $\begin{array}{l}\text { Objects residing as stocks in processes } \\
\text { General stock }\end{array}$ \\
\hline 3 & $\begin{array}{c}\text { Material/Product property } \\
\text { Lifetime } \\
\text { Material composition } \\
\text { Share } \\
\text { Price } \\
\text { Intensity of use } \\
\text { Specific energy consumption }\end{array}$ & $\begin{array}{c}\text { LT } \\
\text { MC } \\
\text { SHA } \\
\text { PR } \\
\text { IU } \\
\text { El }\end{array}$ & Intensive object properties \\
\hline 4 & $\begin{array}{c}\text { Process coefficient (intensive) } \\
\text { Yield coefficient } \\
\text { Process extension } \\
\text { Process factor (per capacity) }\end{array}$ & $\begin{array}{l}\text { PY } \\
\text { PE } \\
\text { PF }\end{array}$ & Intensive process properties \\
\hline 5 & $\begin{array}{c}\text { Extensive process property } \\
\text { Process capacity }\end{array}$ & CAP & $\begin{array}{l}\text { Extensive process properties such as } \\
\text { capacity }\end{array}$ \\
\hline 6 & $\begin{array}{c}\text { General Ratio } \\
\text { Per capita stock/flow }\end{array}$ & $\begin{array}{l}\text { PCS } \\
\text { PCF }\end{array}$ & $\begin{array}{l}\text { Any ratio between two system variables } \\
\text { from the groups 1-5 above }\end{array}$ \\
\hline
\end{tabular}

Table 5.1: The ODYM-RECC parameter groups $1-6$ and assigned parameter types with symbols $F, S, I U S, \ldots$

For example, the ODYM-RECC parameter with ID 4_PY_MaterialProductionRemelting_V2.2 is the yield factor/coefficient of the remelting processes in version 2.2 . 


\subsection{Description of the data gathering process}

Data collection in RECC serves several purposes: First, to inventory datasets from the literature so that they can be easily reused by other team members. Second, inventoried datasets shall ultimately become part of the industrial ecology data commons (https://zenodo.org/communities/indecol/), (Pauliuk et al., 2019). Third, to link several inventoried datasets from the literature to quantify the different ODYM-RECC model parameters in the project-wide classification. All of these goals necessitate harmonization of data reproducibility and of data conversion. Therefore, we use a comprehensive procedure with standardized data files. Each model parameter will be documented in one data file, while the data can be of different sources.

Data collection in the RECC project happens in the following stages: (cf. also Figure 5.1). The next paragraph provides further details.

1) Identification and inventory of data source: Document reference, web link, data license, dataset version, etc., that are to be recorded in a collection template

2) Data are extracted from original sources in their original resolution and stored in table or list format in the collection template.

3) Data are manually (sometimes via a script) converted to RECC resolution and format

4) Data conversion process is reviewed by assigned data reviewer

Repeat steps 1-4 until parameter dataset is finalized

5) Assign version number to dataset and include it in the RECC project database.

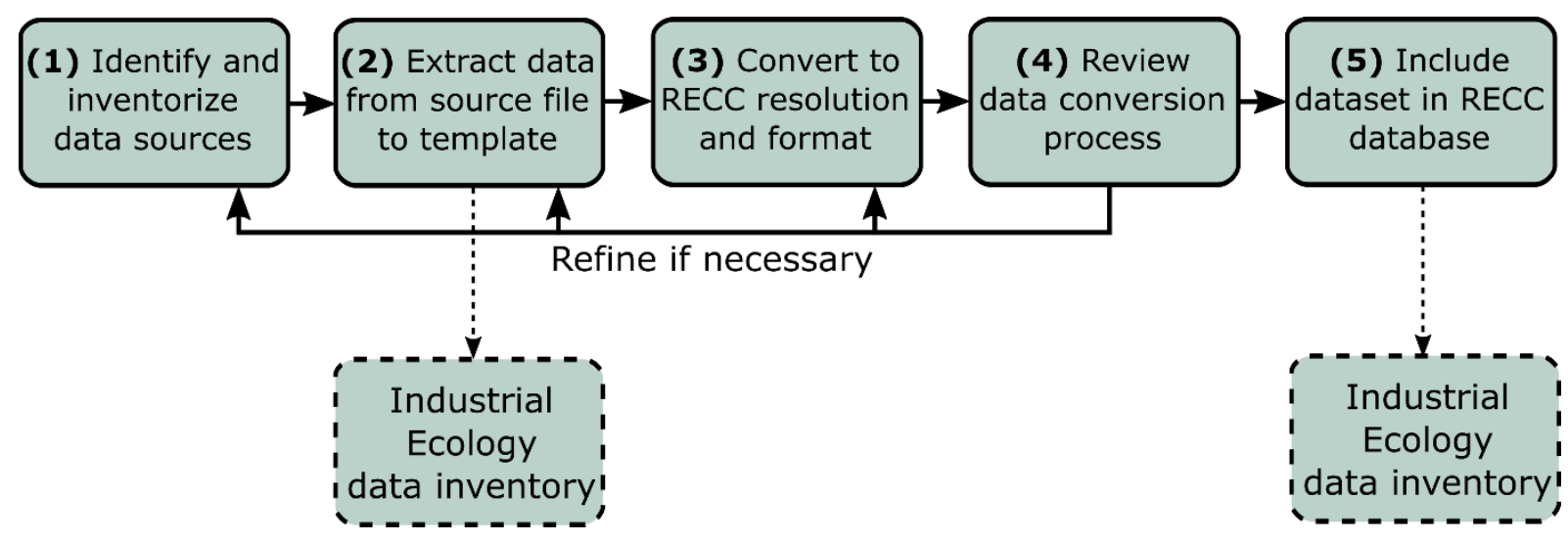

Figure 5.1: RECC data collection scheme.

The data collection steps are described in detail:

1) Identification and inventory of data source: Document reference, web link, data license, dataset version, etc., that are to be recorded in a collection template. For this purpose, each template has a sheet 'Raw Data' (you can add more such sheets if necessary), and on this sheet, each raw data set, from a single number to a larger table, is to be extracted from the literature and described (Fig. 5.2). As an alternative, larger datasets can be archived on Figshare or Zenodo, provided that you have permission to do that. 


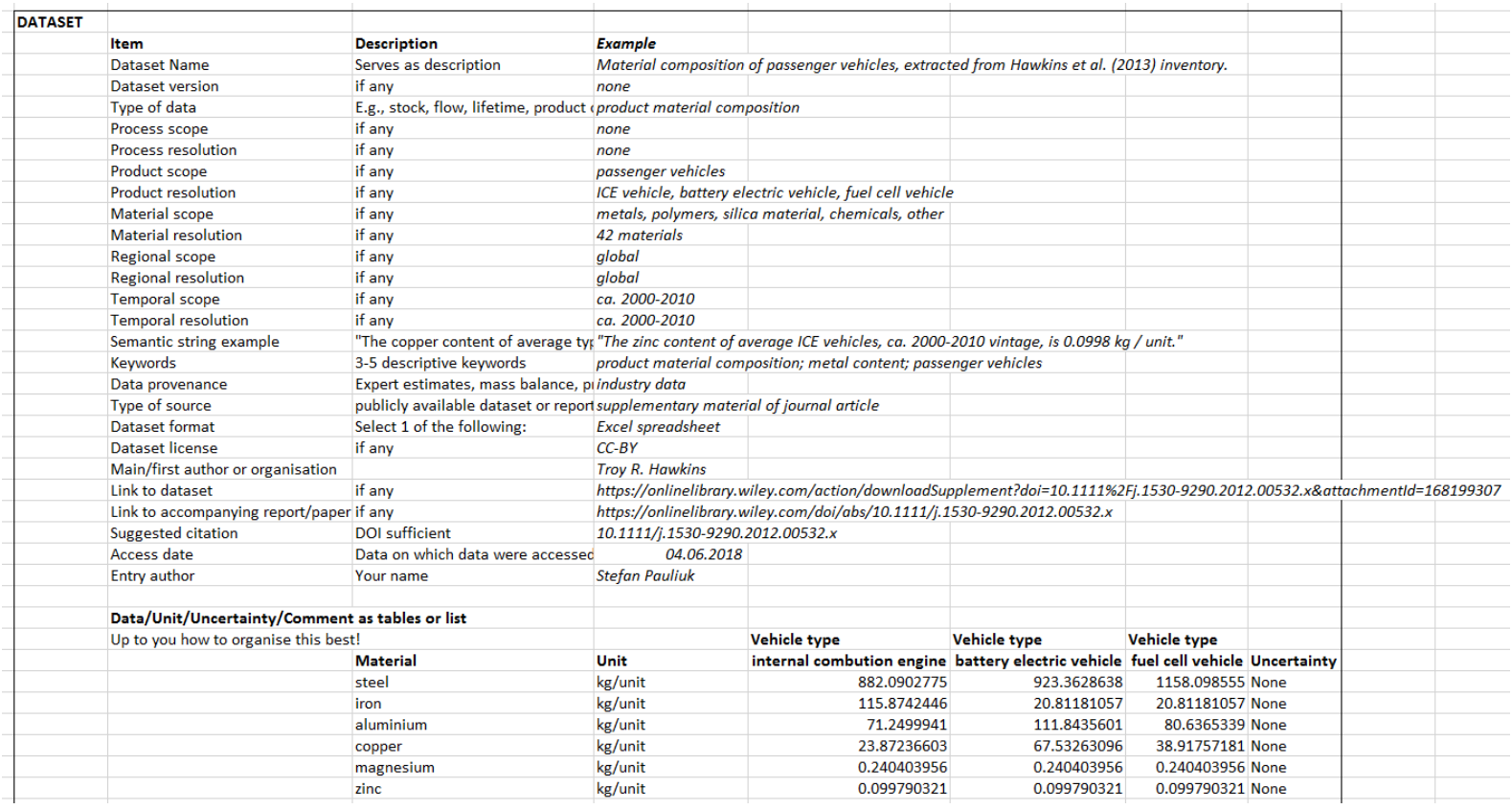

Figure 5.2: Raw data inventory in RECC template. Upper section: Project-wide uniform description of metadata, dataset description, and system location. Lower part: Data as table or list in custom formatting.

In the example above the actual data are organized as a table. Another example for the data section of the raw data template is shown in Fig. 5.3.

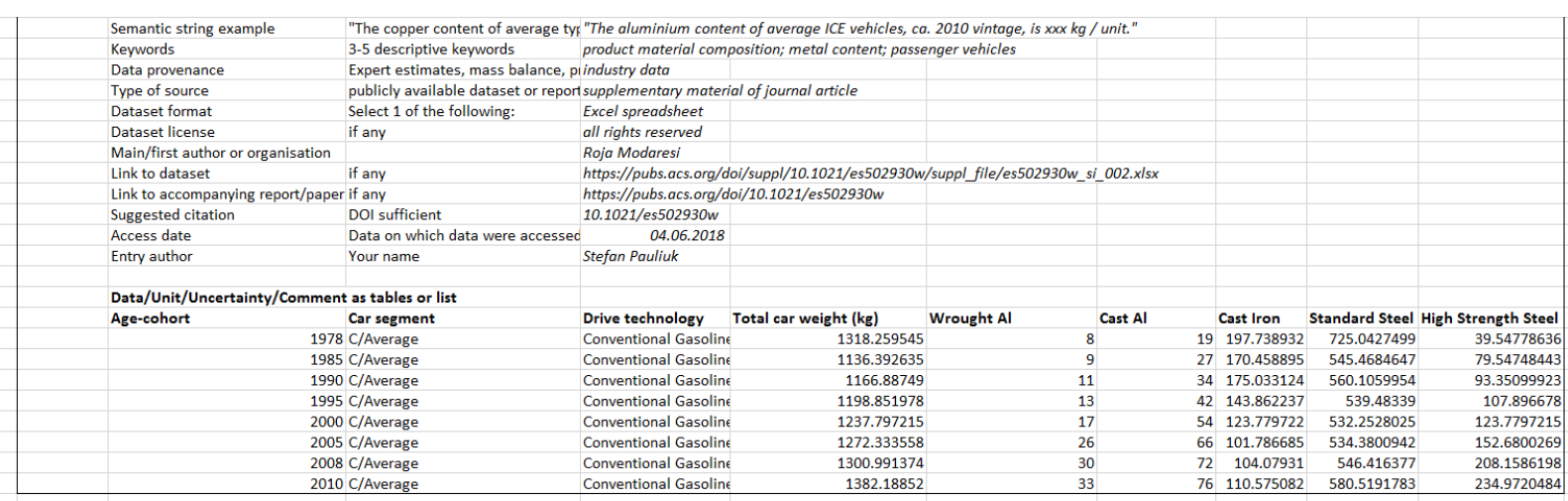

Figure 5.3: Raw data inventory in RECC template, second example. Upper section: Meta data, dataset description, and system location. Lower part: Data as table or list.

Here the data are organised as table with a three-level row index and a single level column index.

While the metadata description follows a fixed form that will facilitate automatic processing later, the numerical data on the sheet 'Raw Data' can be organized at the discretion of the data collectors. Examples for data organisations include 2D tables, tables with multi-indices, list, and combinations thereof.

2) Data are extracted from original sources in their original resolution and stored in table or list format in the collection template. $\rightarrow \mathrm{Cf}$. point 1 above. There will be cases where this is not possible, e.g. database interfaces that need to be queried, very large databases, GIS data, etc. For the scope of the RECC project, however, dataset sizes were manageable with the given template structure.

3) Data are manually converted to RECC resolution and format

Ancillary calculations such as unit conversions, disaggregation, or aggregation of data are to be documented on the sheet 'Ancillary calculations' that is part of each parameter file. From there the 
individual parameter values are then copied or linked to the 'Values' table, which may require conversion of data format, data resolution, and data units, as this sheet comes with a pre-defined format common to all ODYM-RECC parameters and in the project-wide resolution. From the Values sheet the are read by the RECC model. Convert all values to the units that are already defined in the 'Units' sheet. On the 'Comment' sheet each individual value can be commented upon. If existent, uncertainties for each individual value should be recorded on the sheet 'Stats_array_string'. The use of stats_array_strings is explained in section 5.3 of the RECC model description. Note: You may use links and equations (Cell A = SheetXCellB * SheetYCellC) but make sure that these links only refer to other sheets within the same workbook. No links to other workbooks allowed, numbers from other workbooks need to be copied with the 'value only' option.

4) Data conversion process is reviewed by assigned data reviewer

Based on the review outcome, steps 1-4 are repeated until the parameter dataset is finalized.

\section{5) Assign version number to dataset and include it in the RECC project database.}

Once the dataset is regarded as final, it is assigned a version number and added to the RECC project database. All further editing and modification of the data needs to happen as part of a new version of that parameter to keep the database consistent.

\subsection{ODYM-RECC parameters, complete list.}

This subsection lists all 56 model parameters, their index structure and symbols and the major data sources. For each parameter, the complete list of literature data sources is contained in the 'ref' sheet of each parameter file. For the scenario parameters obtained from the target table interpolation, the data sources and assumptions are listed in the transport and building model documentations (Heeren et al., 2019; Wolfram et al., 2019). Additional information about parameter compilation can be found in the data log files under https://github.com/YaleCIE/RECC-data, where the compilation of the assumption and formatting of the data templates is documented.

\subsubsection{Socioeconomic parameters}

The ODYM-RECC basic scenario drivers population, PPP-GDP, and urbanisation are listed in Table 5.2. Population and GDP were downloaded from the IIASA SSP database and brought to ODYM format. They are given for four aspects: time $t$, region $r$, SSP scenario $S$, and SSP Population/GDP model T.

Table 5.2: The ODYM-RECC basic scenario drivers. The aspect/indices are introduced in the index table 3.1. For the scope of the parameters, we distinguish between historic or present base data $(\mathbf{H})$, future scenario $(\mathbf{S})$, future potentials (P), implementation of future potential (I).

\begin{tabular}{|c|c|c|c|}
\hline Name & Symbol(s) and indices, dataset ID & Unit, Scope & Explanation/Example/Source (S) \\
\hline Population & $\begin{array}{c}P(M, t, \mathrm{r}, \mathrm{S}) \\
\text { 2_P_RECC_Population_SSP_32R_V2.1 }\end{array}$ & $\begin{array}{l}\text { Million } \\
\text { Scope: } \mathrm{H}, \mathrm{S}\end{array}$ & $\begin{array}{l}\text { Ex: P (2015, China, SSP1, IIASA-Pop) } \\
=12300000 \\
\text { (KC and Lutz, 2014) }\end{array}$ \\
\hline PPP-GDP & (currently not used) & $\begin{array}{l}\text { Billion } \\
\text { US\$̦2005 } \\
\text { Scope: H,S }\end{array}$ & $\begin{array}{l}\text { Ex: GDP(2015, China, SSP1, IIASA- } \\
\text { Pop) = } 3450 \text { bn Int\$ } \\
\text { (KC and Lutz, 2014) }\end{array}$ \\
\hline $\begin{array}{l}\text { Urbanisation } \\
\text { rate }\end{array}$ & (currently not used) & $\begin{array}{l}\% \\
\text { Scope: H,S }\end{array}$ & $\begin{array}{l}\text { Ex: U (2015, China, SSP1, IIASA- } \\
\text { Pop) }=0.1 \\
\text { (KC and Lutz, 2014) }\end{array}$ \\
\hline
\end{tabular}


The ODYM-RECC socioeconomic parameters for the use phase are listed in Table 5.3:

Table 5.3: The ODYM-RECC basic parameters, use phase. Those that are affected by resource efficiency strategies are labelled in bold face. The indices are introduced in the index table 3.1. For the scope of the parameters, we distinguish between historic or present base data $(\mathbf{H})$, future scenario $(\mathbf{S})$, future potentials $(\mathbf{P})$, implementation of future potential (I).

\begin{tabular}{|c|c|c|c|}
\hline Name & Symbol(s) and indices & Unit, Scope & Explanation/Example/Source (S) \\
\hline $\begin{array}{l}\text { In use stock } \\
2015\end{array}$ & $\begin{array}{l}S_{0}, S_{2015}(2015, \mathrm{c}, p / B, r) \\
\text { 2_S_RECC_FinalProducts_2015 } \\
\text { _passvehicles_V1.1 } \\
\text { 2_S_RECC_FinalProducts_2015 } \\
\text { _resbuildings_V1.1 }\end{array}$ & $\begin{array}{l}\text { Building stock: } \\
\text { Million } \mathrm{m}^{2} \\
\text { Vehicle stocks: } \\
1 \\
\text { Scope: } \mathrm{H}\end{array}$ & $\begin{array}{l}\text { Starting value for In-use stock of buildings, } \\
\text { infrastructure, and products. Ex: } \\
\text { Stock(Residential buildings } 4 \text { storeys, 2010, } \\
\text { China,) = } 123 \mathrm{M} \mathrm{m}^{2} \text {. } \\
\text { (S): Large number of sources, mostly } \\
\text { international and national statistics and journal } \\
\text { articles, listed in model files. }\end{array}$ \\
\hline $\begin{array}{l}\text { Future stock } \\
\text { levels }\end{array}$ & $\begin{array}{l}S_{\text {fut }}(t, \mathrm{r}, G, \mathrm{~S}) \\
\text { 2_S_RECC_FinalProducts_Futur } \\
\text { e_resbuildings_V2.2 }\end{array}$ & $\begin{array}{l}\text { Building stock: } \\
\mathrm{m}^{2} / \text { cap } \\
\text { Scope: } \mathrm{S}\end{array}$ & $\begin{array}{l}\text { Time series for future residential building stock } \\
\text { per capita. Ex: FuturepCStock(Residential } \\
\text { buildings, 2030, China, SSP1) }=30 \mathrm{~m}^{2} / \mathrm{cap} \\
\text { (S): Scenario target table }\end{array}$ \\
\hline $\begin{array}{l}\text { Future } \\
\text { passenger } \\
\text { vehicle } \\
\text { mobility }\end{array}$ & $\begin{array}{l}M_{f u t}(t, \mathrm{r}, G, \mathrm{~S}) \\
\text { 1_F_ServiceFlows_Future_V1.2 }\end{array}$ & $\begin{array}{l}\text { Passenger- } \\
\mathrm{km} / \mathrm{yr} \text { and per } \\
\text { person } \\
\text { Scope: S }\end{array}$ & $\begin{array}{l}\text { Time series for future passenger vehicle } \\
\text { kilometres per person. Ex: PassVehkm(2030, } \\
\text { USA, SSP1) = } 20000 \\
\text { (S): Scenario target table }\end{array}$ \\
\hline $\begin{array}{l}\text { Product } \\
\text { lifetime }\end{array}$ & $\begin{array}{l}\tau(p r), \tau(B c r) \\
\text { 3_LT_RECC_ProductLifetime_pa } \\
\text { ssvehicles_V3.1 } \\
\text { 3_LT_RECC_ProductLifetime_re } \\
\text { sbuildings_V4.0 }\end{array}$ & $\begin{array}{l}\text { yr } \\
\text { Scope: H,S }\end{array}$ & $\begin{array}{l}\text { Mean product lifetime, by cohort, product } \\
\text { group, region, and scenario. Ex: } \\
\text { Lifetime(Residential buildings } 4 \text { storeys, China, } \\
\text { SSP1,2050) = } 80 y r \\
\text { (S): previous work: (Liu et al., 2012; Pauliuk et } \\
\text { al., 2017b, 2013) }\end{array}$ \\
\hline $\begin{array}{l}\text { Obsolete } \\
\text { Stock } \\
\text { formation } \\
\text { rate }\end{array}$ & (currently not used) & $\begin{array}{l}1 \\
\text { Scope: H,S }\end{array}$ & $\begin{array}{l}\text { Share of EoL products that pile up as obsolete } \\
\text { stocks. Ex: Obsolete stocks (buildings } \\
\text { residential, 2020, China, SSP1) }=20 \% \text { (of all EoL } \\
\text { buildings) }\end{array}$ \\
\hline $\begin{array}{l}\text { Intensity of } \\
\text { operation, } \\
\text { use phase }\end{array}$ & $\begin{array}{l}I O(V, \mathrm{r}, t, \mathrm{~S}), I O(c, B, V, r, S) \\
\text { 3_IO_Buildings_UsePhase_V1.2 } \\
\text { 3_IO_Vehicles_UsePhase_V2.2 }\end{array}$ & $\begin{array}{l}\text { Buildings: \% of } \\
\text { area that is } \\
\text { heated or } \\
\text { cooled, } \\
\text { vehicles: } \mathrm{km} / \mathrm{yr} \\
\text { Scope: } \mathrm{S}\end{array}$ & $\begin{array}{l}\text { Denotes how intensively a product is used, e.g., } \\
\text { how many km/yr a vehicle is driven. Ex: Share } \\
\text { of residential building area that is heated } \\
\text { (Germany, 2020, SSP1) = 96\%. } \\
\text { (S): Historical data from a number of sources, } \\
\text { cf. parameter files, } 2015 \text { values extrapolated } \\
\text { into the future. }\end{array}$ \\
\hline Type split & $\begin{array}{l}T S(G, p, t, \mathrm{r}, \mathrm{S}), \\
T S(G, B, r, t, S) \\
\text { 3_SHA_TypeSplit_Buildings_V1. } \\
\text { 2, } \\
\text { 3_SHA_TypeSplit_Vehicles_V2. } \\
\text { 1 }\end{array}$ & $\begin{array}{l}1(\%), \text { share of } 6 \\
\text { vehicle and } 9 \\
\text { building types in } \\
\text { total new } \\
\text { vehicles and } \\
\text { buildings, resp. } \\
\text { Scope: } S\end{array}$ & $\begin{array}{l}\text { Parameter splits good flows into different types } \\
\text { of one good. Ex: Share of low energy multi- } \\
\text { family houses in total new construction } \\
\text { (Germany, 2020, SSP1) = 36\%. } \\
\text { (S): Vehicles: IEA results (OECD/IEA, 2010a), } \\
\text { buildings: scenario target table. }\end{array}$ \\
\hline $\begin{array}{l}\text { Vehicle } \\
\text { occupancy } \\
\text { rate }\end{array}$ & $\begin{array}{l}\text { OR }(G, \mathrm{r}, t, \mathrm{~S}) \\
\text { 6_MIP_VehicleOccupancyRate_- } \\
\text { V1.2 }\end{array}$ & $\begin{array}{l}1 \\
\text { Scope: S }\end{array}$ & $\begin{array}{l}\text { Average occupancy (persons per vehicle) Ex: } \\
\text { Vehicle occupancy (passenger vehicles, USA, } \\
\text { 2015, SSP1) = 1.6. } \\
\text { (S): Transport model documentation }\end{array}$ \\
\hline $\begin{array}{l}\text { Calibration } \\
\text { parameter }\end{array}$ & 6_PR_Calibration_V2.2 & 1 & $\begin{array}{l}\text { For each country/region, the calibration factors } \\
\text { scale the } 2015 \text { and future vehicle annual } \\
\text { kilometrage, the average } \mathrm{MJ} / \mathrm{km} \text { driven, and } \\
\text { the average } \mathrm{MJ} / \mathrm{m}^{2} / \mathrm{yr} \text { of building energy } \\
\text { intensity to match national energy statistics. }\end{array}$ \\
\hline
\end{tabular}




\subsubsection{Technology parameters}

The ODYM-RECC technology parameters for the use phase are listed in Table 5.4:

Table 5.4: The ODYM-RECC technology parameters, use phase. Those that are affected by resource efficiency strategies are labelled in bold face. The indices are introduced in the index table 3.1. For the scope of the parameters, we distinguish between historic or present base data $\mathbf{( H )}$, future scenario $(\mathbf{S})$, future potentials $(\mathbf{P})$, implementation of future potential (I).

\begin{tabular}{|c|c|c|c|}
\hline Name & Symbol(s) and indices & Unit, Scope & Explanation/Example/Source (S) \\
\hline $\begin{array}{l}\text { Product } \\
\text { material } \\
\text { composition }\end{array}$ & $\begin{array}{l}\mu(c, m, p / B, r) \\
\text { 3_MC_RECC_Buildings_ } \\
\text { V1.1 } \\
\text { 3_MC_RECC_Vehicles_V } \\
1.1\end{array}$ & $\begin{array}{l}\text { kg/item, kg per } \\
\text { m2, } \\
\text { Scope: H }\end{array}$ & $\begin{array}{l}\text { Material composition of products in regions and } \\
\text { from age-cohorts (share of different engineering } \\
\text { materials in goods). Ex: } \\
\text { MaterialComposition(2040, EU, road } \\
\text { infrastructure, asphalt) = } 540 \text { ton/km } \\
\text { (S): Only used for historic age-cohorts, various } \\
\text { sources as documented in parameter files. } \\
\text { Future: Mix of different archetypes }\end{array}$ \\
\hline $\begin{array}{l}\text { Product } \\
\text { specific energy } \\
\text { consumption }\end{array}$ & $\begin{array}{l}E I(c, p / B, V, n, r, S) \\
\text { 3_EI_Products_UsePhas } \\
\text { e_passvehicles_V1.1 } \\
\text { 3_EI_Products_UsePhas } \\
\text { e_resbuildings_V1.1 }\end{array}$ & $\begin{array}{l}\text { MJ/km, MJ/m2/yr, } \\
\text { Scope: H }\end{array}$ & $\begin{array}{l}\text { Specific operational energy consumption of } \\
\text { products in regions and from age-cohorts. Ex: } \\
\text { SpecEnergyConsumption(2000, USA, Internal } \\
\text { Combustion Engine, gasoline (ICEG), Driving, all } \\
\text { energy carriers, SSP1) = } 2.7 \mathrm{MJ} / \mathrm{km} \\
\text { (S): Only used for historic age-cohorts, various } \\
\text { sources as documented in parameter files. } \\
\text { Future: Mix of different archetypes }\end{array}$ \\
\hline $\begin{array}{l}\text { Energy carrier } \\
\text { split of } \\
\text { products }\end{array}$ & $\begin{array}{l}\operatorname{ECS}(c, p, o, V, n, S) \\
\operatorname{ECS}(V, R, r, n, t) \\
\text { 3_SHA_EnergyCarrierSpl } \\
\text { it_Buildings_V2.2 } \\
\text { 3_SHA_EnergyCarrierSpl } \\
\text { it_Vehicles_V1.1 }\end{array}$ & $\begin{array}{l}\text { \% (1) } \\
\text { Scope: H,S }\end{array}$ & $\begin{array}{l}\text { Parameter that split the total energy } \\
\text { consumption for operating buildings/vehicles } \\
\text { into the individual energy carriers. Ex: } \\
\text { EnergyCarrierSplit(2015, Hybrid Electric Vehicles } \\
\text { (HEV), world, Driving, SSP1, gasoline) = } 1 \\
\text { (S): Vehicles: by definition of vehicle type (drive } \\
\text { technology dictates energy carrier), buildings: IEA } \\
\text { parameter, (OECD/IEA, 2017) }\end{array}$ \\
\hline $\begin{array}{l}\text { Material } \\
\text { composition of } \\
\text { archetypes }\end{array}$ & $\begin{array}{l}M A(A, r, m) \\
M A(A, m) \\
\text { 3_MC_BuildingArchetyp } \\
\text { es_V1.1 } \\
\text { 3_MC_VehicleArchetype } \\
\text { s_V2.0 }\end{array}$ & $\begin{array}{l}\text { Mt/yr } \\
\text { Scope: P }\end{array}$ & $\begin{array}{l}\text { Material composition of product archetypes. Ex: } \\
\text { MA(USA, single-family house, standard design, } \\
\text { cement) }=48,4 \mathrm{~kg} / \mathrm{m}^{2} \text {. } \\
\text { (S): Building simulation module, Vehicle } \\
\text { simulation module }\end{array}$ \\
\hline $\begin{array}{l}\text { Specific energy } \\
\text { consumption } \\
\text { of archetypes }\end{array}$ & $\begin{array}{l}\operatorname{EIA}(A, n), \\
\operatorname{EIA}(A, V, r, n) \\
\text { 3_El_BuildingArchetype } \\
\text { S_V1.1 } \\
\text { 3_El_VehicleArchetypes } \\
\text { _V4.0 }\end{array}$ & $\begin{array}{l}\text { Mt/yr } \\
\text { Scope: P }\end{array}$ & $\begin{array}{l}\text { Specific energy consumption (use phase) of } \\
\text { product archetypes. Ex: MA(ICEV- } \\
\text { g_Minivan/SUV_Lightweight design, all energy } \\
\text { carriers) = 2,4 MJ/km. } \\
\text { (S): Building simulation module, Vehicle } \\
\text { simulation module }\end{array}$ \\
\hline
\end{tabular}


The ODYM-RECC technology parameters for the material cycles are listed in Table 5.5:

Table 5.5: The ODYM-RECC technology parameters, material cycles. Those that are affected by resource efficiency strategies are labelled in bold face. The indices are introduced in the index table 3.1. For the scope of the parameters, we distinguish between historic or present base data $\mathbf{( H )}$, future scenario $(\mathbf{S})$, future potentials (P), implementation of future potential (I).

\begin{tabular}{|c|c|c|c|}
\hline Name & Symbol(s) and indices & Unit, Scope & Explanation/Example/Source (S) \\
\hline $\begin{array}{l}\text { Fabrication } \\
\text { yield }\end{array}$ & $\begin{array}{l}\lambda(m, w, g, F, t, o) \\
\text { 4_PY_Manufacturing_V2. } \\
1\end{array}$ & $\begin{array}{l}1 \text { (\%) } \\
\text { Scope: H,S }\end{array}$ & $\begin{array}{l}\text { Fabrication yield of materials into products, Ex: } \\
\text { FabYield(steel, car manufacturing, 2010) = 78\%. } \\
\text { (S): Previous work: (Glöser et al., 2013; Liu et al., } \\
\text { 2012; Pauliuk et al., 2013) }\end{array}$ \\
\hline $\begin{array}{l}\text { Remelting } \\
\text { yield }\end{array}$ & $\begin{array}{l}R M Y(w, m, e, W, t, o) \\
\text { 4_PY_MaterialProduction } \\
\text { Remelting_V2.2 }\end{array}$ & $\begin{array}{l}\text { (\%) } \\
\text { Scope: H,S }\end{array}$ & $\begin{array}{l}\text { Remelting yield of scrap into secondary metals, } \\
\text { Ex: RemYield(steel scrap, steel) = 97\%. } \\
\text { (S): Previous work: (Nakamura et al., 2017; } \\
\text { Pauliuk et al., 2017b) and industry information. }\end{array}$ \\
\hline $\begin{array}{l}\text { Scrap recovery } \\
\text { efficiency }\end{array}$ & $\begin{array}{l}\varphi(g, o, m, w, W) \\
\text { 4_PY_EoL_RecoveryRate_ } \\
\text { V2.2 }\end{array}$ & $\begin{array}{l}1 \text { (\%) } \\
\text { Scope: } H, S\end{array}$ & $\begin{array}{l}\text { Efficiency of recovering scrap w' from broad } \\
\text { waste group w. Ex: RecEff(Copper, to Copper } \\
\text { scrap, from E-Waste, EU) = 70\%. } \\
\text { (S): Previous work: (Glöser et al., 2013; Liu et al., } \\
\text { 2012; Pauliuk et al., 2013) }\end{array}$ \\
\hline $\begin{array}{l}\text { Elemental } \\
\text { composition of } \\
\text { materials, } \\
\text { historic stocks } \\
\end{array}$ & $\begin{array}{l}M C e(m, e) \\
\text { 3_MC_Elements_Material } \\
\text { s_ExistingStock_V2.1 }\end{array}$ & $\begin{array}{l}1 \text { (\%) } \\
\text { Scope: H }\end{array}$ & $\begin{array}{l}\text { Iron content of construction steel in historic } \\
\text { (2015) stock is } 0.999 . \\
\text { (S): Assumption, typical value }\end{array}$ \\
\hline $\begin{array}{l}\text { Elemental } \\
\text { composition of } \\
\text { materials, } \\
\text { primary } \\
\text { production }\end{array}$ & $\begin{array}{l}M C p(m, e) \\
\text { 3_MC_Elements_Material } \\
\text { s_Primary_V2.1 }\end{array}$ & $\begin{array}{l}1 \text { (\%) } \\
\text { Scope: S }\end{array}$ & $\begin{array}{l}\text { Al content of primary wrought aluminium is } 0.99 \text {. } \\
\text { (S): Assumption, typical value }\end{array}$ \\
\hline
\end{tabular}

The ODYM-RECC basic parameters for the industry background are listed in Table 5.6:

Table 5.6: The ODYM-RECC material cycle parameters, industry background. Those that are affected by resource efficiency strategies are labelled in bold face. The indices are introduced in the index table 3.1. For the scope of the parameters, we distinguish between historic or present base data $(\mathbf{H})$, future scenario $(\mathbf{S})$, future potentials $(\mathbf{P})$, implementation of future potential (I).

\begin{tabular}{|c|c|c|c|}
\hline Name & Symbol(s) and indices & Unit, Scope & Explanation/Example/Source (S) \\
\hline $\begin{array}{l}\text { Process energy } \\
\text { demand, } \\
\text { manufacturing }\end{array}$ & $\begin{array}{l}\text { EIM }(F, n, c, o) \\
\text { 4_EI_ManufacturingEnergyInt } \\
\text { ensity_V2.1 }\end{array}$ & $\begin{array}{l}\text { MJ/item, } \\
\text { MJ/m2 } \\
\text { Scope: } H, S\end{array}$ & $\begin{array}{l}\text { Per unit-of-output energy demand of the } \\
\text { different processes. Ex: Ext(Electricity demand, } \\
\text { aluminium smelting, Brazil, 2020) }=13.5 \mathrm{GJ} / \text { ton } \\
\text { (S): Ecoinvent mostly }\end{array}$ \\
\hline $\begin{array}{l}\text { Process energy } \\
\text { demand, } \\
\text { primary } \\
\text { production }\end{array}$ & $\begin{array}{l}E I P(P, n, c, o) \\
\text { 4_El_ProcessEnergylntensity_ } \\
\text { V2.1 } \\
\text { Currently not used }\end{array}$ & $\begin{array}{l}\text { MJ/ton } \\
\text { Scope: H,S }\end{array}$ & $\begin{array}{l}\text { Per unit-of-output energy demand of the } \\
\text { different processes. Ex: Ext(Electricity demand, } \\
\text { aluminium smelting, Brazil, 2020) = } 13.5 \mathrm{GJ} / \text { ton } \\
\text { (S): Currently not used, as all primary } \\
\text { production energy consumption is indirectly } \\
\text { accounted for in the GHG parameter } \\
\text { 4_PE_ProcessExtensions_V3.3. }\end{array}$ \\
\hline $\begin{array}{l}\text { Process energy } \\
\text { demand, } \\
\text { waste } \\
\text { management }\end{array}$ & $\begin{array}{l}E I W(w, n, c, o) \\
\text { 4_El_WasteMgtEnergylntensi } \\
\text { ty_V1.1 }\end{array}$ & $\begin{array}{l}\text { MJ/item, } \\
\text { MJ/m2 } \\
\text { Scope: } \mathrm{H}, \mathrm{S}\end{array}$ & $\begin{array}{l}\text { Per unit-of-output energy demand of the } \\
\text { different processes. Ex: Ext(Electricity demand, } \\
\text { aluminium smelting, Brazil, 2020) =13.5 GJ/ton } \\
\text { (S): Ecoinvent mostly }\end{array}$ \\
\hline $\begin{array}{l}\text { Process energy } \\
\text { demand, } \\
\text { remelting }\end{array}$ & $\begin{array}{l}\operatorname{EIRM}(m, n, c, o) \\
\text { 4_EI_RemeltingEnergylntensi } \\
\text { ty_V2.1 }\end{array}$ & $\begin{array}{l}\text { MJ/item, } \\
\text { MJ/m2 } \\
\text { Scope: H,S }\end{array}$ & $\begin{array}{l}\text { Per unit-of-output energy demand of the } \\
\text { different processes. Ex: Ext(Electricity demand, } \\
\text { aluminium smelting, Brazil, 2020) = } 13.5 \mathrm{GJ} / \text { ton } \\
\text { (S): Ecoinvent mostly }\end{array}$ \\
\hline
\end{tabular}




\begin{tabular}{|c|c|c|c|}
\hline $\begin{array}{l}\text { Direct } \\
\text { emissions }\end{array}$ & $\begin{array}{l}G H G D(X, n) \\
\text { 6_PR_DirectEmissions_V1.1 }\end{array}$ & $\begin{array}{l}\text { kg CO2-eq / MJ } \\
\text { Scope: Constant }\end{array}$ & $\begin{array}{l}\text { Direct GHG emissions of energy carrier } \\
\text { combustion. Ex: GHGD(GWP100, Diesel) = } 0.07 \\
\mathrm{~kg} / \mathrm{MJ} \\
\text { (S): Standard values, recorded by Modaresi et } \\
\text { al. (2014) }\end{array}$ \\
\hline $\begin{array}{l}\text { Primary } \\
\text { production } \\
\text { GHG emissions }\end{array}$ & 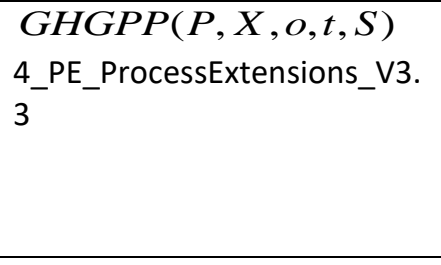 & $\begin{array}{l}\text { kg CO2-eq / kg } \\
\text { Scope: S }\end{array}$ & $\begin{array}{l}\text { Supply chain GHG emissions of primary } \\
\text { material production. Ex: GHGPP(GWP100, } \\
\text { aluminium smelting, 2040, SSP1) = 4.8 ton } \\
\text { CO2eq /ton } \\
\text { (S): Scenario calculations with ecoinvent, } \\
\text { scenario target table. }\end{array}$ \\
\hline $\begin{array}{l}\text { Energy and } \\
\text { electricity } \\
\text { supply GHG } \\
\text { intensity, by } \\
\text { region }\end{array}$ & $\begin{array}{l}\text { GHGE }(X, n, S, R, r, t) \\
\text { 4_PE_GHGIntensityEnergySu } \\
\text { pply_V4.0 }\end{array}$ & $\begin{array}{l}\text { t/GJ } \\
\text { Scope: S }\end{array}$ & $\begin{array}{l}\text { GHG intensity of energy supply. Ex: } \\
\text { GHG(electricity, Soth-East Asia, 2040) = } 4 \mathrm{~kg} \\
\text { CO2-eq /GJ } \\
\text { (S): MESSAGE IAM SSP model runs }\end{array}$ \\
\hline $\begin{array}{l}\text { Energy and } \\
\text { electricity } \\
\text { supply GHG } \\
\text { intensity, } \\
\text { global } \\
\end{array}$ & $\begin{array}{l}\text { GHGW(X, } n, S, R, o, t) \\
\text { 4_PE_GHGIntensityEnergySu } \\
\text { pply_World_V4.0 }\end{array}$ & $\begin{array}{l}\text { t/GJ } \\
\text { Scope: } S\end{array}$ & $\begin{array}{l}\text { GHG intensity of energy supply. Ex: } \\
\text { GHG(electricity, World, 2040) }=4.2 \mathrm{~kg} \text { CO2-eq } \\
\text { /GJ } \\
\text { (S): MESSAGE IAM SSP model runs }\end{array}$ \\
\hline $\begin{array}{l}\text { Electricity } \\
\text { supply GHG } \\
\text { intensity, } \\
\text { global } \\
\text { backstop } \\
\end{array}$ & $\begin{array}{l}\text { GHGBS }(X, n, S, R, t) \\
\text { 4_PE_GHGIntensityElectricity } \\
\text { Supply_Backstop_V1.0 }\end{array}$ & $\begin{array}{l}\text { t/GJ } \\
\text { Scope: S }\end{array}$ & $\begin{array}{l}\text { GHG intensity of energy supply. Ex: } \\
\text { GHG(electricity, World, 2050) = 20g CO2-eq / } \\
\text { MJ } \\
\text { (S): (Hertwich et al., 2015b) }\end{array}$ \\
\hline $\begin{array}{l}\text { Global } \\
\text { warming } \\
\text { potential of } \\
\text { biomass } \\
\text { storage } \\
\end{array}$ & $\begin{array}{l}\text { GWPbio }(c) \\
\text { 6_MIP_GWP_Bio_V1.0 }\end{array}$ & $\begin{array}{l}\text { kg CO2-eq / kg } \\
\text { Scope: S }\end{array}$ & $\begin{array}{l}\text { Climate impact of biomass storage (in use } \\
\text { phase) with subsequent incineration Ex: } \\
\text { GWPbio(80) }=-0.7 \mathrm{t} \mathrm{CO2-eq} \mathrm{/} \mathrm{t} \\
\text { (S): (Guest et al., 2013) }\end{array}$ \\
\hline $\begin{array}{l}\mathrm{CO}_{2} \text { price } \\
\text { index }\end{array}$ & $\begin{array}{l}\text { 3_PR_RECC_CO2Price_SSP_3 } \\
\text { 2R_V2.1 } \\
\text { (currently not used) }\end{array}$ & $\begin{array}{l}\text { US\$2005/ton } \\
\text { Scope: S }\end{array}$ & $\begin{array}{l}\text { Ex: CO2Price(R32BRA, 2050, SSP4, RCP2.6) = } \\
185 \text { US\$w005/ton }\end{array}$ \\
\hline
\end{tabular}

\subsubsection{Resource efficiency parameters}

The ODYM-RECC resource efficiency parameters are listed in Table 5.7: The defining equations for these parameters are introduced in section 6 or in the transport model documentation.

Table 5.7: The ODYM-RECC resource efficiency parameters. The indices are introduced in the index table 3.1. Some data sources are given directly below, but for some parameters, multiple data sources and assumptions were used, and some of the data sources link to the IEDC (http://www.database.industrialecology.unifreiburg.de//), see the parameter files.

\begin{tabular}{|l|l|l|l|}
\hline Name and strategy & Symbol(s), Unit & $\begin{array}{l}\text { Explanation, reference case if not } \\
\text { implemented }\end{array}$ & Example and data source \\
\hline $\begin{array}{l}\text { Implementation } \\
\text { curves of RE } \\
\text { strategies } \\
\text { (cf. section 6.3.3) }\end{array}$ & $\begin{array}{l}\text { IC }(R, O, t, S) \\
\text { Unit: } 1(\%) \\
\text { 3_SHA_RECC_REStrat } \\
\text { egyScaleUp_V3.3 }\end{array}$ & $\begin{array}{l}\text { Functions that contain the ramp-up } \\
\text { of different resource efficiency } \\
\text { potentials defined below. } \\
\text { Not implemented: Curves }=0 .\end{array}$ & $\begin{array}{l}\text { Complete ramp-up until 2040 assumed of a } \\
\text { selected RES strategy is on. } \\
\text { (S): SSP-consistent assumptions, scenario } \\
\text { target tables. }\end{array}$ \\
\hline $\begin{array}{l}\text { MIU: maximal MIU } \\
\text { potential buildings }\end{array}$ & $\begin{array}{l}\Phi_{\text {MIU }}(G, 0, S) \\
\text { 2_S_RECC_FinalProdu } \\
\text { cts_Future_resbuildin } \\
\text { gs_MIUPotential_V1. } \\
\text { 0 }\end{array}$ & $\begin{array}{l}\text { More service per unit of stock. Stock } \\
\text { is reduced as a sufficiency strategy or } \\
\text { following other, not considered } \\
\text { economic or social incentives. } \\
\text { Maximal reduction potential (share } \\
\text { of existing stock) for more intense } \\
\text { use of residential building (reduction }\end{array}$ & $\begin{array}{l}\text { Reduce SSP1 and SSP2 stock levels by up to } \\
\text { 20\% in 2040, (smoothed linear ramp), but } \\
\text { not lower than LED values. } \\
\text { Implementation curves to not apply here! } \\
\text { PHI(res. Buildings, World, SSP1) = 20\% } \\
\text { (S): SSP-consistent assumptions }\end{array}$ \\
\hline
\end{tabular}




\begin{tabular}{|c|c|c|c|}
\hline & & $\begin{array}{l}\text { of per capita floor space). Applies to } \\
\text { buildings only. } \\
\text { Not implemented: stock in } \mathrm{m}^{2} / \mathrm{cap} \\
\text { not changed. }\end{array}$ & \\
\hline $\begin{array}{l}\text { CaS: Car ownership } \\
\text { change under cars- } \\
\text { haring } \\
\text { (cf. transport model } \\
\text { docu) }\end{array}$ & $\begin{array}{l}\text { COS }(S, r) \text { Unit: } \\
1 \\
\text { 6_MIP_CarSharing_St } \\
\text { ock_V1.0 }\end{array}$ & $\begin{array}{l}\text { Ratio of car ownership rate with vs. } \\
\text { without participation in car-sharing }\end{array}$ & $\begin{array}{l}\operatorname{COS}(\mathrm{SSP} 1, \text { France })=0.5 \\
\text { (S): Cf. transport model documentation }\end{array}$ \\
\hline $\begin{array}{l}\text { RiS: Occupancy rate } \\
\text { change under ride- } \\
\text { sharing } \\
\text { (cf. transport model } \\
\text { docu) }\end{array}$ & $\begin{array}{l}\text { ORS }(S, r) \text { Unit: } 1 \\
\text { 6_MIP_RideSharing_- } \\
\text { Occupancy_V1.0 }\end{array}$ & $\begin{array}{l}\text { Ratio of car occupancy with vs. } \\
\text { without participation in ride-sharing }\end{array}$ & $\begin{array}{l}\text { ORS(SSP1,France) = } 1.4 \\
\text { (S): Cf. transport model documentation }\end{array}$ \\
\hline $\begin{array}{l}\text { Car-sharing } \\
\text { (cf. transport model } \\
\text { docu) }\end{array}$ & $\begin{array}{l}\operatorname{CaS}(G, o, t, S) \\
\text { Unit: } 1(\%) \\
\text { 6_PR_CarSharingShar } \\
\text { e_V1.2 }\end{array}$ & $\begin{array}{l}\text { Share of total passenger-vehicle- } \\
\text { based passenger km that is delivered } \\
\text { by shared cars } \\
\text { Not implemented: Parameter }=0 .\end{array}$ & $\begin{array}{l}\text { SSP-consistent assumptions, scenario target } \\
\text { tables. Up to } 30 \% \text {. For justification cf. the } \\
\text { transport model docu! } \\
\text { Implementation curves to not apply here! } \\
\text { (S): SSP-consistent assumptions, scenario } \\
\text { target tables. }\end{array}$ \\
\hline $\begin{array}{l}\text { Ride-sharing } \\
\text { (cf. transport model } \\
\text { docu) }\end{array}$ & $\begin{array}{l}\operatorname{RiS}(G, o, t, S) \\
\text { Unit: } 1(\%) \\
\text { RiS } \\
\text { 6_PR_RideSharingSha } \\
\text { re_V1.2 }\end{array}$ & $\begin{array}{l}\text { Share of total passenger-vehicle- } \\
\text { based passenger km that is delivered } \\
\text { by shared rides (several persons } \\
\text { sharing one car) } \\
\text { Not implemented: Parameter }=0 .\end{array}$ & $\begin{array}{l}\text { SSP-consistent assumptions, scenario target } \\
\text { tables. Up to } 30 \% \text {. For justification cf. the } \\
\text { transport model docu! } \\
\text { Implementation curves to not apply here! } \\
\text { (S): SSP-consistent assumptions, scenario } \\
\text { target tables. }\end{array}$ \\
\hline $\begin{array}{l}\text { ULD: Product } \\
\text { Downsizing } \\
\text { (cf. transport and } \\
\text { building model docu) }\end{array}$ & $\begin{array}{l}D S(s, r, t, S), \\
D S(u, r, t, S) \\
\text { Unit: } 1(\%) \\
\text { 3_SHA_DownSizing_V } \\
\text { ehicles_V2.3 } \\
\text { 3_SHA_DownSizing_B } \\
\text { uildings_V1.3 }\end{array}$ & $\begin{array}{l}\text { Share of new passenger } \\
\text { vehicles/buildings that are built with } \\
\text { leaner design (buildings) or of a } \\
\text { smaller segment (vehicles). Mix of } \\
\text { standard and down-sized archetypes }\end{array}$ & $\begin{array}{l}\text { Share of lean-design buildings in UK, } 2040 \text {, } \\
\text { SSP1 is } 65 \% \text {. } \\
\text { (S): SSP-consistent assumptions, scenario } \\
\text { target tables. } \\
\text { Implementation curves do not apply. }\end{array}$ \\
\hline $\begin{array}{l}\text { MSu: Product Light- } \\
\text { weighting } \\
\text { (cf. transport and } \\
\text { building model docu) }\end{array}$ & $\begin{array}{l}M S(G, r, t, S) \\
M S(p, r, t, S) \\
\text { 3_SHA_LightWeightin } \\
\text { g_Buildings_V2.2 } \\
\text { 3_SHA_LightWeightin } \\
\text { g_Vehicles_V1.2 }\end{array}$ & $\begin{array}{l}\text { Share of new passenger } \\
\text { vehicles/buildings that are built } \\
\text { lighter by substituting materials. Mix } \\
\text { of standard and down-sized } \\
\text { archetypes }\end{array}$ & $\begin{array}{l}\text { Share of material-substituted buildings in } \\
\text { UK, } 2040, \text { SSP } 1 \text { is } 65 \% \text {. } \\
\text { (S): SSP-consistent assumptions, scenario } \\
\text { target tables. } \\
\text { Implementation curves do not apply. }\end{array}$ \\
\hline $\begin{array}{l}\text { LTE: Product lifetime } \\
\text { extension }\end{array}$ & $\begin{array}{l}\text { LTE }(p, o, S), \operatorname{LTE}(B, r, S) \\
\text { Unit: } 1(\%) \\
\text { 6_PR_LifeTimeExtensi } \\
\text { on_passvehicles_V2.1 } \\
\text { 6_PR_LifeTimeExtensi } \\
\text { on_resbuildings_V2.2 }\end{array}$ & $\begin{array}{l}\text { Longer product life. } \\
\text { Not implemented: Lifetimes stays at } \\
\text { given value }\end{array}$ & $\begin{array}{l}\text { (S): } 90 \% \text { for res. Buildings, } 20 \% \text { for pass. } \\
\text { Vehs., following Milford et al. (2013), DOI: } \\
\text { 10.1021/es } 3031424 \\
\text { Implementation curves apply. }\end{array}$ \\
\hline $\begin{array}{l}\text { Obsolete stock } \\
\text { formation reduction }\end{array}$ & Unit: 1 (\%) & $\begin{array}{l}\text { Fewer products going to obsolete } \\
\text { stocks. }\end{array}$ & Not considered! \\
\hline $\begin{array}{l}\text { ReU: Re-use of } \\
\text { products and their } \\
\text { components }\end{array}$ & $\begin{array}{l}\operatorname{Re} U(m, B, o), \\
\operatorname{ReU}(m, p, r, t, S) \\
\text { Unit: } 1(\%) \\
\text { Vehicles: } \\
\text { 6_PR_ReUse_Veh_V1 } \\
.2 \\
\text { Buildings: } \\
\text { 6_PR_ReUse_Bld_V3. } \\
1\end{array}$ & $\begin{array}{l}\text { Share of materials in end-of-life } \\
\text { products that gets reused or } \\
\text { remanufactured without undergoing } \\
\text { recycling } \\
\text { Not implemented: Re-use flow }=0\end{array}$ & $\begin{array}{l}\text { All vehicle values from scenario target table, } \\
\text { documentation in transport model docu. } \\
\text { Buildings: } \\
\text { (S): Up to } 29 \% \text { for construction steel, } \\
\text { following Milford et al. (2013), DOI: } \\
\text { 10.1021/es3031424 } \\
\text { Up to } 27 \% \text { for concrete (in concrete } \\
\text { elements), estimated from Shanks et al. } \\
\text { (2019), DOI } \\
\text { 10.1016/j.resconrec.2018.11.002 } \\
\text { Implementation curves apply. }\end{array}$ \\
\hline
\end{tabular}




\begin{tabular}{|c|c|c|c|}
\hline $\begin{array}{l}\text { EoL: EoL recovery } \\
\text { rate improvement }\end{array}$ & $\begin{array}{l}\operatorname{EoL}(G, o, m, w, W \\
\text { Unit: } 1 \text { (p.p.) } \\
\text { 6_PR_EoL_RR_Improv } \\
\text { ement_V2.2 }\end{array}$ & $\begin{array}{l}\text { Improvement of current EoL recovery } \\
\text { rates of postconsumer scrap from } \\
\text { EoL products entering waste mgt. }\end{array}$ & $\begin{array}{l}26 \text { p.p. for automotive steel, } 2 \text { p.p. for cast } \\
\text { iron, } 8 \text { p.p. for Al, } 15 \text { p.p. for Cu. } \\
\text { Implementation curves apply. } \\
\text { (S): Two main sources: Cullen Sankey work } \\
2012 \text { and World Steel Bulleting, for details } \\
\text { cf. parameter files. }\end{array}$ \\
\hline $\begin{array}{l}\text { FYI: Fabrication yield } \\
\text { improvement }\end{array}$ & $\begin{array}{l}\text { FYI }(m, g, o, S) \\
\text { Unit: } 1 \text { (p.p.) } \\
\text { 6_PR_FabricationYiel } \\
\text { dlmprovement_V2.1 }\end{array}$ & $\begin{array}{l}\text { Improvement of current fabrication } \\
\text { yield loss rates }\end{array}$ & $\begin{array}{l}\text { (S): } 10 \text { p.p. for automotive steel, following } \\
\text { DOI } 10.1021 / \text { es } 3031424 \\
\text { 1.5 p.p. for concrete in construction, } \\
\text { following DOI } \\
\text { 10.1016/j.resconrec. } 2018.11 .002 \\
\text { Implementation curves apply. }\end{array}$ \\
\hline $\begin{array}{l}\text { FSD: Fabrication } \\
\text { scrap diversion }\end{array}$ & $\begin{array}{l}\text { FSD }(m, w, o, S) \\
\text { Unit: } 1 \text { (p.p.) } \\
\text { 6_PR_FabricationScra } \\
\text { pDiversion_V1.2 }\end{array}$ & $\begin{array}{l}\text { Share of fabrication scrap that is } \\
\text { diverted into other manufacturing } \\
\text { sectors instead of being remelted. }\end{array}$ & $\begin{array}{l}\text { (S): Up to } 80 \% \text { of automotive steel } \\
\text { fabrication scrap can be diverted, following } \\
\text { DOI } \\
\text { 10.1021/es } 3031424 \\
\text { Implementation curves apply. }\end{array}$ \\
\hline
\end{tabular}

The list below provides a summary of which parameters relate to the different material efficiency strategies. A number of strategies is modelled as technical potentials scaled up by an implementation curve, which is defined in the parameter 3_SHA_RECC_REStrategyScaleUp: This parameter quantifies the extent to which a given industry RE strategy will be implemented (\%). It applies to all industry RE strategy parameter and is dependent on time $t$, socioeconomic scenario $S$, and climate policy scenario R. In the current implementation (ODYM-RECC V2.2), a linear increase of the scale-up curve from $0 \%$ in 2019 to $100 \%$ in 2040 is assumed, followed by a splint interpolation to reduce the changes in the first derivative. This curve is applied to all regions and climate policy scenarios.

- MIU: More intense use (buildings) [2_S_RECC_FinalProducts_Future_resbuildings_V2.2, 2_S_RECC_FinalProducts_Future_resbuildings_MIUPotential_V1.0]

- CaS: Car-sharing: [1_F_ServiceFlows_Future, 6_MIP_CarSharing_Stock, 6_PR_CarSharingShare]

- RiS: Ride-sharing: [1_F_ServiceFlows_Future, 6_MIP_RideSharing_Occupancy, 6_PR_RideSharingShare]

- ULD: Light-weighting by car segment shift or using less material by design [3_MC_BuildingArchetypes_V1.1, 3_MC_VehicleArchetypes_V1.1, 3_SHA_DownSizing_Vehicles_V2.3, 3_SHA_DownSizing_Buildings_V1.3] (Feedback on use phase energy intensity is implemented via parameters 3_EI_VehicleArchetypes_V4.0 and 3_El_BuildingArchetypes_V1.1)

- MSu: Substitution of materials [3_MC_BuildingArchetypes_V1.1, 3_MC_VehicleArchetypes_V1.1, 3_SHA_LightWeighting_Vehicles_V1.2, 3_SHA_LightWeighting_Buildings_V2.2] (Feedback on use phase energy intensity is implemented via parameters 3_EI_VehicleArchetypes_V4.0 and 3_El_BuildingArchetypes_V1.1)

- LTE: Lifetime extension [3_SHA_RECC_REStrategyScaleUp, 6_PR_LifeTimeExtension_passvehicles, 6_PR_LifeTimeExtension_resbuildings]

- ReU: Re-use [3_SHA_RECC_REStrategyScaleUp, 6_PR_ReUse_Bld, 6_PR_ReUse_Veh]

- FYI: Fabrication scrap reduction (yield improvement) [3_SHA_RECC_REStrategyScaleUp, 6_PR_FabricationYieldImprovement]

- EoL: Improved recovery efficiency of scrap from end-of-life (EoL) products [3_SHA_RECC_REStrategyScaleUp, 6_PR_EOL_RR_Improvement]

- FSD: Fabrication scrap diversion [3_SHA_RECC_REStrategyScaleUp, 6_PR_FabricationScrapDiversion] 


\subsection{Numerical data, units, and uncertainty in ODYM-RECC}

Numerical data are stored as float type, usually in numpy arrays, where each data aspect spans one array dimension.

Each system variable and each model parameter has a unit, and this unit is specified in the parameter files (either as global unit or for each individual value), and in the model code (for system variables). Note: At this development stage, the software does not verify the correct application of units, this is up to the model user. Special attention needs to be kept in situations where a single parameter has mixed units, e.g., the material composition of products, which is measured in $\mathrm{kg} /$ item for vehicles and $\mathrm{kg} / \mathrm{m}^{2}$ for buildings.

In the ODYM-RECC model uncertainty of numerical values is recorded using stats_array strings, a concept developed by Chris Mutel (http://stats-arrays.readthedocs.io/en/latest/). The type of uncertainty information for a numerical value is coded via table 5.8, and the parameters (if any) for each type are defined in the subsequent colums loc, scale, shape, min, and max.

Table 5.8: The stats_array coding system. Taken from http://stats-arrays.readthedocs.io/en/latest/ and extended.

\begin{tabular}{|l|r|l|l|l|l|l|}
\hline Name & ID & loc & scale & shape & min & max \\
\hline undefined & $\mathbf{0}^{*}$ & static value & & & & \\
\hline No uncertainty & $\mathbf{1}$ & static value & & & & \\
\hline Lognormal & $\mathbf{2}$ & $\mathrm{mu}$ & sigma & & & \\
\hline Normal & $\mathbf{3}$ & $\mathrm{mu}$ & sigma & & & \\
\hline Uniform & $\mathbf{4}$ & & & & $\min$ & $\max$ \\
\hline Triangular & $\mathbf{5}$ & mode & & & min & max \\
\hline Bernoulli & $\mathbf{6}$ & $\mathrm{p}$ & & & lower bound & upper bound \\
\hline Discrete uniform & $\mathbf{7}$ & & & & min & upper bound \\
\hline Weibull & $\mathbf{8}$ & offset & lambda & $\mathrm{k}$ & & \\
\hline Gamma & $\mathbf{9}$ & offset & theta & $\mathrm{k}$ & & \\
\hline Beta & $\mathbf{1 0}$ & alpha & upper bound & beta & & \\
\hline $\begin{array}{l}\text { Generalized } \\
\text { extreme value }\end{array}$ & $\mathbf{1 1}$ & mu & sigma & xi & & \\
\hline Student's T & $\mathbf{1 2}$ & median & scale & nu & & \\
\hline low-mean-high & $\mathbf{1 3}$ & low & high & & & \\
\hline & $\mathbf{1 4}$ & & & & & \\
\hline & $\mathbf{1 5}$ & & & & & \\
\hline
\end{tabular}

${ }^{*}$ ) or just 'none'

The current list is available under:

\section{http://www.database.industrialecology.uni-freiburg.de/uncertainty.aspx}

In ODYM RECC the uncertainty information is coded as a string in the following format:

$$
\text { 'ID; loc; scale; shape; min; max' }
$$

Empty fields are filled with 'none' or 'None'. References to the numerical value given for the data item are denoted with 'value' or 'Value'.

For example, a normally distributed value of mean 10 and standard deviation 1.5 has the stats_array string ' $3 ; 10 ; 1.5$; none; none; none'. 
A value with undefined or unkown uncertainty has the stats_array_string

' 0 ; Value; none; none; none; none'.

A uniformly distributed data item with lower bound 0 and upper bound 1 is denoted by

' 4 ; none; none; none; $0 ; 1$ '.

A value for which low and high alternatives are given is characterized by

'13; low; high; none; none; none' (where both high and low alternative are present),

'13; low; none; none; none; none' (where only low alternative is present),

'13; none; high; none; none; none' (where only high alternative is present),

'13;0.8*value;1.2*value; none; none; none' (where high and low alternative are taken as $80 \%$ and $120 \%$ of the given value).

\subsection{ODYM-RECC parameter list and rationales}

The following table 5.9 lists the 56 ODYM-RECC v2.2 parameters introduced above, lists the version and aspects used as well as the unit, and provides a rationale for the central parameters and points to the individual parameter files. For the scenario parameters obtained from the target table interpolation, the data sources and assumptions are listed in the transport and building model documentations (Heeren et al., 2019; Wolfram et al., 2019).

Table 5.9: The ODYM-RECC parameter list. Left: Parameter name // version number // aspect structure (cf. Table 3.1) // unit. Right: reference to parameter and (if applicable) rationale of parameter choice.

\begin{tabular}{|c|c|}
\hline ODYM-RECC parameter & Reference and (if applicable) rationale of parameter choice \\
\hline $\begin{array}{l}\text { 2_P_RECC_Population_SSP_32R } \\
\text { V2.1 } \\
\text { MtrS } \\
\text { Million }\end{array}$ & $\begin{array}{l}\text { See the ODYM_RECC v2.2 parameter file 2_P_RECC_Population_SSP_32R_V2.1.xIsx for } \\
\text { details. https://zenodo.org/record/3566865 }\end{array}$ \\
\hline $\begin{array}{l}\text { 2_S_RECC_FinalProducts_2015_passvehicles } \\
\text { V1.1 } \\
\text { tcpr } \\
\text { vehicles: million units. buildings: billion } \mathrm{m} 2\end{array}$ & $\begin{array}{l}\text { See the ODYM_RECC v2.2 parameter file } \\
\text { 2_S_RECC_FinalProducts_2015_passvehicles_V1.1.xlsx for details. } \\
\text { https://zenodo.org/record/3566865 }\end{array}$ \\
\hline $\begin{array}{l}\text { 2_S_RECC_FinalProducts_2015_resbuildings } \\
\text { V1.1 } \\
\text { tcBr } \\
\text { vehicles: million units. buildings: billion m2 }\end{array}$ & $\begin{array}{l}\text { See the ODYM_RECC v2.2 parameter file } \\
\text { 2_S_RECC_FinalProducts_2015_resbuildings_V1.1.xlsx for details. } \\
\text { https://zenodo.org/record/3566865 }\end{array}$ \\
\hline $\begin{array}{l}\text { 1_F_ServiceFlows_Future } \\
\text { V1.2 } \\
\text { GrtS } \\
\text { inhabitant*m2*yr/yr and passenger-km/yr }\end{array}$ & $\begin{array}{l}\text { See the ODYM_RECC v2.2 parameter file 1_F_ServiceFlows_Future_V1.2.xlsx for details. } \\
\text { https://zenodo.org/record/3566865 } \\
\text { Transport service demand to be fulfilled by vehicles in total, from } 2015 \text { to } 2100 \text {, for each } \\
\text { region. See the corresponding section in the "Transport modeling documentation". }\end{array}$ \\
\hline
\end{tabular}




\begin{tabular}{|c|c|}
\hline $\begin{array}{l}\text { 2_S_RECC_FinalProducts_Future_resbuildings } \\
\text { V2.2 } \\
\text { StGr } \\
\text { buildings: } m 2 \text { per person }\end{array}$ & 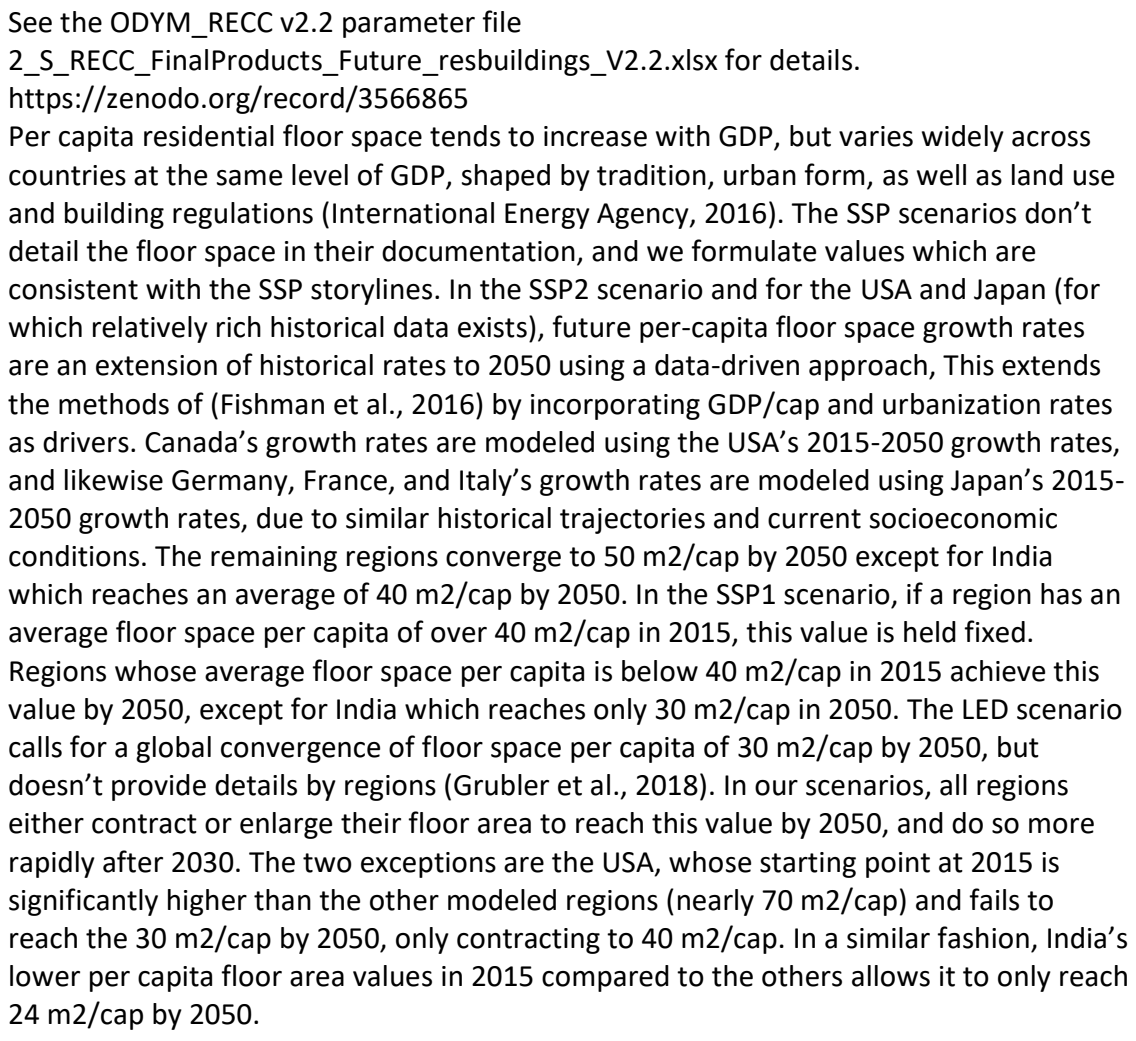 \\
\hline $\begin{array}{l}\text { 2_S_RECC_FinalProducts_Future_ } \\
\text { resbuildings_MIUPotential } \\
\text { V1.0 } \\
\text { GoS } \\
\%\end{array}$ & $\begin{array}{l}\text { See the ODYM_RECC v2.2 parameter file } \\
\text { 2_S_RECC_FinalProducts_Future_resbuildings_MIUPotential_V1.0.xIsx for details. } \\
\text { https://zenodo.org/record/3566865 } \\
\text { This parameter describes the maximum reduction potential for per-capita floor space. } \\
\text { This potential is gradually seized over time, starting from the } 2015 \text { reference value. } \\
\text { Based on various literature sources that describe scenarios for the reduction of per } \\
\text { capita floor space (Rao and Baer 2012, DOI 10.3390/su4040656, Grubler et al. 2018, DOI } \\
10.1038 / \text { s41560-018-0172-6) or material demand for residential buildings due to more } \\
\text { intense use (Milford et al., 2013, DOI: } 10.1021 / \text { es } 3031424 \text { ) a value of } 20 \% \text { was chosen. } \\
\text { Moreover, it is ensured that the resulting reduced per capita floor space does not fall } \\
\text { below the scenario curve of the low energy demand scenario (LED), which, with a target } \\
\text { value of } 30 \text { m2/cap, is the bottom line of the assessment. To that end, the actual floor } \\
\text { space for each region and year is calculated as maximum(LEDvalue, value obtained from } \\
\text { MIU implementation). }\end{array}$ \\
\hline $\begin{array}{l}\text { 3_El_Products_UsePhase_passvehicles } \\
\text { V1.1 } \\
\text { cpVnrS } \\
\text { Vehicles: MJ/km. Buildings: MJ } / \mathrm{m} 2 / \mathrm{yr}\end{array}$ & $\begin{array}{l}\text { See the ODYM_RECC v2.2 parameter file } \\
\text { 3_EI_Products_UsePhase_passvehicles_V1.1.xlsx for details. } \\
\text { https://zenodo.org/record/3566865 }\end{array}$ \\
\hline $\begin{array}{l}\text { 3_El_Products_UsePhase_resbuildings } \\
\text { V1.1 } \\
\text { cBVnrS } \\
\text { Vehicles: MJ } / \mathrm{km} \text {. Buildings: } \mathrm{MJ} / \mathrm{m} 2 / \mathrm{yr}\end{array}$ & $\begin{array}{l}\text { See the ODYM_RECC v2.2 parameter file } \\
\text { 3_EI_Products_UsePhase_resbuildings_V1.1.xIsx for details. } \\
\text { https://zenodo.org/record/3566865 }\end{array}$ \\
\hline $\begin{array}{l}\text { 3_IO_Vehicles_UsePhase } \\
\text { V2.2 } \\
\text { VrtS } \\
\text { vehicles: } \mathrm{km} / \mathrm{yr}\end{array}$ & $\begin{array}{l}\text { See the ODYM_RECC v2.2 parameter file 3_IO_Vehicles_UsePhase_V2.2.xlsx for details. } \\
\text { https://zenodo.org/record/3566865 }\end{array}$ \\
\hline
\end{tabular}




\begin{tabular}{|c|c|}
\hline $\begin{array}{l}\text { 6_MIP_VehicleOccupancyRate } \\
\text { V1.2 } \\
\text { GrtS } \\
1\end{array}$ & $\begin{array}{l}\text { See the ODYM_RECC v2.2 parameter file 6_MIP_VehicleOccupancyRate_V1.2.xlsx for } \\
\text { details. https://zenodo.org/record/3566865 } \\
\text { Occupany rates for vehicles in different regions from 2015-2100. The rates are assumed } \\
\text { to be uniform for all vehicle archetypes. See the corresponding section in the "Transport } \\
\text { modeling documentation". }\end{array}$ \\
\hline $\begin{array}{l}\text { 3_IO_Buildings_UsePhase } \\
\text { V1.2 } \\
\text { cBVrS } \\
\text { share of } \mathrm{m} 2 \text { heated and cooled }\end{array}$ & $\begin{array}{l}\text { See the ODYM_RECC v2.2 parameter file 3_IO_Buildings_UsePhase_V1.2.xlsx for details. } \\
\text { https://zenodo.org/record/3566865 }\end{array}$ \\
\hline $\begin{array}{l}\text { 3_LT_RECC_ProductLifetime_passvehicles } \\
\text { V3.1 } \\
\text { pr } \\
\text { yr }\end{array}$ & $\begin{array}{l}\text { See the ODYM_RECC v2.2 parameter file } \\
\text { 3_LT_RECC_ProductLifetime_passvehicles_V3.1.xlsx for details. } \\
\text { https://zenodo.org/record/3566865 }\end{array}$ \\
\hline $\begin{array}{l}\text { 3_LT_RECC_ProductLifetime_resbuildings } \\
\text { V4.0 } \\
\text { Brc } \\
\text { yr }\end{array}$ & $\begin{array}{l}\text { See the ODYM_RECC v2.2 parameter file } \\
\text { 3_LT_RECC_ProductLifetime_resbuildings_V4.0.xlsx for details. } \\
\text { https://zenodo.org/record/3566865 }\end{array}$ \\
\hline $\begin{array}{l}\text { 3_MC_RECC_Buildings } \\
\mathrm{V} 1.1 \\
\mathrm{cmBr} \\
\mathrm{kg} / \mathrm{m} 2\end{array}$ & $\begin{array}{l}\text { See the ODYM_RECC v2.2 parameter file 3_MC_RECC_Buildings_V1.1.xlsx for details. } \\
\text { https://zenodo.org/record/3566865 }\end{array}$ \\
\hline $\begin{array}{l}\text { 3_MC_RECC_Vehicles } \\
\text { V1.1 } \\
\text { cmpr } \\
\text { kg/unit }\end{array}$ & $\begin{array}{l}\text { See the ODYM_RECC v2.2 parameter file 3_MC_RECC_Vehicles_V1.1.xlsx for details. } \\
\text { https://zenodo.org/record/3566865 }\end{array}$ \\
\hline $\begin{array}{l}\text { 3_MC_Elements_Materials_ExistingStock } \\
\text { V2.1 } \\
\text { me } \\
1(\mathrm{~kg} / \mathrm{kg})\end{array}$ & $\begin{array}{l}\text { See the ODYM_RECC v2.2 parameter file } \\
\text { 3_MC_Elements_Materials_ExistingStock_V2.1.xlsx for details. } \\
\text { https://zenodo.org/record/3566865 }\end{array}$ \\
\hline $\begin{array}{l}\text { 3_MC_Elements_Materials_Primary } \\
\text { V2.1 } \\
\text { me } \\
1(\mathrm{~kg} / \mathrm{kg})\end{array}$ & $\begin{array}{l}\text { See the ODYM_RECC v2.2 parameter file 3_MC_Elements_Materials_Primary_V2.1.xlsx } \\
\text { for details. https://zenodo.org/record/3566865 }\end{array}$ \\
\hline $\begin{array}{l}\text { 3_PR_RECC_CO2Price_SSP_32R } \\
\text { V2.1 } \\
\text { RtrS } \\
\text { US\$2005/ton }\end{array}$ & $\begin{array}{l}\text { See the ODYM_RECC v2.2 parameter file 3_PR_RECC_CO2Price_SSP_32R_V2.1.xlsx for } \\
\text { details. https://zenodo.org/record/3566865 }\end{array}$ \\
\hline $\begin{array}{l}\text { 3_SHA_RECC_REStrategyScaleUp } \\
\text { V3.3 } \\
\text { RotS } \\
1\end{array}$ & $\begin{array}{l}\text { See the ODYM_RECC v2.2 parameter file 3_SHA_RECC_REStrategyScaleUp_V3.3.xIsx for } \\
\text { details. https://zenodo.org/record/3566865 } \\
\text { This parameter quantifies the extent to which a given industry RE strategy will be } \\
\text { implemented (\%). It applies to all industry RE strategy parameters and is dependent on } \\
\text { time t, socioeconomic scenario S, and climate policy scenario R. In the current } \\
\text { implementation (ODYM-RECC V2.2), a linear increase of the scale-up curve from } 0 \% \text { in } \\
2019 \text { to } 100 \% \text { in } 2040 \text { is assumed, followed by a spline interpolation to reduce the } \\
\text { changes in the first derivative. This curve is applied to all regions and climate policy } \\
\text { scenarios. }\end{array}$ \\
\hline $\begin{array}{l}\text { 4_PE_GHGIntensityEnergySupply } \\
\text { V4.0 } \\
\text { XnSRrt } \\
\text { kg of CO2-eq/MJ }\end{array}$ & $\begin{array}{l}\text { See the ODYM_RECC v2.2 parameter file 4_PE_GHGIntensityEnergySupply_V4.0.xlsx for } \\
\text { details. https://zenodo.org/record/3566865 }\end{array}$ \\
\hline
\end{tabular}




\begin{tabular}{|c|c|}
\hline $\begin{array}{l}\text { 4_PE_GHGIntensityEnergySupply_World } \\
\text { V4.0 } \\
\text { XnSRot } \\
\text { kg of CO2-eq/MJ }\end{array}$ & $\begin{array}{l}\text { See the ODYM_RECC v2.2 parameter file } \\
\text { 4_PE_GHGIntensityEnergySupply_World_V4.0.xlsx for details. } \\
\text { https://zenodo.org/record/3566865 }\end{array}$ \\
\hline $\begin{array}{l}\text { 4_PE_GHGIntensityElectricitySupply_Backstop } \\
\text { V1.0 } \\
\text { XnSRt } \\
\text { kg of CO2-eq/MJ }\end{array}$ & $\begin{array}{l}\text { See the ODYM_RECC v2.2 parameter file } \\
\text { 4_PE_GHGIntensityElectricitySupply_Backstop_V1.0.xlsx for details. } \\
\text { https://zenodo.org/record/3566865 }\end{array}$ \\
\hline $\begin{array}{l}\text { 4_PE_ProcessExtensions } \\
\text { V3.3 } \\
\text { PXotS } \\
\mathrm{kg} / \mathrm{kg}\end{array}$ & $\begin{array}{l}\text { See the ODYM_RECC v2.2 parameter file 4_PE_ProcessExtensions_V3.3.xIsx for details. } \\
\text { https://zenodo.org/record/3566865 } \\
\text { This parameter describes the lifecycle kg of GHG emissions associated with production } \\
\text { of } 1 \mathrm{~kg} \text { of the main construction and manufacturing materials considered in this study. } \\
\text { Values are based on ecoinvent and recalculated for changing global electricity mix and } \\
\text { assumptions on production efficiency (Vadnepaer et al. 2019). }\end{array}$ \\
\hline $\begin{array}{l}\text { 4_El_ProcessEnergylntensity } \\
\text { V2.1 } \\
\text { Pnco } \\
\text { MJ/kg }\end{array}$ & $\begin{array}{l}\text { See the ODYM_RECC v2.2 parameter file 4_EI_ProcessEnergyIntensity_V2.1.xIsx for } \\
\text { details. https://zenodo.org/record/3566865 }\end{array}$ \\
\hline $\begin{array}{l}\text { 4_EI_ManufacturingEnergylntensity } \\
\text { V2.1 } \\
\text { Fnco } \\
\text { MJ/kg }\end{array}$ & $\begin{array}{l}\text { See the ODYM_RECC v2.2 parameter file 4_EI_ManufacturingEnergyIntensity_V2.1.xlsx } \\
\text { for details. https://zenodo.org/record/3566865 }\end{array}$ \\
\hline $\begin{array}{l}\text { 4_PY_EoL_RecoveryRate } \\
\text { V2.2 } \\
\text { gomwW } \\
\%\end{array}$ & $\begin{array}{l}\text { See the ODYM_RECC v2.2 parameter file 4_PY_EoL_RecoveryRate_V2.2.xIsx for details. } \\
\text { https://zenodo.org/record/3566865 }\end{array}$ \\
\hline $\begin{array}{l}\text { 4_PY_Manufacturing } \\
\text { V2.1 } \\
\text { mwgFto } \\
1\end{array}$ & $\begin{array}{l}\text { See the ODYM_RECC v2.2 parameter file 4_PY_Manufacturing_V2.1.xlsx for details. } \\
\text { https://zenodo.org/record/3566865 }\end{array}$ \\
\hline $\begin{array}{l}\text { 4_PY_MaterialProductionRemelting } \\
\text { V2.2 } \\
\text { wmeWto } \\
1\end{array}$ & $\begin{array}{l}\text { See the ODYM_RECC v2.2 parameter file 4_PY_MaterialProductionRemelting_V2.2.xIsx } \\
\text { for details. https://zenodo.org/record/3566865 }\end{array}$ \\
\hline $\begin{array}{l}\text { 4_El_WasteMgtEnergylntensity } \\
\text { V1.1 } \\
\text { wnco } \\
\text { MJ/kg }\end{array}$ & $\begin{array}{l}\text { See the ODYM_RECC v2.2 parameter file 4_EI_WasteMgtEnergyIntensity_V1.1.xlsx for } \\
\text { details. https://zenodo.org/record/3566865 }\end{array}$ \\
\hline $\begin{array}{l}\text { 4_El_RemeltingEnergylntensity } \\
\text { V2.1 } \\
\text { mnco } \\
\mathrm{MJ} / \mathrm{kg}\end{array}$ & $\begin{array}{l}\text { See the ODYM_RECC v2.2 parameter file 4_EI_RemeltingEnergyIntensity_V2.1.xlsx for } \\
\text { details. https://zenodo.org/record/3566865 }\end{array}$ \\
\hline $\begin{array}{l}\text { 6_PR_EoL_RR_Improvement } \\
\text { V2.2 } \\
\text { gomwW } \\
\text { percentage points }\end{array}$ & $\begin{array}{l}\text { See the ODYM_RECC v2.2 parameter file 6_PR_EoL_RR_Improvement_V2.2.xIsx for } \\
\text { details. https://zenodo.org/record/3566865 }\end{array}$ \\
\hline $\begin{array}{l}\text { 6_PR_LifeTimeExtension_passvehicles } \\
\text { V2.1 } \\
\text { poS } \\
1\end{array}$ & $\begin{array}{l}\text { See the ODYM_RECC v2.2 parameter file } \\
\text { 6_PR_LifeTimeExtension_passvehicles_V2.1.xIsx for details. } \\
\text { https://zenodo.org/record/3566865 }\end{array}$ \\
\hline
\end{tabular}




\begin{tabular}{|c|c|}
\hline $\begin{array}{l}\text { 6_PR_LifeTimeExtension_resbuildings } \\
\text { V2.2 } \\
\mathrm{BrS} \\
1\end{array}$ & $\begin{array}{l}\text { See the ODYM_RECC v2.2 parameter file } \\
\text { 6_PR_LifeTimeExtension_resbuildings_V2.2.xlsx for details. } \\
\text { https://zenodo.org/record/3566865 }\end{array}$ \\
\hline $\begin{array}{l}\text { 6_PR_FabricationYieldlmprovement } \\
\text { V2.1 } \\
\text { mgoS } \\
1\end{array}$ & $\begin{array}{l}\text { See the ODYM_RECC v2.2 parameter file 6_PR_FabricationYieldImprovement_V2.1.xIsx } \\
\text { for details. https://zenodo.org/record/3566865 }\end{array}$ \\
\hline $\begin{array}{l}\text { 6_PR_FabricationScrapDiversion } \\
\text { V1.2 } \\
\text { mwoS } \\
1\end{array}$ & $\begin{array}{l}\text { See the ODYM_RECC v2.2 parameter file 6_PR_FabricationScrapDiversion_V1.2.xlsx for } \\
\text { details. https://zenodo.org/record/3566865 }\end{array}$ \\
\hline $\begin{array}{l}\text { 6_PR_ReUse_Bld } \\
\text { V3.1 } \\
\text { mBo } \\
1\end{array}$ & $\begin{array}{l}\text { See the ODYM_RECC v2.2 parameter file 6_PR_ReUse_Bld_V3.1.xlsx for details. } \\
\text { https://zenodo.org/record/3566865 }\end{array}$ \\
\hline $\begin{array}{l}\text { 6_PR_ReUse_Veh } \\
\text { V1.2 } \\
\text { mprtS } \\
1\end{array}$ & $\begin{array}{l}\text { See the ODYM_RECC v2.2 parameter file 6_PR_ReUse_Veh_V1.2.xIsx for details. } \\
\text { https://zenodo.org/record/3566865 } \\
\text { Reuse rates for different materials (e.g., \% of cast Al from reuse of vehicle components) } \\
\text { in } 6 \text { vehicle archetypes, from } 2015 \text { to } 2100 \text {, for each region. No further adjustment is } \\
\text { made for weight options or size segments. See the corresponding section in the } \\
\text { "Transport modeling documentation". }\end{array}$ \\
\hline $\begin{array}{l}\text { 6_PR_DirectEmissions } \\
\text { V1.1 } \\
\text { Xn } \\
\text { kg of CO2-eq/MJ }\end{array}$ & $\begin{array}{l}\text { See the ODYM_RECC v2.2 parameter file 6_PR_DirectEmissions_V1.1.xlsx for details. } \\
\text { https://zenodo.org/record/3566865 }\end{array}$ \\
\hline $\begin{array}{l}\text { 6_PR_CarSharingShare } \\
\text { V1.2 } \\
\text { GotS } \\
1\end{array}$ & $\begin{array}{l}\text { See the ODYM_RECC v2.2 parameter file 6_PR_CarSharingShare_V1.2.xlsx for details. } \\
\text { https://zenodo.org/record/3566865 }\end{array}$ \\
\hline $\begin{array}{l}\text { 6_PR_RideSharingShare } \\
\text { V1.2 } \\
\text { GotS } \\
1\end{array}$ & $\begin{array}{l}\text { See the ODYM_RECC v2.2 parameter file 6_PR_RideSharingShare_V1.2.xIsx for details. } \\
\text { https://zenodo.org/record/3566865 } \\
\text { Percentage of transport service demand fulfilled by ride sharing from } 2015 \text { to } 2100 \text {, } \\
\text { assumed to be identical for all regions and all archetypes. See the corresponding section } \\
\text { in the "Transport modeling documentation". }\end{array}$ \\
\hline $\begin{array}{l}\text { 3_SHA_TypeSplit_Vehicles } \\
\text { V2.1 } \\
\text { GptrS } \\
\%\end{array}$ & $\begin{array}{l}\text { See the ODYM_RECC V2.2 parameter file 3_SHA_TypeSplit_Vehicles_V2.1.xlsx for } \\
\text { details. https://zenodo.org/record/3566865 } \\
\text { As part of the project-wide effort to link the ODYM-RECC parameters to existing } \\
\text { scenarios, the IEA Energy Technology Perspectives results, featuring a business as usual } \\
\text { and a } 2^{\circ} \mathrm{C} \text {-compatible BLUE MAP scenario, were used as they were available to us. These } \\
\text { scenario results are from } 2010 \text { and the BLUE MAP contains all relevant electric drive } \\
\text { technologies but does not yet reflect a mostly complete shift to electric mobility. The } \\
\text { mapping of the IEA scenarios to the ones used by us is as follows: BAU for SSP3 and } 5 \text {, } \\
\text { BLUE MAP for LED, SSP } 1 \text { and } 4 \text {, (BAU + BLUE MAP)/2 for SSP2. Clearly, these are proxy } \\
\text { choices, and an update to more recent, ambitious, and better matching vehicle type } \\
\text { split scenarios is a high priority area for future model improvement. }\end{array}$ \\
\hline
\end{tabular}




\begin{tabular}{|c|c|}
\hline $\begin{array}{l}\text { 3_SHA_TypeSplit_Buildings } \\
\text { V1.2 } \\
\text { BrtS } \\
\%\end{array}$ & $\begin{array}{l}\text { See the ODYM_RECC V2.2 parameter file 3_SHA_TypeSplit_Buildings_V1.2.xlsx for } \\
\text { details. https://zenodo.org/record/3566865 } \\
\text { This parameter describes the split of residential buildings along two dimensions, } \\
\text { category (single family housing, multifamily housing, informal) and energy efficiency } \\
\text { standard (non-standard, standard, efficient, zero-energy-building). Projections are made } \\
\text { in line with the socioconomic storylines, while the shares of multifamily housing is } \\
\text { linked to the narrative on urbanisation and use intensity. Higher shares of efficienct } \\
\text { buildings are assumed in the SSP1 and LED scenarios. }\end{array}$ \\
\hline $\begin{array}{l}\text { 3_SHA_EnergyCarrierSplit_Vehicles } \\
\text { V1.1 } \\
\text { cpoVnS } \\
\%\end{array}$ & $\begin{array}{l}\text { See the ODYM_RECC v2.2 parameter file 3_SHA_EnergyCarrierSplit_Vehicles_V1.1.xlsx } \\
\text { for details. https://zenodo.org/record/3566865 }\end{array}$ \\
\hline $\begin{array}{l}\text { 3_SHA_EnergyCarrierSplit_Buildings } \\
\text { V2.2 } \\
\text { VRrnt } \\
\%\end{array}$ & $\begin{array}{l}\text { See the ODYM_RECC v2.2 parameter file 3_SHA_EnergyCarrierSplit_Buildings_V2.2.xlsx } \\
\text { for details. https://zenodo.org/record/3566865 } \\
\text { As part of the project-wide effort to link the ODYM-RECC parameters to existing } \\
\text { scenarios, the IEA Energy Technology Perspectives results, featuring a reference } \\
\text { technology and a } 2^{\circ} \mathrm{C} \text {-compatible scenario, were used. These scenario results are from } \\
2017 \text { and were provided to us at the country level, from which we aggregated them to } \\
\text { the regional resolution of the RECC assessment. The raw data report the total } \\
\text { residential energy consumption by energy carrier, from which we calculated the share } \\
\text { of the individual energy carriers in the total mix. }\end{array}$ \\
\hline $\begin{array}{l}\text { 3_MC_VehicleArchetypes } \\
\text { V2.0 } \\
\text { Am } \\
\mathrm{kg} / \mathrm{unit}, \mathrm{kg} / \mathrm{m} 2\end{array}$ & $\begin{array}{l}\text { See the ODYM_RECC v2.2 parameter file 3_MC_VehicleArchetypes_V2.0.xlsx for details. } \\
\text { https://zenodo.org/record/3566865 } \\
\text { material composition (in kg) of } 48 \text { vehicle archetypes ( } 6 \text { powertrains } x 2 \text { weight options } \\
\text { x } 4 \text { size segments), assumed to be identical for all regions and all time. The values are } \\
\text { derived from the material composition data in GREET2 vehicle cycle model. See the } \\
\text { corresponding section in the "Transport modeling documentation". }\end{array}$ \\
\hline $\begin{array}{l}\text { 3_El_VehicleArchetypes } \\
\text { V4.0 } \\
\text { An } \\
M J / k m, M J / m 2 / y r\end{array}$ & $\begin{array}{l}\text { See the ODYM_RECC v2.2 parameter file 3_EI_VehicleArchetypes_V4.0.xlsx for details. } \\
\text { https://zenodo.org/record/3566865 } \\
\text { Fuel economy (in MJ/km) of } 48 \text { vehicle archetypes ( } 6 \text { powertrains x } 2 \text { weight options x } 4 \\
\text { size segments), assumed to be identical for all regions and all time. The values are } \\
\text { derived from "Future Automotive Systems Technology Simulator" (FASTSim). See the } \\
\text { corresponding section in the "Transport modeling documentation". }\end{array}$ \\
\hline $\begin{array}{l}\text { 3_MC_BuildingArchetypes } \\
\text { V1.1 } \\
\text { Arm } \\
\text { kg/unit, kg/m2 }\end{array}$ & $\begin{array}{l}\text { See the ODYM_RECC v2.2 parameter file 3_MC_BuildingArchetypes_V1.1.xlsx for } \\
\text { details. https://zenodo.org/record/3566865 } \\
\text { This parameter describes the material composition of building archetypes, in terms of } \\
\text { mass per unit floor space }(\mathrm{kg} / \mathrm{m} 2) \text {. Values are calculated based on Taylor et al. } 2015 \text { and } \\
\text { Heeren and Fishman } 2019 .\end{array}$ \\
\hline $\begin{array}{l}\text { 3_El_BuildingArchetypes } \\
\text { V1.1 } \\
\text { ArVn } \\
\mathrm{MJ} / \mathrm{km}, \mathrm{MJ} / \mathrm{m} 2 / \mathrm{yr}\end{array}$ & $\begin{array}{l}\text { See the ODYM_RECC v2.2 parameter file 3_EI_BuildingArchetypes_V1.1.xlsx for details. } \\
\text { https://zenodo.org/record/3566865 } \\
\text { This parameter describes the energy intensity per unit of floor area. It covers energy } \\
\text { services of three major energy end-uses in residential buildings: space heating, space } \\
\text { cooling, and domestic hot water. Values are defined for each of the building 'types' } \\
\text { defined in 3_SHA_TypeSplit_Buildings, and are based on a simluation of energy } \\
\text { consumption using energyplus and based on archetypes from Taylor et al. } 2015 \text {. }\end{array}$ \\
\hline $\begin{array}{l}\text { 3_SHA_DownSizing_Vehicles } \\
\text { V2.3 } \\
\text { srtS } \\
\%\end{array}$ & $\begin{array}{l}\text { See the ODYM_RECC v2.2 parameter file 3_SHA_DownSizing_Vehicles_V2.3.xlsx for } \\
\text { details. https://zenodo.org/record/3566865 } \\
\text { market share of each size segment of vehicles in the production (inflows) of new } \\
\text { vehicles each year, from } 2015 \text { to } 2100 \text {, for each region. See the corresponding section in } \\
\text { the "Transport modeling documentation". }\end{array}$ \\
\hline
\end{tabular}




\begin{tabular}{|c|c|}
\hline $\begin{array}{l}\text { 3_SHA_LightWeighting_Vehicles } \\
\text { V1.2 } \\
\text { prtS } \\
\%\end{array}$ & $\begin{array}{l}\text { See the ODYM_RECC v2.2 parameter file 3_SHA_LightWeighting_Vehicles_V1.2.xlsx for } \\
\text { details. https://zenodo.org/record/3566865 } \\
\text { Market share of lightweighted vehicles of each powertrain in the production (inflows) of } \\
\text { new vehicles each year, from } 2015 \text { to } 2100 \text {, for each region. See the corresponding } \\
\text { section in the "Transport modeling documentation". }\end{array}$ \\
\hline $\begin{array}{l}\text { 3_SHA_DownSizing_Buildings } \\
\text { V1.3 } \\
\text { urtS } \\
\%\end{array}$ & $\begin{array}{l}\text { See the ODYM_RECC v2.2 parameter file 3_SHA_DownSizing_Buildings_V1.3.xlsx for } \\
\text { details. https://zenodo.org/record/3566865 } \\
\text { This parameter describes the share of new constructions which are considered in the } \\
\text { lightweighting Material Efficiency Strategy. }\end{array}$ \\
\hline $\begin{array}{l}\text { 3_SHA_LightWeighting_Buildings } \\
\text { V2.2 } \\
\text { GrtS } \\
\%\end{array}$ & $\begin{array}{l}\text { See the ODYM_RECC v2.2 parameter file 3_SHA_LightWeighting_Buildings_V2.2.xlsx for } \\
\text { details. https://zenodo.org/record/3566865 } \\
\text { This parameter describes the share of new residential buildings which is built a } \\
\text { predominantly timber-frame structure, as opposed to concrete. It is based on the } \\
\text { construction styles most often implemented in each country currently (e.g. US, Canada, } \\
\text { and Japan start with already high shares of 'lightweight' buildings). Generally, countries } \\
\text { which do not currently have a large share of lightweighted buildings are projected build } \\
\text { more timber-frame structures so that the share of lightweighted buildings in new } \\
\text { construction reaches } 85 \% \text { (LED), 50\% (SSP1), and 10\% (SSP2) in 2050, while countries } \\
\text { with already high shares generally remain stable or slightly increase the share of } \\
\text { lightweighted buildings to } 95 \% \text { in } 2050\end{array}$ \\
\hline $\begin{array}{l}\text { 6_PR_Calibration } \\
\text { V2.2 } \\
\mathrm{Cr} \\
\text { ratio }\end{array}$ & $\begin{array}{l}\text { See the ODYM_RECC v2.2 parameter file 6_PR_Calibration_V2.2.xlsx for details. } \\
\text { https://zenodo.org/record/3566865 }\end{array}$ \\
\hline $\begin{array}{l}\text { 6_MIP_CarSharing_Stock } \\
\text { V1.0 } \\
\text { Sr } \\
1\end{array}$ & $\begin{array}{l}\text { See the ODYM_RECC v2.2 parameter file 6_MIP_CarSharing_Stock_V1.0.xIsx for details. } \\
\text { https://zenodo.org/record/3566865 } \\
\text { Ratio of per capita passenger vehicle stock with vs. without carsharing to describe the } \\
\text { reduction of vehicle stock due to car-sharing in different regions, assumed to be } \\
\text { identical for all time. The rates are assumed to be uniform for all vehicle archetypes. See } \\
\text { the corresponding section in the "Transport modeling documentation". }\end{array}$ \\
\hline $\begin{array}{l}\text { 6_MIP_RideSharing_Occupancy } \\
\text { V1.0 } \\
\text { Sr } \\
1\end{array}$ & $\begin{array}{l}\text { See the ODYM_RECC v2.2 parameter file 6_MIP_RideSharing_Occupancy_V1.0.xlsx for } \\
\text { details. https://zenodo.org/record/3566865 } \\
\text { Occupany rates for ride-sharing vehicles in different regions, assumed to be identical for } \\
\text { all time. The rates are assumed to be uniform for all vehicle archetypes. See the } \\
\text { corresponding section in the "Transport modeling documentation". }\end{array}$ \\
\hline $\begin{array}{l}\text { 6_MIP_GWP_Bio } \\
\text { V1.0 } \\
\text { c } \\
1\end{array}$ & $\begin{array}{l}\text { See the ODYM_RECC v2.2 } \\
\text { parameter file } \\
\text { 6_MIP_GWP_Bio_V1.0.xIsx for } \\
\text { details. } \\
\text { https://zenodo.org/record/3566865 }\end{array}$ \\
\hline
\end{tabular}




\section{The ODYM-RECC model}

The timeline for the G7-IRP RECC report is short. There is only one year between inception of the project in fall 2017 and the deadline for first solid results and a zero order draft, which is in October 2018 (Hertwich et al., 2017), and the final set of RECC scenarios in October 2019. We need to proceed quickly and it is therefore clear that a number of desirable features cannot be implemented in the first model version but at a later stage only. Many important system linkages will not be implemented in ODYM-RECC 2.2, including a detailed depiction of the waste management cascade and an assessment of the costs of the different ME strategies.

\subsection{Theoretical foundation of ODYM-RECC}

Our starting point is that ODYM-RECC described the material aspects and system linkages of socioeconomic metabolism and in-use stocks as the biophysical layer of human society as complex self-reproducing system (Fischer-Kowalski and Weisz, 1999).

- The functioning of social systems requires humans to organize energy and material flows for their own bodies' reproduction and the reproduction of the built up in-use stocks, i.e., socioeconomic metabolism.

- The particular way in which socioeconomic metabolism is operated determines the system's environmental impacts.

- Basic laws of natural science (thermodynamics, constancy of matter) also apply to social and economic systems and are to be respected (Ayres and Kneese, 1969), also when modelling substitution between materials and other production factors.

In a complex self-reproducing system including humans it is not possible to capture all linkages, not even all relevant linkages. Many important linkages (changes in attitude, political situation, new technologies) have to be omitted from the model or represented in a stylized manner only. Table 6.1 list the system linkages that are captured and those that are not captured.

Table 6.1: System linkages captured and not captured by ODYM-RECC.

\begin{tabular}{|l|l|}
\hline System linkage & Degree of capture \\
\hline Wellbeing and service demand & Not covered \\
\hline Service demand and stocks & $\begin{array}{l}\text { Partly covered. Stocks serve as proxy for services in the building } \\
\text { sector, and their the intensity of use is modelled. Passenger } \\
\text { vehicle transport is modelled as service flow of annual passenger- } \\
\text { km by vehicles }\end{array}$ \\
\hline Stock-flow & $\begin{array}{l}\text { Fully covered by dynamic stock model (population balance } \\
\text { model), stock-driven approach }\end{array}$ \\
\hline Flow-material & $\begin{array}{l}\text { Fully covered by material intensity and material substitution } \\
\text { parameters }\end{array}$ \\
\hline Flow-waste/scrap & $\begin{array}{l}\text { Fully covered by detailed description of waste management } \\
\text { industries }\end{array}$ \\
\hline Scrap-material & Fully covered \\
\hline Material-alloy-element & $\begin{array}{l}\text { Partly covered (chemical elements are considered but no } \\
\text { evaluation or constraints regarding this linkage) }\end{array}$ \\
\hline Product life cycles & $\begin{array}{l}\text { Partly covered by material cycle foreground model and partly by } \\
\text { extension for energy and services. }\end{array}$ \\
\hline
\end{tabular}


Our main motivation for this approach, instead of using an economic model, is twofold: First, the higher resolution and biophysical consistency that a biophysical model offers, and second: the nature of the strategy implementation, i.e., whether it is implemented via economic incentives, regulations, or lifestyle changes, is yet unclear. Our approach allows to explore the sociometabolic consequences of a certain implementation pattern without prescribing the nature of its implementation.

\subsection{Reference to methods and software used.}

Once we have either a product consumption or a product stock demand we can use the established and available dynamic MFA routines to

+ determine product inflow and outflow, and the material composition of these flows (using product material composition data and product lifetimes) (Müller, 2006; van der Voet et al., 2002), Python code available.

+ determine the optimal response of the waste management industries to the end-of life product flows (using EoL recovery efficiencies and waste management process descriptions), Python code available and running for simple case, unresolved nonlinear constraint for the case where alloying elements are considered. (Gaustad et al., 2011; Kondo and Nakamura, 2005; Løvik et al., 2014) [not implemented]

+ determine the resulting level of primary production, (using the process inventories of the primary metal producers, the available scrap supply, and metal demand from manufacturing).

+ determine the resulting mining output (using available mining inventories by the Monash colleagues), mining exploitation routine is still under development and not implemented. (Northey et al., 2017, 2014a)

+ determine the impact of material efficiency on the metal cycles (using scenarios for resource and material efficiency). (Milford et al., 2013; Modaresi et al., 2014; Pauliuk et al., 2013)

+ estimate energy demand from the metal cycles and mining operation for comparison with other scenario results (using process inventory data).

+ quantify the resulting environmental impact and GHG emissions savings from the different resource efficiency strategies (using scenarios for resource and material efficiency and applying them across the modelled system)

+ 10 model scenario building and prospective hybrid LCA (Hertwich et al., 2015a), not implemented.

\subsection{Basic ODYM-RECC modules and model equations}

The model aspects and the resolution (classification items) of ODYM-RECC v2.2 are listed above. Here we define the system variables, model equations and modules, and the model parameters for the basic version v2.2, without the consideration of costs, optimisation, and rebound effects.

The ODYM-RECC model equations are based on the system definition in Figure 6.1.

The modules that have been implemented in v2.2 are listed below.

The generic system definition in Fig. 6.1 (identical to Fig. 3.2) provides an overview of the processes, flows, stocks, and resource efficiency strategies covered for ODYM-RECC v2.2. 


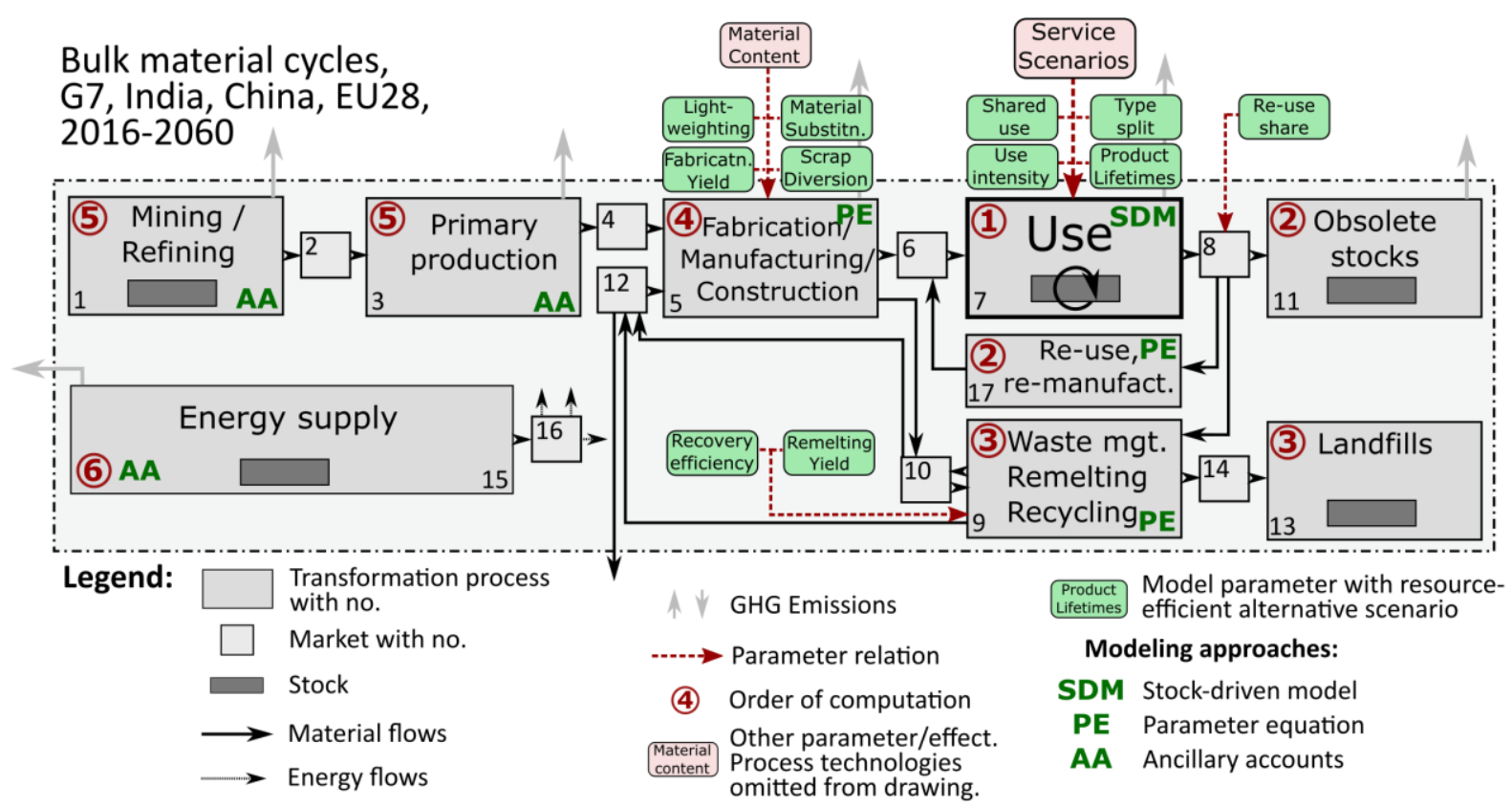

Figure 6.1: System definition of ODYM-RECC assessment with model parameters, resource efficiency strategies, and the modelling approaches taken for the computation of the material cycle response to resource efficiency. This figure is identical to figure 3.2 and is repeated here for convenience.

\subsubsection{ODYM-RECC modules, overview}

The design principle of ODYM-RECC is modular to facilitate update of parts, versioning, testing, and code management. The different modules are built on the underlying ODYM software framework (Pauliuk and Heeren, 2019).

Table 6.2: The ODYM-RECC modules

\begin{tabular}{|c|c|c|c|}
\hline Module and function & Layers & coverage & Comment/feature \\
\hline $\begin{array}{l}\text { Use phase UP: translate in-use } \\
\text { stock targets into commodity } \\
\text { inflows and outflows (stock- } \\
\text { driven model) }\end{array}$ & $\begin{array}{l}\text { Product } \\
\text { layer }\end{array}$ & $\begin{array}{l}\text { All regions and products } \\
\text { defined }\end{array}$ & $\begin{array}{l}\text { Split product groups (pass. } \\
\text { Vehicles) into individual } \\
\text { product types }\end{array}$ \\
\hline $\begin{array}{l}\text { Waste management and } \\
\text { recycling WR: Determine amount } \\
\text { of re-used products and recycled } \\
\text { materials }\end{array}$ & $\begin{array}{l}\text { Products, } \\
\text { materials, } \\
\text { chem. } \\
\text { elements }\end{array}$ & $\begin{array}{l}\text { All regional waste streams } \\
\text { aggregated to one global } \\
\text { flow, treatment by global } \\
\text { industry modelled }\end{array}$ & $\begin{array}{l}\text { Fabrication scrap is buffered } \\
\text { for one year, thus the } \\
\text { elemental composition is } \\
\text { known for all flows. }\end{array}$ \\
\hline $\begin{array}{l}\text { Manufacturing MF: Determine } \\
\text { use of secondary material, } \\
\text { primary production necessary, } \\
\text { and fabrication scrap }\end{array}$ & $\begin{array}{l}\text { Products, } \\
\text { materials, } \\
\text { chem. } \\
\text { elements }\end{array}$ & $\begin{array}{l}\text { One global industry for } \\
\text { each product group }\end{array}$ & \\
\hline $\begin{array}{l}\text { Primary production PP: calculate } \\
\text { energy demand, } \\
\text { ore/concentrage/resource } \\
\text { demand, and emissions of } \\
\text { primary material production }\end{array}$ & $\begin{array}{l}\text { Materials, } \\
\text { chem. } \\
\text { elements }\end{array}$ & $\begin{array}{l}\text { One global industry for } \\
\text { each material }\end{array}$ & \\
\hline $\begin{array}{l}\text { Mining and refining: MR: } \\
\text { calculate energy demand, } \\
\text { resource demand, and emissions } \\
\text { of mining and refining operations }\end{array}$ & $\begin{array}{l}\text { Minerals, } \\
\text { chem. } \\
\text { elements }\end{array}$ & $\begin{array}{l}\text { [planned: mine-specific } \\
\text { where data are available] }\end{array}$ & $\begin{array}{l}\text { Currently not part of ODYM- } \\
\text { RECC }\end{array}$ \\
\hline $\begin{array}{l}\text { Material and element } \\
\text { breakdown ME: Determine } \\
\text { element composition of materials }\end{array}$ & $\begin{array}{l}\text { Materials, } \\
\text { chem. } \\
\text { elements }\end{array}$ & All materials covered & $\begin{array}{l}\text { Determines the average } \\
\text { element composition of the } \\
\text { materials used in }\end{array}$ \\
\hline
\end{tabular}




\begin{tabular}{|l|l|l|l|}
\hline & & & $\begin{array}{l}\text { manufacturing, the final } \\
\text { consumption of materials in } \\
\text { products, and the in-use } \\
\text { stock. }\end{array}$ \\
\hline $\begin{array}{l}\text { Energy consumption and } \\
\text { environmental extensions EX: } \\
\begin{array}{l}\text { Calculate the energy } \\
\text { consumption by energy carrier } \\
\text { for all processes and the relevant } \\
\text { environmental extensions, such } \\
\text { as GHG emissions. }\end{array}\end{array}$ & $\begin{array}{l}\text { Energy } \\
\text { carriers, } \\
\text { env. } \\
\text { pressure } \\
\text { and impact } \\
\text { categories }\end{array}$ & $\begin{array}{l}\text { All processes in the system } \\
\text { definition, all energy } \\
\text { carriers selected, region- } \\
\text { specific emissions factors } \\
\text { for energy supply }\end{array}$ & \\
\hline
\end{tabular}

Calculation order (cf. also Fig. 6.1): ODYM-RECC first calculates the use phase model UP for all regions, products and years. The modules WR, MF, PP, and ME are solved in a year-by-year loop, because the element composition of materials needs to be determined for all previous years before the waste management module can be solved (solution depends on element composition of materials, e.g., copper content of steel). The MR module is currently not part of ODYM-RECC, the emissions factors for primary production used cover the supply chain including mining. The EX module is called last.

\subsubsection{System variables}

The ODYM-RECC system variables are listed in Table 6.3. The entire model is run for a specific socioeconomic and climate policy scenario (SSP/RCP), and the two related indices, $\mathrm{S}$ and $\mathrm{R}$, apply to all system variables and there therefore omitted here.

Table 6.3: The ODYM-RECC system variables, as defined in the system definition Fig. 6.1. The variable aspects are case sensitive: $S$ denotes the socioeconomic scenario, $s$ the car segments, $R$ the climate policy scenario, $r$ the 32 SSP regions, etc. For convenience reasons, the material flows are listed as they are defined in the ODYMRECC model Python code.

\begin{tabular}{|l|l|l|}
\hline Name & Symbol(s) & Explanation \\
\hline $\begin{array}{l}\text { Service flow from use } \\
\text { phase }\end{array}$ & $F_{s 7}(V, t, c, r, g)$ & $\begin{array}{l}\text { Shelter provided in area-degree-person- } \\
\text { hours, transport provided in passenger-km }\end{array}$ \\
\hline Material stocks & $\begin{array}{l}\text { Cf. definition of ODYM- } \\
\text { RECC stock dictionary in } \\
\text { list below this table }\end{array}$ & $\begin{array}{l}\text { In-use stock of buildings, infrastructure, and } \\
\text { products, losses at different stages of the } \\
\text { system. }\end{array}$ \\
\hline Material flows & $\begin{array}{l}\text { Cf. definition of ODYM- } \\
\text { RECC flow dictionary in } \\
\text { list below this table }\end{array}$ & All material flows \\
\hline Energy flows & $E_{x_{-} y}(\mathrm{n}, \mathrm{t}, \ldots)$ & $\begin{array}{l}\text { Energy flows to operate the different } \\
\text { processes in the system }\end{array}$ \\
\hline Emissions flows & $G H G_{x_{-} y}(\mathrm{t}, \ldots)$ & $\begin{array}{l}\text { Emissions flows from the different processes } \\
\text { in the system, for ODYM-RECC v2.2: GHG } \\
\text { only }\end{array}$ \\
\hline
\end{tabular}


The ODYM-RECC flow list:

RECC_System.FlowDict['F_0_3'] = msc.Flow (Name='ore input', P_Start=0, P_End=3, Indices='t,m,e', Values=None, Uncert=None, Color=None, ID=None, UUID=None)

RECC_System.FlowDict ['F_3_4'] = msC.Flow (Name='primary material production', P_Stärt $=3, P_{-}$End $=4$, Indices $=' t, \mathbf{m}, \mathbf{e} '$, Values=None, Uncert=None, Color $=$ None, $I \bar{D}=$ None, UUI $\bar{D}=$ None)

RECC_System.FlowDict['F_4_5'] = msC.Flow (Name='primary material consumption' , $\mathrm{P}$ Stärt $=4, \mathrm{P}$ End $=5$, Indices $=$ ' $t, \mathbf{m}, \mathbf{e}$ ', Values=None, Uncert=None, Cólor $=$ None, $\overline{I D}=$ None, $\operatorname{UUID}=$ None)

RECC_System.FlowDict['F_5_6'] = msC.Flow (Name='manufacturing output' , P_Start = 5, $\mathrm{P}$ End $=6$, Indices $=-\bar{t}, 0, \mathbf{g}, \mathbf{m}, \mathbf{e}^{\prime}$, Values=None, Uncert=None,

Color $=$ None, $I D=$ None, UUID $=$ None)

RECC_System.FlowDict['F_6_7'] = msC.Flow (Name='final consumption', P_Start=6, P_End $=7$, Indices $=' t, r, g, \mathbf{m}_{\mathbf{c}} \mathbf{e}^{\prime}$, Values=None, Uncert=None,

Cōlor=None, ID=None, UUID=None)

RECC_System.FlowDict['F_7_8'] = msC.Flow (Name='Eol products', P_Start = 7, P_End $=8$, Indices $=' t, \mathbf{c}, \mathbf{r}, \mathbf{g}, \mathbf{m}, \mathbf{e}$ ', Values=None, Uncert=None,

Color $=$ None, $I D=$ None, UUID $=$ None)

RECC System.FlowDict['F_8_0'] = msC.Flow (Name='obsolete stock formation',

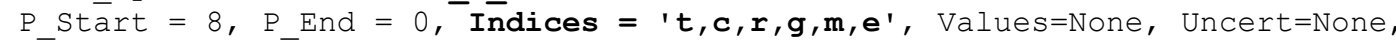

Cōlor $=$ None, $\overline{\mathrm{I}} \mathrm{D}=$ None, $\mathrm{UUID}=$ None)

RECC_System.FlowDict['F_8_9'] = msC.Flow (Name='waste mgt. input', P_Start $=8$, $\mathrm{P} \operatorname{En} \bar{d}=9$, Indices $=\mathbf{t}_{\mathbf{t}} \mathbf{r}, \mathbf{g}, \mathbf{m}, \mathbf{e} '$, Values=None, Uncert=None,

Cölor $=$ None, $\mathrm{ID}=$ None, $\mathrm{UUID}=$ None)

RECC_System.FlowDict['F_8_17'] = msC.Flow (Name='product re-use in', P_Start = 8, $\mathrm{P}_{-} \mathrm{En} \overline{\mathrm{d}}=17$, Indices $=\mathbf{\overline { t }}, \overline{\mathbf{c}}, \mathbf{r}, \mathbf{g}, \mathbf{m}, \mathbf{e} '$, Values=None, Uncert $=$ None,

Color $=$ None, ID $=$ None, $\operatorname{UUID}=$ None)

RECC System.FlowDict ['F_17_6'] = msc.Flow (Name='product re-use out', P_Start = $17, \bar{P}_{-}$End $=6$, Indices $\overline{\bar{x}}, \overline{\mathbf{t}}, \mathbf{c}, \mathbf{r}, \mathbf{g}, \mathbf{m}, \mathbf{e} '$, Values=None, Uncert=None,

Color $=$ None, ID $=$ None, UUID $=$ None)

RECC_System.FlowDict['F_9_10'] = msC.Flow (Name='old scrap', P_Start = 9, P_End = $10, \overline{I n d i c e s}=' t, \mathbf{r}, \mathbf{w}, \mathbf{e}$ ', $\overline{\text { Values}}=$ None, Uncert=None,

Color $=$ None, $I D=$ None, UUID $=$ None)

RECC_System.FlowDict['F_5_10'] = msc.Flow (Name='new scrap', P_Start = 5, P_End = $10, \overline{\text { Indices }}=\mathbf{t}, \mathbf{0}, \mathbf{w}, \mathbf{e}$ ', $\overline{\text { Values}}=$ None, Uncert=None,

Color $=$ None, $I D=$ None, $\operatorname{UUID}=$ None)

RECC_System.FlowDict['F_10_9'] = msc.Flow (Name='scrap use', P_Start = 10, P_End = 9, Indices $=' t, \mathbf{o}, \mathbf{w}, \mathbf{e} ', \overline{V a} \bar{l}$ ues $=$ None, Uncert $=$ None,

Color $=$ None, $\mathrm{ID}=$ None, $\mathrm{UUID}=$ None)

RECC_System.FlowDict ['F_9_12'] = msC.Flow (Name='secondary material production' , P_Start $=9$, P_End $=12, \bar{I}$ indices $=' t, \mathbf{o}, \mathbf{m}, \mathbf{e}^{\prime}$, Values=None, Uncert=None,

Cōlor $=$ None, $\bar{I} D=$ None, $\operatorname{UUID}=$ None)

RECC_System.FlowDict ['F_10_12'] = mSC.Flow (Name='fabscrapdiversion', P_Start = 10, $\mathrm{P}_{-} \mathrm{En \overline {d }}=12$, Indices $=\bar{t}, \mathbf{o}, \mathbf{m}, \mathbf{e} '$, Values=None, Uncert=None,

Cölor $=$ None, ID $=$ None, UUID $=$ None)

RECC_System.FlowDict['F_12_5'] = msC.Flow (Name='secondary material consumption', P_Start $=12$, P_End $=5$, Indices $=' t, o, \mathbf{m}, \mathbf{e} '$, Values=None, Uncert= None, Color $=$ None, $I \bar{D}=$ None, UUID $=$ None)

RECC_System.FlowDict ['F_12_0'] = msC.Flow (Name='excess secondary material' , P Start $=12, P$ End $=0$, Indices $=' t, \mathbf{o}, \mathbf{m}, \mathbf{e} '$, Values=None, Uncert=None, Color $=$ None, $\mathrm{I} \overline{\mathrm{D}}=$ None, $\mathrm{UUID}=$ None) 
RECC_System.FlowDict['F_9_0'] = msc.Flow (Name='waste mgt. and remelting losses',

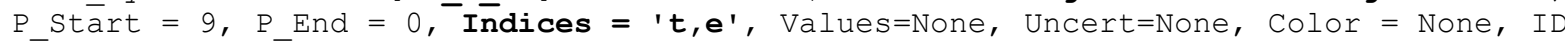
= None, UUID $=$ None)

The ODYM-RECC stock and stock change list:

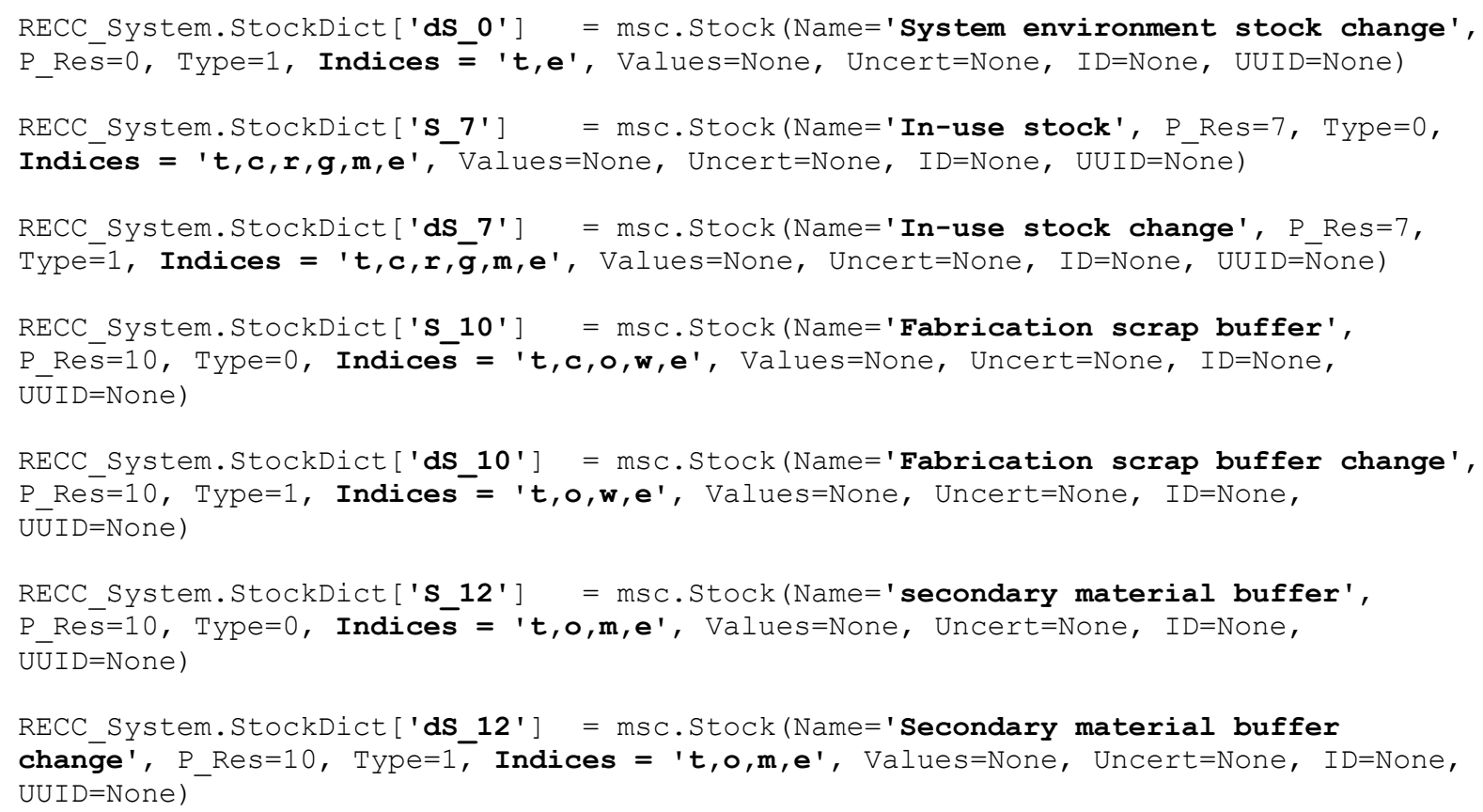

\subsubsection{General description of resource efficiency strategies}

To allow for a homogenous presentation of the future rollout of resource efficiency strategies, we split each strategy representation into two parameters: a) the maximum potential and b) the extent to which the maximum potential is seized. The maximal potential is determined by literature review, expert interviews, and estimations; it is scenario-independent. The scenario- and time-dependent implementation levels are modelled in a stylized manner, by two-parameter implementation curves (Fig. 6.2).

A main motivation for this approach, instead of an economic model, is that the nature of the strategy implementation, i.e., whether it is implemented via economic incentives, regulations, or lifestyle changes, is yet unclear. Our approach allows to explore the sociometabolic consequences of a certain implementation pattern and estimate the technical potential, without prescribing or implying the nature of its implementation.

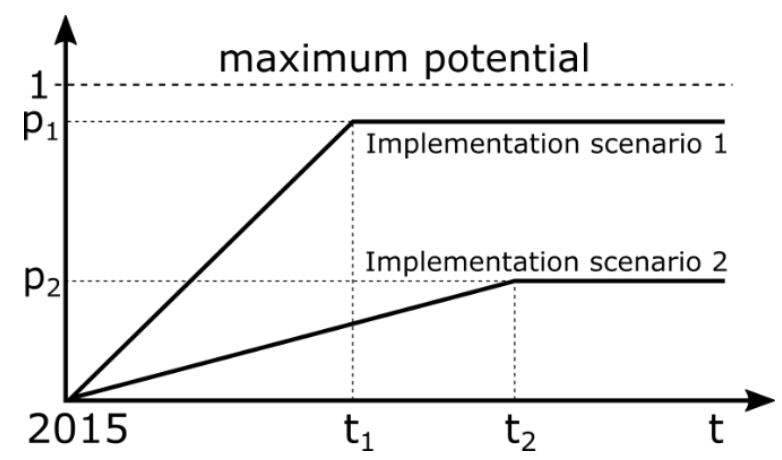

Fig. 6.2: Implementation curve for a resource efficiency strategy, with the total implementation level (in \%) and the time of full implementation. 
Example: Lifetime extension: With $\tau_{0}(c, r, g)$ being the BAU (business as usual) product lifetime for future age-cohorts of products, the maximum lifetime extension potential can (and will) be defined as percent increase from the base value. For each material efficiency scenario $S$, the actual product lifetime, $\tau_{a c t}(C, r, g, S)$, is then determined as the sum of the original and the product of implementation curve $I C$, maximal implementation potential $\phi$, and base lifetime:

$$
\tau_{a c t}(c, r, g, S)=\tau_{0}(c, r, g)+I C_{\tau}(\mathrm{t}=\mathrm{c}, \mathrm{r}, \mathrm{g}, S) \cdot \Phi_{\tau}(\mathrm{r}, \mathrm{g}) \cdot \tau_{0}(c, r, g)
$$

For already existing age-cohorts we have to decide whether those are affected and if so, how the remaining lifetime scales with $\phi$. Similar equations are defined below for all ME parameters.

The model equations below are formulated for the parameters without explicit scenario indices. If a scenario is to be calculated, the baseline parameters are simply replaced by their scenario values, and for each RE-relevant parameter, we specify how exactly the maximal implementation potential $\phi$ is defined (e.g., whether it is a maximum percentage increase or an absolute increase).

Below the basic model equations and the different resource efficiency strategies (RES) are introduced, cf. also Fig. 6.1.

\subsubsection{The use phase module (UP)}

ODYM-RECC is a stock-driven model, meaning that the starting point for all future material cycle modelling are the exogenous trajectories for the in-use stock $S_{7}(t, \mathrm{r}, G, \mathrm{~S})=S_{\text {fut }}(t, \mathrm{r}, G, \mathrm{~S})$, which is calculated from the future per-capita stock (lower case $s$ ) and the population.

$$
S_{7}(t, r, G, S)=P(t, r, S) \cdot s_{7}(t, r, G, S)
$$

For some stocks, the physical stock unit is also the unit of the service, e.g., $\mathrm{m}^{2}$ of residential building space, and for others, the intensity of use needs to be factored in, e.g., for vehicles ( $\mathrm{km} / \mathrm{yr}$ ). For passenger transport, the future annual passenger-km are converted to vehicle-km first, using the occupancy rate, and then to stocks, using kilometrage (Fig. 3.4), cf. also the transport model docu. We determine the future per capita service flows (vehicles) and residential building stocks from the starting value in 2015 combined with the target values in the scenario target table. To avoid model artefacts the value of the extrapolation function in the year 2015 must be equal to the actual stock in that year:

$$
S_{2015}(2015, c, G, r)=S_{7}(2015, r, G, S)
$$

We now introduce the model equations in the order they are implemented and executed in the ODYMRECC model script. All system variables are scenario-dependent, and the index $S$ is therefore omitted below.

Passenger vehicles: translating service into stock, implementing car-sharing and ride-sharing: With the carsharing and ridesharing parameters the total passenger-km are divided into four sections: First, we divided into passenger-vehicle mobility provided by privately owned vs carsharing cars and second, we divided into cars with normal occupancy rate and ride-shared cars (model parameters CaS and RiS). While the carsharing sector has a different vehicle kilometrage than privately owned cars, the ridesharing sector has a different occupancy rate, all described by the model parameters $C O S$ and ORS. From these ratios and parameters the total vehicle-km driven are calculated and by dividing them by the annual kilometrage, the required per capita vehicle stock $s_{7}(t, r, G)$ for $\mathrm{G}=0$ is calculated.

The modelling approach is documented in detail below. For details regarding the data used, please check the transport model documentation. 
Step I: Convert passenger-km into vehicle-km: For the ODYM-RECC scenarios, we assume that the number of total passenger-km travelled per capita and year, $M_{f u t}$, is given as exogenous parameter, after having considered total transport demand (sufficiency) and modal split. The following accounting equation for any given subset $x$ of the total vehicle stock links vehicle stock $s_{x}$ with annual kilometrage $v k m_{x}$, the occupancy rate $O R_{x}$ (passengers per vehicle, driver only counts if he/she also benefits from travel service), and the delivered passenger-km $P K M_{x}$. It holds for each sector and for the total stock:

$$
P K M_{x}=O R_{x} \cdot \mathrm{VKM}_{x} \cdot \mathrm{s}_{x}(4)
$$

The total car fleet as well as the total person- $\mathrm{km}$ can now be split in to the four sectors:

- Mobility by privately-owned and not shared vehicle stock

- Mobility by car-shared but not ride-shared vehicle stock

- Mobility by ride-shared but not car-shared vehicle stock

- Mobility by car-shared and ride-shared vehicle stock

We break down the total per capital vehicle stock and delivered PKM into these sectors, assuming that there are only two split parameters, one for car-sharing, and one for ride-sharing, that apply to the entire transportation demand. In other words, the share of ride-shared passenger-km is the same for privately owned and car-sharing cars, and vice versa, the share of car-shared passenger-km is the same for privately owned and ride-sharing cars:

$$
\begin{aligned}
P K M & =P K M_{0}+P K M_{C a S}+P K M_{R i S}+P K M_{C a S+R i S} \\
& =O R_{0} \cdot V K M_{0} \cdot \mathrm{s}_{0} \\
& +O R_{C a S} \cdot V K M_{C a S} \cdot \mathrm{s}_{C a S} \\
& +O R_{R i S} \cdot V K M_{R i S} \cdot \mathrm{s}_{R i S} \\
& +O R_{C a S+R i S} \cdot V K M_{C a S+R i S} \cdot \mathrm{s}_{C a S+R i S}
\end{aligned}
$$

With the following model approaches and assumptions for $O R$ and VKM:

$$
\begin{array}{ll}
O R_{0} & =O R_{C a S} \\
O R_{C a S+R i S} & =O R_{R i S}=: O R S \cdot O R_{0}
\end{array}
$$

Here, $O R S$ is the factor by which $O R$ increases under ride-sharing (current value: 1.4, cf. transport model docu). And for the kilometrage:

$$
\begin{aligned}
V K M_{0} & =\mathrm{VKM}_{R i S} \\
V K M_{C a S+R i S} & =\mathrm{VKM}_{C a S}=: \frac{V K M_{0}}{C O S}
\end{aligned}
$$

Here, COS is the factor by which car ownership decreases under car-sharing (current value: 2.0, cf. transport model docu), and, as a consequence, the utilisation or annual kilometrage of each carsharing car goes up by a factor of $1 /$ COS.

From these definitions and simplifications, it follows:

$$
P K M=\mathrm{OR}_{0} \cdot \mathrm{VKM}_{0} \cdot\left(s_{0}+\operatorname{COS}^{-1} \cdot s_{C a S}+O R S \cdot s_{R i S}+O R S \cdot \operatorname{COS}^{-1} \cdot s_{C a S+R i S}\right)
$$

With the following definitions for ride-sharing and car sharing 


$$
C a S:=\frac{P K M_{C a S}+P K M_{C a S+R i S}}{P K M}
$$

and

$$
R i S:=\frac{P K M_{R i S}+P K M_{C a S+R i S}}{P K M}
$$

and the assumption that these shares are homogenous across all sectors (e.g., the share of rideshared PKM in the car-shared PKM is the same as the share of ride-shared PKM in the total PKM etc. pp), we can write:

$$
\begin{aligned}
P K M & =1 \cdot P K M \\
& =1 \cdot 1 \cdot P K M \\
& =(C a S+1-C a S) \cdot(R i S+1-R i S) \cdot P K M \\
& =[C a S \cdot R i S+(1-C a S) \cdot R i S+\mathrm{CaS} \cdot(1-R i S)+(1-C a S) \cdot(1-R i S)] \cdot P K M
\end{aligned}
$$

where each of the terms denotes the PKM delivered by one of the four sector of the stock listed above.

Hence, we can calculate the size of the stock sectors directly from equating the respective terms:

$$
\begin{aligned}
& s_{0}=(1-C a S) \cdot(1-R i S) \cdot P K M /\left(O R_{0} \cdot V K M_{0}\right) \\
& s_{C a S}=C a S \cdot(1-R i S) \cdot P K M /\left(O R_{0} \cdot V K M_{0}\right) \\
& s_{R i S}=(1-C a S) \cdot R i S \cdot P K M /\left(O R_{0} \cdot V K M_{0}\right) \\
& s_{C a S+R i S}=C a S \cdot R i S \cdot P K M /\left(O R_{0} \cdot V K M_{0}\right)
\end{aligned}
$$

Note, that these calculations work both at the per capita stock and at the total stock level. Here, per capita stock levels are calculated and later multiplied with the scenario-specific population parameter.

From this result, we can calculate the total stock needed as the sum of the sectors, the resulting average VKM, and the resulting average OR:

$$
\begin{aligned}
& s_{f u t}=s_{0}+s_{C a S}+s_{R i S}+s_{C a S+R i S} \\
& V K M_{f u t}=\left[s_{0}+\operatorname{COS}^{-1} \cdot s_{C a S}+s_{R i S}+\operatorname{COS}^{-1} \cdot s_{C a S+R i S}\right] \cdot V K M_{0} / s_{f u t} \\
& O R_{f u t}=M_{f u t} /\left[s_{f u t} \cdot V K M_{f u t}\right] \\
& P K M=M_{f u t} \\
& O R_{0}=O R(2015) \\
& V K M_{0}=I O(2015)
\end{aligned}
$$

Finally, the model parameters are linked to the following datasets: The future PKM is given by the parameter $M_{f u t}$, the future baseline (no RiS) occupancy rate and the future baseline (no CaS) vehicle kilometrage are assumed to remain constant at their 2015 levels, respectively. 
The results $s_{f u t}$ and $V K M_{f u t}$ enter the subsequent ODYM-RECC model calculations as parameter time series.

Also, the lifetime distribution needs to be modified. Assuming a constant total vehicle kilometrage over the entire vehicle lifetime, the lifetime of car sharing cars scales with the COS parameter. Hence, there will be a bi-modal lifetime distribution, which we can simplify by calculating the resulting average new lifetime $\tau_{\text {eff }}$ from the original lifetime $\tau_{0}$ according to the share of car-sharing cars in the fleet, which is also an ODYM-RECC parameter

$$
\tau_{\text {eff }}=\tau_{0} \cdot s_{f u t}^{-1} \cdot\left(s_{0}+\operatorname{COS} \cdot s_{C a S}+s_{R i S}+\operatorname{COS} \cdot s_{C a S+R i S}\right)
$$

The setup described above allows us to apply car-sharing and ride-sharing as to independent strategies and to calculate the effect of either of them not being implemented.

Residential buildings: More intense use of floorspace: Unlike service sufficiency, which leads to a reduction of stocks due to lower service demand, a more intense use of products means that total service demand remains constant but is achieved with smaller stocks. Examples include car-sharing, shared office spaces, denser urban form, parents moving to smaller apartments when their kids move out, and a higher occupancy rate in public transport. With the more intense use potential $\phi_{\text {MIU }}$ defined as the maximum share of the original stock that can be reduced, resulting new stock is then given below:

$$
\begin{aligned}
& s_{7_{-} M I U}(t, r, G)=\left(1-I C_{M I U}(t) \cdot \Phi_{I U}(G)\right) \cdot s_{7}(t, r, G) \\
& S_{7_{-} M I U}(t, r, G)=P(t, r) \cdot s_{7_{-} M I U}(t, r, G)
\end{aligned}
$$

Here, $I C_{\text {MIU }}$ is the ramp-up curve for the more intense use of the building stock. Unlike the materialrelated ME strategies, which are ramped up with a function that is a sequence of linear changes, the more intense use of buildings needs a smoother curve as sudden changes in the derivative of the stock curve cause jumps in the material flows. Hence, for $I C_{M I U}$ a slower ramp up by 2050 and a subsequent splint interpolation is applied.

All products: Product lifetime extension: The lifetime of new and existing products is prolonged, due to more robust design that allows for easier exchange for parts that wear down quicker than the structural components, or that change more rapidly than the latter due to changes in consumer preference (fashion) or safety standards.

a) Future age-cohorts:

$$
\tau_{a c t}(c, r, g, E)=\left(1+I C_{\tau}(\mathrm{t}=\mathrm{c}, \mathrm{r}, \mathrm{g}, E) \cdot \Phi_{\tau}(\mathrm{r}, \mathrm{g})\right) \cdot \tau_{0}(c, r, g)
$$

The probability density function of a product leaving the stock ( $p d f_{a c t}$ ) is then determined according to which lifetime distribution model is set, and with the average lifetime equal to $\tau_{\text {act }}$.

b) Past age-cohorts: For some products, e.g., buildings, the lifetime of existing units can be extended, but this is not implemented in ODYM-RECC V2.2, as building renovation is not considered.

All products: Stock-driven model: With the parameters prepared according to the equations above, we can apply a stock-driven model (Müller, 2006), which is implemented as part of ODYM in the class dynamic_stock_model (Pauliuk and Heeren, 2019). The computations are done model year by model year, starting with the historic stock in the first year. First, the stock from the last model year is transferred to the present year (ageing). 


$$
\left.S_{7}^{*}(t, c, r, g)\right)=S_{7}(t-1, c, r, g)
$$

Then, the outflow of the existing stock is computed and subtracted from the preliminary stock $S_{7}{ }^{*}$, and corrected for lifetime extension of historic age-cohorts. Here, $p d f_{\text {act }}$ is the probability density function of discard calculated from the lifetime after including lifetime extension.

$$
\begin{aligned}
& F_{7 \_8}(t, \mathrm{c}, r, g)=S_{7}^{*}(t, c, r, g) \cdot p d f_{a c t}(t-c, r, g) \\
& F_{7_{-} 8}(t, r, g)=\sum_{c} F_{7_{-} 8}(t, \mathrm{c}, r, g) \\
& S_{7}(t, c, r, g)=S_{7}^{*}(t, c, r, g)-F_{7 \_8}(t, \mathrm{c}, r, g)
\end{aligned}
$$

In a stock-driven model, the total current stock must equal the exogenously specified value. The inflow (apparent consumption) necessary to maintain and expand the stock is obtained and added as youngest age-cohort to the existing stock. Below, we sum up over all products $g$ belonging to a certain product group/sector $G$ :

$$
\begin{aligned}
& F_{6_{-} 7}(t, G, r)=S_{7_{-} M I U}(t, G, r)-\sum_{c, g \in G} S_{7}(t, c, r, g) / 1 y r \\
& S_{7}(t, c=t, G, r)=F_{6_{-7}}(t, G, r) \cdot 1 y r
\end{aligned}
$$

The inflow of products is split into different types (of vehicles, buildings, etc.) with the type split:

$$
F_{6_{-} 7}(t, r, g)=T S(t, r, G, g) \cdot F_{6_{-} 7}(t, r, G)
$$

Product material composition and energy use in use phase: Products can be light-weighted by better design, downsizing, or different material choices and substitution. Two strategies that change the material composition of products are considered: A reduction of weight per product via downsizing, i.e., smaller vehicles, and a reduction via material substitution. e.g., aluminium for steel in vehicles or timer for concrete in buildings.

A number of vehicle archetypes was simulated. For the six vehicle types, there are four segments (microcar, passenger car, minivan/SUV, and light truck) that come in two versions each: one with conventional material choice and one with a material substituted design. $6 * 4 * 2=48$ archetypes in total.

A number of building archetypes was simulated, there are four archetypes for each building type: one for a standard building, one for a lightweight design, one for a material substituted, and one for a lightweight design and material-substituted archetype. In addition, the building archetypes are region-dependent to account for different climates and building conventions.

The different archetypes are then scaled up using the share of downsized and light-weighted prototypes, respectively, as shown in the equations below. The ULD and MSu strategies are used to model a switch to different archetypes of products by changing the mix of archetypes and calculate the resulting changes in material composition and operational energy consumption of the average product from a given age-cohort:

+ Vehicles: 


$$
\begin{aligned}
& \mu(c, m, p, r)= \\
& \sum_{s} D S(G, s, r, c=t) \cdot M S(G, r, c=t) \cdot M A_{L W E}(s, p, m)+ \\
& \sum_{s} D S(G, s, r, c=t) \cdot(1-M S(G, r, c=t)) \cdot M A_{c o n v}(s, p, m) \\
& E I(c, p, n, r)= \\
& \sum_{s} D S(G, s, r, c=t) \cdot M S(G, r, c=t) \cdot E I A_{L W E}(s, p, n)+ \\
& \sum_{s} D S(G, s, r, c=t) \cdot(1-M S(G, r, c=t)) \cdot E I A_{c o n v}(s, p, n)
\end{aligned}
$$

In the equations above, $\mathrm{G}$ is the sector that $\mathrm{p}$ belongs to, and $M A_{\text {conv }}$ is the material composition of the conventionally designed archetypes without material substitution, and $M A_{L W E}$ the $M C$ of the material-substituted archetypes, same for the EIA parameters.

+ Buildings:

$$
\begin{aligned}
& \mu(c, m, B, r)= \\
& D S(G, r, c=t) \cdot M S(G, r, c=t) \cdot M A_{L W E_{-} M S u}(B, r, m)+ \\
& D S(G, r, c=t) \cdot(1-M S(G, r, c=t)) \cdot M A_{L W E}(B, r, m)+ \\
& (1-D S(G, r, c=t)) \cdot M S(G, r, c=t) \cdot M A_{M S u}(B, r, m)+ \\
& (1-D S(G, r, c=t)) \cdot(1-M S(G, r, c=t)) \cdot M A_{c o n v}(B, r, m) \\
& E I(c, n, V, B, r)= \\
& D S(G, r, c=t) \cdot M S(G, r, c=t) \cdot E I A_{L W E_{-} M S u}(B, r, V, n)+ \\
& D S(G, r, c=t) \cdot(1-M S(G, r, c=t)) \cdot E I A_{L W E}(B, r, V, n)+ \\
& (1-D S(G, r, c=t)) \cdot M S(G, r, c=t) \cdot E I A_{M S u}(B, r, V, n)+ \\
& (1-D S(G, r, c=t)) \cdot(1-M S(G, r, c=t)) \cdot E I A_{c o n v}(B, r, V, n)
\end{aligned}
$$

In the equations above, $\mathrm{G}$ is the sector that $\mathrm{B}$ belongs to, and $M A_{\text {conv }}$ is the material composition of the conventionally designed archetypes without material substitution and lightweight design, $M A_{M S u}$ is the material composition of the material-substituted archetypes, $M A_{L W E}$ is the material composition of the lightweight design archetypes, and $M A_{L W E_{-} M S U}$ the $M C$ of the material-substituted and lightweight design archetypes, same for the EIA parameters.

While the material composition is known from the scenario parameters at the start of the model run, the elemental composition of materials needs to be determined from the available waste flows and their remelting, together with the required primary production to satisfy total material demand.

That means that the material composition for chemical elements together (recorded under element 0 , 'all'), can be calculated from the total material composition parameter

$$
\mu(c, r, g, m, e=0, S)
$$


at any point in the model, whereas the elemental breakdown needs to be determined after the material cycle have been closed at the total mass level. Hence, a loop over all future model years is programmed.

Different vintages of materials and different flows in the system have different chemical element composition of the materials they contain. For example, the element composition of the materials entering manufacturing (primary production and secondary materials) each have their own element composition, and the composition of the newly manufactured goods is the mass-weighted average of the two input values.

If re-use of products is present, the element composition of the final consumption flow is different of the manufacturing outflow material composition. Also here, a weighted average is computed to ensure the mass balance at the chemical element level also here.

With the product material composition parameters calculated above, the product flows can be converted to material flows at any time during the model run, e.g.:

$$
F_{6_{-} 7}(t, r, g, m)=\mu(t, g, r, m) \cdot F_{6_{-} 7}(t, r, g)(26)
$$

\subsubsection{The waste management and recycling module (WR)}

Obsolete stock formation and obsolete stock formation reduction [currently not implemented]: A fraction of the products and buildings that leaves the use phase is not made available for reuse or material recovery. These obsolete stocks are determined with a dedicated parameter and a corresponding reduction strategy

$$
F_{8 \_0}(t, r, g,)=\left(1-I C_{O B S}(\mathrm{t}, \mathrm{r}, \mathrm{g}) \cdot \Phi_{O B S}(\mathrm{r}, \mathrm{g})\right) \cdot O B S(\mathrm{t}, \mathrm{r}, \mathrm{g}) \cdot F_{7 \_8}(t, r, g)
$$

Re-use of end-of-life (EoL) products: A fraction of the available end-of-life products can be re-used, which is modelled with a re-use factor diverting products away from waste management and reinserting them back into the market for final products:

$$
F_{8 \_17}(t, r, g)=I C_{\mathrm{Re} U s e}(t, r, g) \cdot \Phi_{\mathrm{Re} U s e}(r, g) \cdot\left(F_{7 \_}(t, r, g)-F_{8 \_0}(t, r, g)\right)
$$

The complement of the obsolete stock formation and re-use,

$$
F_{8 \_9}(t, r, g, m)=F_{7 \_8}(t, r, g, m)-F_{8 \_0}(t, r, g, m)-F_{8 \_17}(t, r, g, m)
$$

is sent to the waste management industries for treatment.

Waste management is modelled as a cascade: first, scrap is extracted from the end-of-life (EoL) products that are sent to the waste management industries. This is modelled by a simple factor endof-life recovery rate.

$$
F_{9 \_10}(t, w, e)=\sum_{g, m, W, r} \operatorname{EoL} L_{-} R R(g, r, m, w, W) \cdot F_{8_{-} 9}(t, g, r, m, e)_{(30)}
$$

At this point, the element composition of the flows is still known, since only EoL products with historic or previously determined (earlier in the for loop over $\mathrm{t}$ ) age-cohort are contained in this flow.

RES7: End-of-life recovery rate improvement: The current EoL-RR values can be improved by better dismantling and sorting. This effect is modelled by a separate RE strategy:

$$
E o L_{-} R R(g, r, m, w, W)=E o L_{-} R R(g, r, m, w, W)+I C_{E o L}(t, r, g) \cdot \Phi_{E o L}(g, r, m, w, W)
$$


Here, the improvement potential $\Phi_{E O L}$ is measured in percentage points by definition, so that it can be directly added to the baseline value.

Moreover, since waste and scrap can be traded, the regional dimension is no longer considered here and is collapsed. In the equations, $r$ is thus not shown as aspect for the material flows at global scale, but in the model, the values are assigned to the region 'World' with index letter $o$.

The fabrication scrap flow from last year, which is buffered as stock on the scrap market, is added to the resulting old scrap flow (but quality differences are kept by distinguishing between the different scrap and material classes $w$ and $m$ ) and sent to remelting (also part of process 9 ), from where the recycled material flow is determined by the parameter Remelting yield RMY:

$$
F_{9 \_12}(t, m, e)=\sum_{W, w} R M Y(w, m, e, W, t) \cdot\left(F_{9 \_10}(t, w, e)+F_{5-10}(t-1, w, e)\right)
$$

From the above equation, it also becomes clear why the introduction of the time lag for the scrap flow simplifies the computation: As the elemental composition of the fabrication scrap of last year is already known, one can directly compute the elemental composition of the secondary material produced during the current year.

\subsubsection{Link to service provision and energy consumption (module EX)}

To link the stocks to service provision type $V$ and use phase energy consumption the model follows the scheme shown in Fig. 3.4. The following equations are used, and the parameters therein are explained in Table 6.4 below. Below is the general equation for linking a stock to a service provided:

$$
F_{S 7}(t, c, r, g, V)=I U(t, c, r, g, V) \cdot I O(t, c, r, g, V) \cdot S_{7}(t, c, r, g)
$$

For passenger vehicles, the intensity of operation (IO) parameter denotes the annual kilometrage, and for buildings, 10 denotes the share of the built-up area that provides building services: heating, cooling, and domestic hot water generation, all at a standard level for which average specific energy consumption is reported.

For passenger vehicles, the intensity of use (IU) parameter denotes the occupancy rate (average number of people per car) and for buildings, IU denotes the number of building occupants enjoying a certain number degree-days of thermal comfort if the service unit is thermal comfort, and 1 if the service unit is simply $\mathrm{m}^{2}$ of living space, all per $\mathrm{m}^{2}$.

The direct energy consumption is then determined by multiplying the specific energy consumption (energy intensity El, energy intensity of service type $\mathrm{V}$ ) of operating the products to the intensity of use of the stock. Then, the result is multiplied with ECS, the energy carrier split of energy consumption for delivering service type $\mathrm{V}$ into energy carrier $\mathrm{n}$.

$$
E_{16_{-} 7}(n, t, r, g, V)=\sum_{c} \operatorname{ECS}(n, c, r, g, V) \cdot E I(c, r, g, V) \cdot I O(t, c, r, g, V) \cdot S_{7}(t, c, r, g)
$$

For vehicles, $\mathrm{El}$ is measured in $\mathrm{MJ} / \mathrm{km}$ driven, for building services in $\mathrm{kWh}$ per $\mathrm{m}^{2}$ and year. Energy Flow $E_{16} 7$ is then multiplied with the scenario-specific emissions factors to obtain the use phase carbon footprint. 
Table 6.4: Coupling between stock $S_{7}$, service provision $F_{S 7}$, and energy consumption $E_{16}$. . Cf. Also Fig. 3.4.

\begin{tabular}{|l|l|l|l|l|l|}
\hline Sector & $\begin{array}{l}\text { Service } \\
\text { flow unit } \\
\text { and } \\
\text { description }\end{array}$ & $\begin{array}{l}\text { Intensity of } \\
\text { operation }(\mathrm{IO}) \text { unit } \\
\text { and description }\end{array}$ & $\begin{array}{l}\text { Intensity of use } \\
\text { (IU) unit and } \\
\text { description }\end{array}$ & $\begin{array}{l}\text { Energy } \\
\text { intensity unit } \\
\text { and } \\
\text { description }\end{array}$ & $\begin{array}{l}\text { Product stock unit } \\
\text { and description }\end{array}$ \\
\hline $\begin{array}{l}\text { Passenger } \\
\text { vehicles }\end{array}$ & $\begin{array}{l}\text { Passenger- } \\
\mathrm{km} / \mathrm{yr}\end{array}$ & $\mathrm{km} /$ vehicle/year & $\begin{array}{l}\text { Passengers per } \\
\text { vehicle }\end{array}$ & $\mathrm{MJ} / \mathrm{km}$ & $\begin{array}{l}\text { Vehicles } \\
\text { (product of vehicle } \\
\text { ownership and } \\
\text { population) }\end{array}$ \\
\hline $\begin{array}{l}\text { Residential } \\
\text { buildings }\end{array}$ & $\begin{array}{l}\text { Person- } \\
\text { comfort } \\
\mathrm{m}^{2 *} \mathrm{yr} / \mathrm{yr}\end{array}$ & $\begin{array}{l}\text { Share of built area } \\
\text { that provides } \\
\text { services: heating, } \\
\text { cooling, hot water } \\
\text { access }\end{array}$ & 1 & $\mathrm{kWh} / \mathrm{m}^{2} / \mathrm{yr}$ & $\begin{array}{l}\mathrm{m}^{2} \text { of residential } \\
\text { buildings } \\
\text { (product of per } \\
\text { capita floor space } \\
\text { and population) }\end{array}$ \\
\hline
\end{tabular}

Process emissions, direct emissions, and indirect emissions of energy supply are considered by defining appropriate emissions and energy intensity factors. These are multiplied to the material and service flows, e.g., the energy flow into manufacturing and the related GHG emissions of its supply:

$$
\begin{aligned}
& E_{16 \_5}(n, t, o)=\sum_{g, r} \operatorname{EIM}(F=g, n, t=c, o) \cdot F_{55_{6}}(t, r, g) \\
& G H G_{5}(t)=\sum_{n, o(=0)} \operatorname{GHGW}(X=0, n, o, t) \cdot E_{16{ }_{-} 5}(n, t, o)
\end{aligned}
$$

Analog equations apply to the other processes (waste management and remelting, primary material production) and the other emissions types: direct combustion and process emissions.

\subsubsection{Manufacturing (MF module) and the closure of the recycling loop}

The manufacturing process is described by two parameters: the manufacturing yield and the energy demand of manufacturing.

In the simplest case, the total material demand of manufacturing/construction (process 5 ), $F_{-} x \_5$ is determined from manufacturing yield $\lambda$, material content $\mu$, and product demand $F_{-} 5 \_6$ :

$$
F_{x_{-} 5}(m, t, o)=\sum_{g, r} \frac{1}{\sum_{w} \lambda(m, w, g, F=g, t, o)} \cdot \mu(m, c=t, r, g) \cdot F_{5_{-} 6}(t, r, g)
$$

Resource efficiency in manufacturing: Several resource efficiency strategies apply (Fig. 3.4): Material substitution, which is depicted by exogenous scenarios; light-weighting of products, also depicted by exogenous scenarios; fabrication yield improvement, depicted by a resource efficiency parameter applied to the fabrication yield, and fabrication scrap diversion, which is modelled by a new flow F_10_12 consisting of part of the fabrication scrap that is assumed to have a quality and workability that makes it a suitable input to other manufacturing sectors.

The change of the manufacturing yield is modelled in the same manner as the other RE strategies affecting process parameters. 
The primary production is now determined from the mass balance, assuming that all available secondary material is used first. No rebound effects of recycling (Hertwich, 2005; Zink and Geyer, 2017) are considered here.

$$
F_{3{ }_{-} 4}(m, t, o)=F_{x_{-} 5}(m, t, o)-F_{12{ }_{-} 5}(m, t, o)(38)
$$

If there is excess supply of secondary material for the sectors studied (e.g. more construction steel cascaded from Eol vehicle steel than needed in new residential buildings), the affected elements of $F_{-} 3$ _ 4 are set to zero and the excess secondary material is exported from the system via the flow F_12_0 instead.

\subsubsection{Link to material composition of products and materials (ME module)}

One central feature of ODYM is that it can work at different layers: Material, product, chemical element, etc. Because of the service perspective, the product stocks are modelled first. With the use phase inflow and outflow of products known, one can add the material composition of products and the element content of materials, e.g.:

$$
F_{8 \_17}(t, r, g, m, e)=\mu(r, g, m, e) \cdot F_{8 \_17}(t, r, g)
$$

Check also the section Product material composition and energy use in use phase above, where the determination of the material composition parameter $\mu$ from archetype data is explained for convenience reasons.

The determination of the element composition of materials is calculated after the primary production $F_{-} 3 \_4$ and the scrap export $F_{-} 12 \_0$ have been determined. After this correction (the export of excess scrap), and since the element composition of both flows on the right side of the last equation is known, one can now also calculate the breakdown of the total material flows into individual chemical elements:

$$
F_{x_{-} 5}(m, t, e, o)=F_{3_{-} 4}(m, t, e, o)+F_{9{ }_{1} 12}(m, t, e, o)+F_{10_{-} 12}(m, t, e, o)-F_{12 \_0}(m, t, e, o)
$$

From that equation, the manufacturing output $F_{-} 5 \_6$ and the fabrication scrap $F_{-} 5 \_10$ can be broken down into individual chemical elements as well. The scrap contained in the latter flow will then be recycled in the next model year:

To simplify the computation of the material loops, it is assumed that all fabrication scrap is sorted and remelted in the following year, meaning that the time for a material passing through the recycling loop for fabrication scrap is one year. Internal scrap in remelting, so called home scrap, is not included as a separate flow, but indirectly via the loss rates and the energy consumption.

\subsubsection{The primary material production (PP module)}

Primary production (F_3_4) is determined as the amount of material required to fill the gap between demand from manufacturing and supply of secondary material from within the sector. The associated supply chain energy demand is not calculated in model version 2.2. Instead, the entire supply chain emissions GHG_3 are calculated by multiplying $F_{-} 3 \_4$ with GHGPP.

\subsubsection{Mining industries (MR module)}

Impacts from mining are currently included in the supply chain emissions parameter for primary production, GHGPP. Further detail on future mining, including a deposit-specific exploration and production model (Mudd et al., 2013; Norgate and Haque, 2010; Northey et al., 2014b), is currently under development by the colleagues whose work is cited here, but not published yet. 


\subsubsection{Socioeconomic impacts}

Socioeconomic impacts, like labour demand, costs, or value added in the different industrial processes modelled are not implemented yet.

\subsection{Sensitivity analysis and scenarios}

In prospective modelling, one needs to be clear about the purpose and the storyline behind each model run. We distinguish between sensitivity analysis (impact of single or combined parameter variation(s) on model outcomes) and scenarios (a set of parameter variations combined into a storyline). The scenarios are constrained by mass balance, resource availability, and stock inertia, but at this stage, we do not regard some scenarios as more likely to happen than others. All scenarios depicted represent possible futures from a biophysical point of view, and an assessment of their likelihood (how realistic they are) is beyond the scope of our work.

In the sensitivity analysis, we quantify the impact of variations in parameters on model outcome, one by one. This procedure helps us the understand model behaviour better and it allows us to identify the key model parameters for the material efficiency-climate change mitigation link. The parameter variations include both epistemic (we actually don't know the true parameter value) and aleatory (the parameter value takes different values for different members of the sample) uncertainty (Laner et al., 2014). For the parameter product lifetime, for example, the epistemic uncertainty is analysed by changing the mean value of the lifetime distribution, and the aleatory uncertainty is analysed by changing the standard deviation of the lifetime distribution.

In the scenario analysis, we run a socioeconomic scenario several times and add the different ME strategies, the so-called ME strategy cascade, cf. Table 4.2 and the explanations there. 


\section{Modelling environment, work flow, and interfaces}

In this section the setup of the ODYM-RECC working environment is described and it is explained how the user can run custom scenarios.

\subsection{Modelling environment: Software, database, and sharing}

To set up the working environment for the ODYM-RECC model, four elements are necessary:

0. A local copy of the ODYM model framework for dynamic MFA

1. A local copy of the RECC model

2. A local copy of the RECC database (or path to the Dropbox repo)

3. A local result folder

Ad 1) The ODYM-RECC assessment is based on the software framework and database structure of ODYM. The model classes and functions of ODYM are hosted on the open source platform GitHub under the label of the already existing organisation Industrial Ecology:

https://github.com/IndEcol/ODYM

It can be copied from there, either by direct download or by the git clone command.

Ad 2) The ODYM-RECC model and config files are shared via the (currently private) repo https://github.com/YaleCIE/RECC-ODYM

It can be copied from there, either by direct download or by the git clone command.

Ad 3) The data, in the format required for the model, are exchanged via Dropbox and - to the extent the licences allow - will be made openly available upon publication on Zenodo so that anyone with the sufficient computer skills will be able to replicate all scientific claims made.

The internal project data archive folder is \Dropbox\G7 RECC\Data\RECC_Database\CURRENT\

Ad 4) A local result folder needs to be created.

An example of the folder structure of ODYM-RECC is shown in Fig. 7.1.

In the RECC model main folder, which is also the working directory, a local git-ignored file "RECC_Paths.py" must be present that contains the following paths (see also Fig. 7.2):

- odym_path, points to local ODYM copy (Note that ODYM is not a package yet as it is still at an experimental stage)

- data_path, points to the local copy of the RECC project database.

- results_path, points to folder where model results are stored.

The main RECC_Model folder, which is also the working directory, contains the model configuration file RECC_Config_V2_2.xlsx and the different model scripts, each of which is configured in RECC_Config_V2_2.xIsx. 


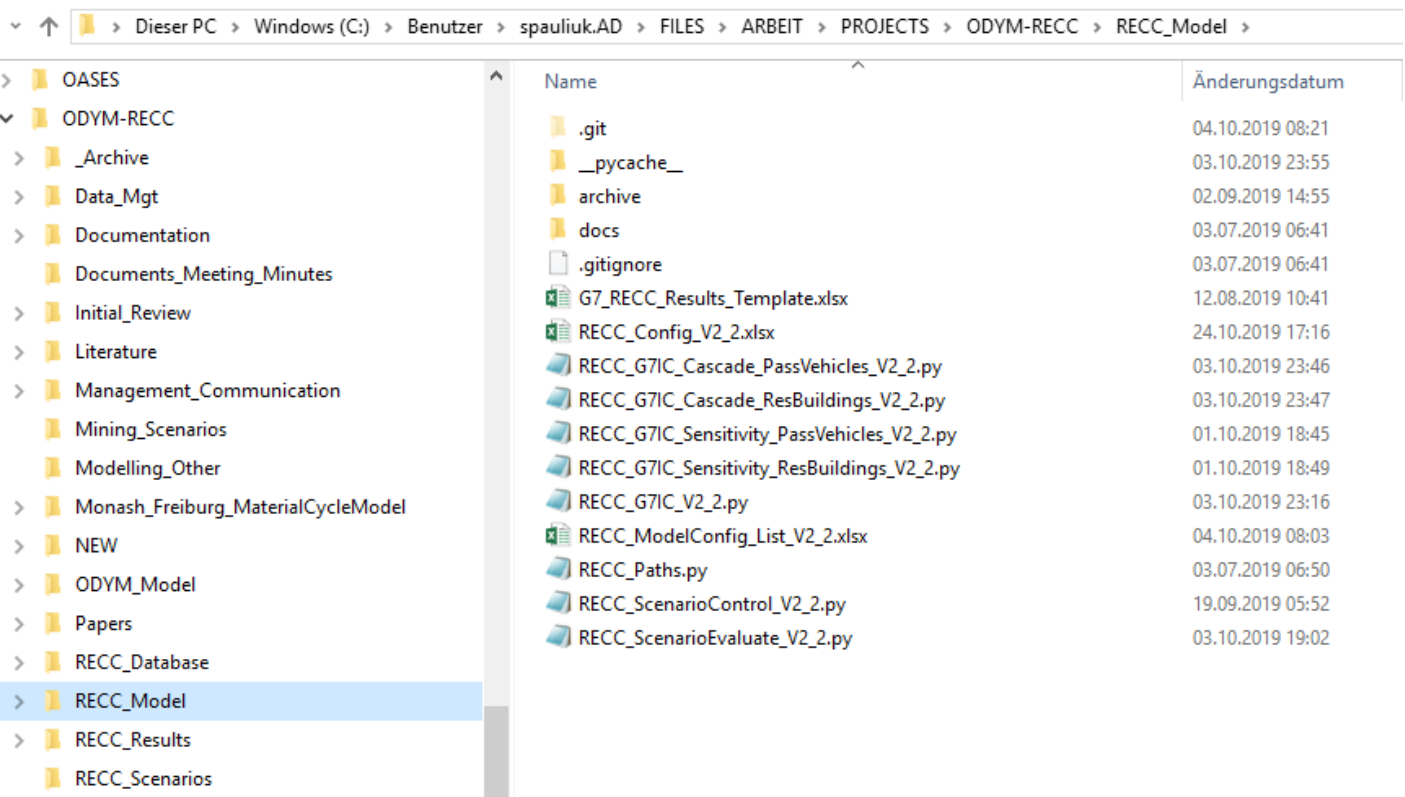

Figure 7.1: Example of folder structure of ODYM-RECC. There need to be four folders: one with the ODYM model, one with the RECC model (which is also the working directory), one with the RECC database and one result folder.

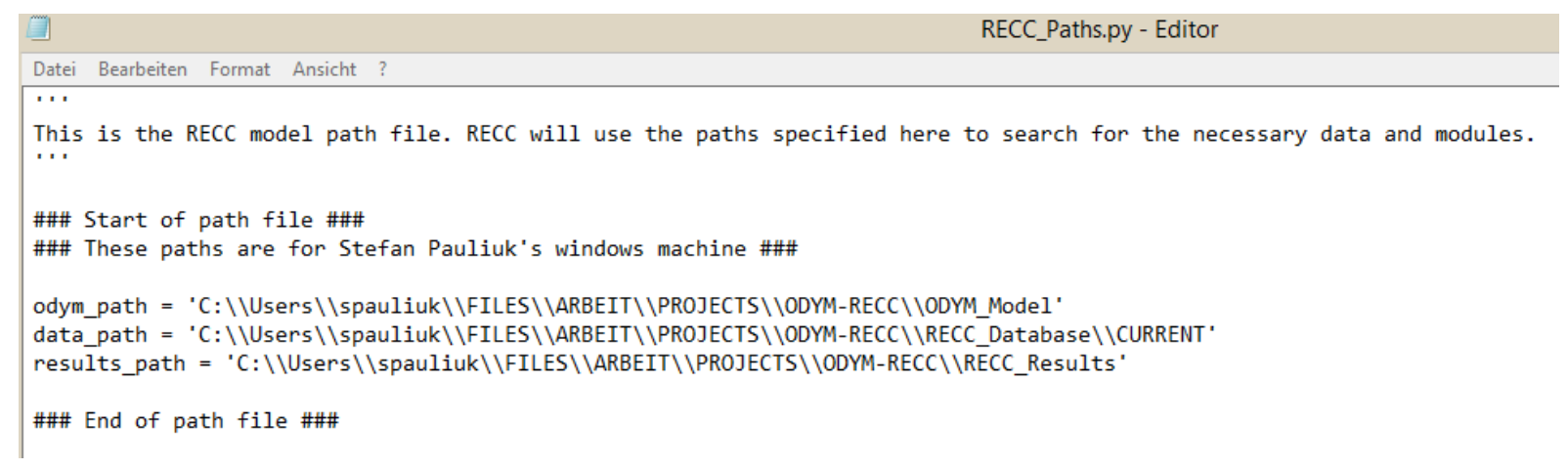

Figure 7.2: The RECC path file setup. This example contains absolute MS-Windows paths but relative paths and LINUX are possible as well, as they will be combined with Python's operating system independent os.join() method.

When called, the RECC model script will determine its location in the directory tree of your computer and from there, look for the path file and the config file. From the path file the location of the data, the ODYM modules, and the result folder is determined.

\subsection{Running the ODYM-RECC model}

To run the RECC model, there are a number of options as described below. First, we list the available scripts and functions in the main model folder:

- RECC_G7IC_V2_2.py: Main model script, is organised as a function so that it can be called by the scenario control script for batch processing. If you want to add or change features of ODYM-RECC, create a git branch and convert the main model script to script mode (by commenting out the function definition and un-tabbing the main code).

- RECC_ScenarioControl_V2_2.py: This script is used to run a larger number of model configurations defined in RECC_ModelConfig_List_V2_2.xlsx. For each model run, it will load 
the model configuration parameters defined in RECC_ModelConfig_List_V2_2.xlsx, write them to the model config file RECC_Config_V2_2.xlsx, and run the main script RECC_G7IC_V2_2.py

- RECC_ScenarioEvaluate_V2_2.py: This script is used to evaluate a larger number of model configurations defined in RECC_ModelConfig_List_V2_2.xlsx. After

RECC_ScenarioControl_V2_2.py has completed, the resulting list with the result folders of the individual model runs is stored in RECC_ModelConfig_List_V2_2.xIsx, and

RECC_ScenarioEvaluate_V2_2.py is called to read the different results, call the single-sector evaluation scripts for each model region (RECC_G7IC_Cascade....py and RECC_G7IC_Sensitivity.....py, cf. below), and write the result overview to an excel file.

- RECC_G7IC_Cascade.....py and RECC_G7IC_Sensitivity....py: These scripts create a number of evaluation tables and plots for a given sector and given regions. They are called by RECC_ScenarioEvaluate_V2_2.py

To run ODYM-RECC, follow these steps:

1. Pull or clone latest model version from GitHub (https://github.com/YaleCIE/RECC-ODYM) to your local working directory.

2. Create a path file with your local paths and add it to the model folder. An example can be found on \Dropbox\G7 RECC\Modeling\ODYM-RECC and in fig. 7.2.

3. Copy the project database from Zenodo or Dropbox (\Dropbox\G7 RECC\Data\ RECC_Database (CURRENT\) into the data folder specified in the path file.

For single model runs:

4. Open the model config file RECC_Config_V2_2.xlsx and define the model run parameters in the respective country sheets, then specify the name of the country in cell D4 of the Config sheet. Comment out the function definition of the main script and run the main script RECC_G7IC_V2_2.py. The results will be stored in a single folder and be available in the workspace of the programming environment after the model run.

For multiple model runs:

5. Open the RECC_ModelConfig_List_V2_2.xIsx file and specify the model configurations you want to run by modifying existing model config lists or creating a new list (must use exact same structure as template provided)

6. Open the RECC config file and modify parameters that are not listed in RECC_ModelConfig_List_V2_2.xlsx.

7. Open the model script caller RECC_ScenarioControl_V2_2.py, specify the sheet with the model configs from RECC_ModelConfig_List_V2_2.xIsx that you want to run, and press F5. The main model script will now be called with new configurations as many times as there are model configs in RECC_ModelConfig_List.xlsx.

8. Copy the list ResultsFolders created by Python to the sheet "Evaluate_Config_IRP_V1" in RECC_ModelConfig_List_V2_2.xlsx, save, and run the scenario evaluation control script RECC_ScenarioEvaluate_V2_2.py, which will in turn call the scenario comparison and sensitivity scripts RECC_G7IC_Cascade....py and RECC_G7IC_Sensitivity....py as many times as needed. 


\subsection{RECC project work flows and database status}

To keep the project manageable and the workflow productive a set of rules is necessary.

\section{RECC core rules:}

- Do not modify or delete any files in the main database \Dropbox \G7

RECC \Data\RECC_Database \CURRENT \without talking to the person responsible for each file.

- Do not push changes to the RECC model repo (https://github.com/YaleCIE/RECC-ODYM), create pull requests instead!

RECC workflows, internally:

Responsibilities: \Dropbox\G7 RECC\Data\admin\overview.xlsx

Data management scheme: \Dropbox\G7 RECC\Data\README.docx

The current status of the ODYM-RECC model database as well as the grouping of the different parameters is shown in Table 7.1 below.

Table 7.1: The ODYM-RECC parameters and their aspects/index structure, ODYM-RECC v2.2. For the italic parameters, own scenario modelling was conducted and used.

\begin{tabular}{|c|c|c|c|}
\hline Parameter Name & $\begin{array}{l}\text { Version } \\
\text { no. }\end{array}$ & aspects & Unit \\
\hline 2_P_RECC_Population_SSP_32R & V2.1 & MtrS & $\begin{array}{l}\text { Million } \\
\text { vehicles: million units. buildings: billion }\end{array}$ \\
\hline 2_S_RECC_FinalProducts_2015_passvehicles & V1.1 & tcpr & $\begin{array}{l}\mathrm{m} 2 \\
\text { vehicles: million units. buildings: billion }\end{array}$ \\
\hline 2_S_RECC_FinalProducts_2015_resbuildings & V1.1 & $\mathrm{tcBr}$ & $\begin{array}{l}\mathrm{m} 2 \\
\text { inhabitant*m } 2 * y r / y r \text { and passenger- }\end{array}$ \\
\hline 1_F_ServiceFlows_Future & V1.2 & GrtS & $\mathrm{km} / \mathrm{yr}$ \\
\hline 2_S_RECC_FinalProducts_Future_resbuildings & V2.2 & StGr & buildings: $\mathrm{m} 2$ per person \\
\hline 2_S_RECC_FinalProducts_Future_resbuildings_MIUPotential & V1.0 & GoS & $\%$ \\
\hline 3_EI_Products_UsePhase_passvehicles & V1.1 & cpVnrS & Vehicles: MJ/km. Buildings: MJ/m2/yr \\
\hline 3_El_Products_UsePhase_resbuildings & V1.1 & cBVnrS & Vehicles: MJ/km. Buildings: MJ/m2/yr \\
\hline 3_IO_Vehicles_UsePhase & V2.2 & VrtS & vehicles: $\mathrm{km} / \mathrm{yr}$ \\
\hline 6_MIP_VehicleOccupancyRate & V1.2 & GrtS & 1 \\
\hline 3_IO_Buildings_UsePhase & V1.2 & cBVrS & share of $\mathrm{m} 2$ heated and cooled \\
\hline 3_LT_RECC_ProductLifetime_passvehicles & V3.1 & pr & $\mathrm{yr}$ \\
\hline 3_LT_RECC_ProductLifetime_resbuildings & V4.0 & Brc & $\mathrm{yr}$ \\
\hline 3_MC_RECC_Buildings & V1.1 & $\mathrm{cmBr}$ & $\mathrm{kg} / \mathrm{m} 2$ \\
\hline 3_MC_RECC_Vehicles & V1.1 & cmpr & $\mathrm{kg} /$ unit \\
\hline 3_MC_Elements_Materials_ExistingStock & V2.1 & me & $1(\mathrm{~kg} / \mathrm{kg})$ \\
\hline 3_MC_Elements_Materials_Primary & V2.1 & me & $1(\mathrm{~kg} / \mathrm{kg})$ \\
\hline 3_PR_RECC_CO2Price_SSP_32R & V2.1 & RtrS & US\$2005/ton \\
\hline 3_SHA_RECC_REStrategyScaleUp & V3.3 & RotS & 1 \\
\hline 4_PE_GHGIntensityEnergySupply & V4.0 & XnSRrt & $\mathrm{kg}$ of $\mathrm{CO} 2-\mathrm{eq} / \mathrm{MJ}$ \\
\hline 4_PE_GHGIntensityEnergySupply_World & V4.0 & XnSRot & $\mathrm{kg}$ of $\mathrm{CO} 2-\mathrm{eq} / \mathrm{MJ}$ \\
\hline 4_PE_GHGIntensityElectricitySupply_Backstop & V1.0 & XnSRt & $\mathrm{kg}$ of $\mathrm{CO} 2-\mathrm{eq} / \mathrm{MJ}$ \\
\hline 4_PE_ProcessExtensions & V3.3 & PXotS & $\mathrm{kg} / \mathrm{kg}$ \\
\hline 4_El_ProcessEnergyIntensity & V2.1 & Pnco & $\mathrm{MJ} / \mathrm{kg}$ \\
\hline 4_EI_ManufacturingEnergyIntensity & V2.1 & Fnco & $\mathrm{MJ} / \mathrm{kg}$ \\
\hline
\end{tabular}




\begin{tabular}{|c|c|c|c|}
\hline 4_PY_EoL_RecoveryRate & V2.2 & gomwW & $\%$ \\
\hline 4_PY_Manufacturing & V2.1 & mwgFto & 1 \\
\hline 4_PY_MaterialProductionRemelting & V2.2 & wmeWto & 1 \\
\hline 4_EI_WasteMgtEnergyIntensity & V1.1 & wnco & $\mathrm{MJ} / \mathrm{kg}$ \\
\hline 4_EI_RemeltingEnergyIntensity & V2.1 & mnco & $\mathrm{MJ} / \mathrm{kg}$ \\
\hline 6_PR_EoL_RR_Improvement & V2.2 & gomwW & percentage points \\
\hline 6_PR_LifeTimeExtension_passvehicles & V2.1 & pos & 1 \\
\hline 6_PR_LifeTimeExtension_resbuildings & V2.2 & BrS & 1 \\
\hline 6_PR_FabricationYieldImprovement & V2.1 & mgos & 1 \\
\hline 6_PR_FabricationScrapDiversion & V1.2 & mwoS & 1 \\
\hline 6_PR_ReUse_Bld & V3.1 & $\mathrm{mBo}$ & 1 \\
\hline 6_PR_ReUse_Veh & V1.2 & mprts & 1 \\
\hline 6_PR_DirectEmissions & V1.1 & Xn & $\mathrm{kg}$ of $\mathrm{CO} 2-\mathrm{eq} / \mathrm{MJ}$ \\
\hline 6_PR_CarSharingShare & V1.2 & GotS & 1 \\
\hline 6_PR_RideSharingShare & V1.2 & GotS & 1 \\
\hline 3_SHA_TypeSplit_Vehicles & V2.1 & GptrS & $\%$ \\
\hline 3_SHA_TypeSplit_Buildings & V1.2 & BrtS & $\%$ \\
\hline 3_SHA_EnergyCarrierSplit_Vehicles & V1.1 & cpoVnS & $\%$ \\
\hline 3_SHA_EnergyCarrierSplit_Buildings & V2.2 & VRrnt & $\%$ \\
\hline 3_MC_VehicleArchetypes & V2.0 & Am & $\mathrm{kg} / \mathrm{unit}, \mathrm{kg} / \mathrm{m} 2$ \\
\hline 3_EI_VehicleArchetypes & V4.0 & An & $\mathrm{MJ} / \mathrm{km}, \mathrm{MJ} / \mathrm{m} 2 / \mathrm{yr}$ \\
\hline 3_MC_BuildingArchetypes & V1.1 & Arm & $\mathrm{kg} / \mathrm{unit}, \mathrm{kg} / \mathrm{m} 2$ \\
\hline 3_EI_BuildingArchetypes & V1.1 & ArVn & $\mathrm{MJ} / \mathrm{km}, \mathrm{MJ} / \mathrm{m} 2 / \mathrm{yr}$ \\
\hline 3_SHA_DownSizing_Vehicles & V2.3 & srtS & $\%$ \\
\hline 3_SHA_LightWeighting_Vehicles & V1.2 & prtS & $\%$ \\
\hline 3_SHA_DownSizing_Buildings & V1.3 & urts & $\%$ \\
\hline 3_SHA_LightWeighting_Buildings & V2.2 & GrtS & $\%$ \\
\hline 6_PR_Calibration & V2.2 & $\mathrm{Cr}$ & ratio \\
\hline 6_MIP_CarSharing_Stock & V1.0 & Sr & 1 \\
\hline 6_MIP_RideSharing_Occupancy & V1.0 & $\mathrm{Sr}$ & 1 \\
\hline 6_MIP_GWP_Bio & V1.0 & c & 1 \\
\hline
\end{tabular}

\subsection{Interfaces from and to the ODYM-RECC model}

From the scenario database (I) to ODYM-RECC (IV):

Most ODYM-RECC parameters are scenario-dependent (cf. Table 7.1). Some parameters, like population or GDP (not used by ODYM-RECC v2.2) are obtained directly from the SSP database at http://www.iiasa.ac.at/web/home/research/researchPrograms/Energy/SSP Scenario Database.html while other need to be compiled by the RECC project team based on the SSP storylines. The parameters for which own scenario work needs to be done are highlighted in italics in Table 7.1. 
All other parameters currently labelled as scenario depended are taken from other databases (4_PE_GHGIntensityEnergySupply from SSP/MESSAGE scenario database), set constant or modelled with an LCA scenario tool (4_EI_ProcessEnergyIntensity, 4_EI_WasteMgtEnergyIntensity, etc.), or are determined by the scale-up of the RE strategies (6_PR_MorelntenseUse,

6_PR_FabricationYieldImprovement), etc. For the latter group, there is no SSP dependency but scenario-independent potentials, and the only scenario-dependent RE parameter will be 3_SHA_RECC_REStrategyScaleUp.

GHG emissions per MJ produced for the different energy carriers and 11 world regions are available from the MESSAGE results database (Riahi et al., 2017a). In addition, data for hydrogen production were used from the IEA WEO model (OECD/IEA, 2010a). To reflect that the CURRENT electricity mix in the individual countries differs from the regional total modelled by MESSAGE, we introduced a linear interpolation from today's g $\mathrm{CO} 2 / \mathrm{kWh}$ for each country to the aggregate regional number from MESSAGE in 2040. This way, we can reflect current and mid-term regional difference but assume ultimate convergence to the regional average as electricity supply becomes more international to facilitate the integration of renewable sources of electricity.

From the archetype model (II) to ODYM-RECC (IV):

Table 7.2. lists the interface between the archetype model (II) and the ODYM-RECC scenario model (IV). ODYM-RECC does not deal with archetypes, just the average of each building type for each agecohort, which, for future age-cohorts, can be represented as mix of different archetypes/prototypes, as explained in the section 'Product material composition and energy use in use phase' above. That means that the archetypes defined by the product modelling teams are mixed together (e.g., $x \%$ standard and $100 \%-\mathrm{x} \%$ alternative, where $\mathrm{x}$ is time- and scenario-dependent) when entering the calculations.

Table 7.2: ODYM-RECC parameters for which scenarios are derived from mixing different archetypes within the RECC project.

\begin{tabular}{|l|l|l|}
\hline Parameter name & Description & Resolution of parameter \\
\hline 3_MC_RECC_Buildings & $\begin{array}{l}\text { Future material composition of } \\
\text { buildings }\end{array}$ & $\begin{array}{l}\text { Age-cohort } x \text { material } x \text { building } \\
\text { type } x \text { region }\end{array}$ \\
\hline 3_MC_RECC_Vehicles & $\begin{array}{l}\text { Future material composition of } \\
\text { vehicles }\end{array}$ & $\begin{array}{l}\text { Age-cohort } x \text { material } x \text { vehicle } \\
\text { type } x \text { region }\end{array}$ \\
\hline 3_El_Products_UsePhase_passvehicles & $\begin{array}{l}\text { Energy intensity, MJ/km, of } \\
\text { vehicles in use }\end{array}$ & $\begin{array}{l}\text { Age-cohort } x \text { product type } x \\
\text { service } x \text { energy carrier } x \text { region } \\
\text { x scenario }\end{array}$ \\
\hline 3_El_Products_UsePhase_resbuildings & $\begin{array}{l}\text { Energy intensity, MJ/m2/yr, for } \\
\text { buildings in use }\end{array}$ & $\begin{array}{l}\text { Age-cohort } x \text { product type } x \\
\text { service } x \text { energy carrier } x \text { region } \\
x \text { scenario }\end{array}$ \\
\hline
\end{tabular}

\section{From the LCIA (III) to ODYM-RECC (IV):}

The ODYM-RECC model produces scenarios for energy demand in all industrial processes and the use phase in Figure 6.1. It also contains parameters from the LCIA part III for process and direct GHG emissions (aspect $\mathrm{X}$ ) so that currently, the GHG emissions of the entire system are computed within ODYM-RECC ('GHG emissions' part in model IV). Other extensions can be added to the $\mathrm{X}$ aspect as well.

For each model run, the material and energy flows are exported in table format so that other assessments can be made. 


\section{Outlook, future model expansion and development}

The ODYM-RECC model will be expanded both in terms of regional and sectoral scope and in terms of modelling capability.

\subsection{Expanding the scope of the ODYM-RECC model}

P1) The following extensions are currently planned:

+ add remaining world countries in 5 aggregated regions for passenger vehicles and residential buildings

+ add electricity generation in 11 regions (MESSAGE results) and appliances and non-residential buildings in one global region (IMAGE results).

+ Consider infrastructure, other transport, and a detailed representation of non-residential buildings, as well as all climate-relevant bulk materials, using the results of existing assessments and previous work (Elshkaki et al., 2018; Schipper et al., 2018; van der Voet et al., 2018).

P2) Model a sufficiently large fraction of the total use of a metal in detailed ODYM-RECC sectors and then scale up to total demand using empirical relationships. This is first planned for copper.

P3) The second priority is to make our scenarios consistent with other prominent macro-scale assessments, such as the SSP scenario runs of IAMs or the work done for the Global Resources Outlook (UNEP-IRP, 2019).

\subsection{Expanding the capabilities of the ODYM-RECC model}

Further incorporating basic economic accounts and effects into ODYM-RECC would be a major breakthrough, as the model and scenarios would gain substantial 'socioeconomic credibility'. The theory of physical production functions seems underdeveloped. Winning et al. (2017) list the cost structures of material producing sectors (a column of the A-matrix, aggregated to 10-15 categories). We could go further in the aggregation of inputs and include KLEMS-accounts for each process covered by the model. The KLEMS accounts can be scaled for different scenarios to estimate future costs, economic impact, and labour input of the material cycles. In a second step, the KLEMS accounts can enter an optimisation model. A future combination with a CGE model should be planned for as a further model integration step.

There is ongoing work on decomposing LCl data and incorporating them into IAMs (Arvesen et al., 2018; Pehl et al., 2017). This approach could be a blueprint for more systematically linking life cycle thinking with material cycle modelling and subsequent indicator development and needs further investigation. Also, the issue of variability of emissions over time and the question of dynamic characterisation factors needs more investigation (Levasseur et al., 2013, 2010).

Finally, we plan to link the ODYM-RECC primary production scenario to a mining supply module to have consistent metal demand-mining supply models at the global scale, with copper as the first case study (Mudd et al., 2013; Norgate and Haque, 2010; Northey et al., 2014b).

\subsection{Interface to other modelling frameworks}

\section{Integrated assessment models}

ODYM is developed as a self-contained standalone prospective modelling framework. Like all prospective models that involve social systems, ODYM needs a set of exogenous parameters to run, and these parameters need to follow a certain scenario storyline. ODYM-RECC scenarios share their storylines with integrated assessment models (IAMs) by using the Shared Socioeconomic Pathways as exogenous scenarios. Different degrees of coupling tightness between ODYM and IAMs are applied: 
In the most basic case, where sufficient detail from the available IAM scenarios is absent, the only shared parameters are the main SSP scenario drivers population, GDP per capita, and urbanisation. Within the RECC team, we then used the scenario target tables to add detail to the storylines, cf. the scenario modelling docu. Regression models similar to the ones use by, e.g., GCAM and IMAGE, to build scenarios for the service delivered by buildings, transport, and industrial output, were only used in rare cases. For example, regression-based ARIMAX model forecasts are used for the USA and Japan for floor space per capita in the SSP2 scenario, as here, sufficiently long time series were present and the SSP2 storyline can be seen as a continuation of historic trends.

For this approach, exact comparability to other scenario model results will not be achieved, only the broad model drivers will be the same. This coupling mode is the initial running mode for the ODYMRECC as the time frame of the first assessment is too narrow to successfully establish a close interaction with IAMs.

In a tighter coupling option, ODYM will service demand directly from IAM results. In the simplest case, this would just mean that the regression model equations are replaced by formatted IAM model output. Such approach has already been lined out for the five materials $\mathrm{Cu}, \mathrm{Co}, \mathrm{Li}, \mathrm{Nd}$, and and $\mathrm{Ta}$, where IMAGE model output for the use phase was converted to material in-use stocks, inflows, and outflows of the use phase (Deetman et al., 2019, 2018). Also, the implementation of the material cycle consequences of electricity generation installation from MESSAGE is already under way. This approach only covers the sectors that are well represented in the IAM, while other sectors are not considered. That means that for the full material cycle picture a large-scale scenario target table, regression, or upscaling model will be needed in parallel to the sector-specific assessment done in coupling to the IAM.

\subsection{ODYM-RECC FAQS}

Q: What kind of computer is needed to run ODYM-RECC v2.2.? A: A normal PC or laptop is sufficient, as long as it has a large enough working memory. For a single-region run, at least 12 GB RAM are required, and for running multiple regions in one go, like the $\mathrm{G} 7$ (seven regions) or EU28 (nine regions in the project's classification), $32 \mathrm{~GB}$ are required. For a single region, 35 product groups selected, and a not too fancy Windows laptop with 32 GB RAM, the main model script takes 35-50 seconds to run through.

Q: Do I have to use the data formatting templates when running ODYM models? A: The ODYM functions can be used without the database structure and the parameter files. Data can be read using custom-made routines. For reproducible group work a more professional setup is necessary, however, and the data formatting templates were developed to simplify data parsing (all data files are parsed by a single routine) and to prepare for the storage of data as data packages. For the ODYM-RECC model, all data come in the ODYM templates v0.2.

Q: Can I use the RECC project database without using the ODYM-RECC model framework? A: Yes, no problem. The model framework and the database are two interlinked but separate things.

Q: Can I use the ODYM-RECC model without using the RECC project database? A: No. ODYM-RECC needs a certain set of data, and these data are stored in the RECC project database.

Q: Why is ODYM-RECC open access? A: Because we believe that open science creates a positive pressure to do better work, because external expertise and feedback can be obtained and incorporated easy, and because we believe that future industrial ecology scenario modelling needs to be more collaborative to progress more quickly and make increasingly relevant contributions to tackling pressing sustainability challenges. 
Q: How can I contribute to the development of ODYM-RECC? A: Both the database and the model need extension. Please check the model repo wiki on https://github.com/YaleCIE/RECC-ODYM for pending tasks and open issues! 


\section{References}

Allwood, J.M., Ashby, M.F., Gutowski, T.G., Worrell, E., 2011. Material efficiency: A white paper. Resour. Conserv. Recycl. $55,362-381$.

Allwood, J.M., Cullen, J.M., Carruth, M.A., Cooper, D.R., McBrien, M., Milford, R.L., Moynihan, M., Patel, A.C.H., 2012. Sustainable Materials: With Both Eyes Open. UIT Cambridge, UK, Cambridge, UK.

Arvesen, A., Luderer, G., Pehl, M., Leon, B., Hertwich, E.G., 2018. Environmental Modelling \& Software Deriving life cycle assessment coef fi cients for application in integrated assessment modelling. Environ. Model. Softw. 99, 111-125.

Ayres, R.U., Ayres, L.W., Masini, A., 2006. An Application of Exergy Accounting to Five Basic Metal Industries. Eco-Efficiency in Industry and Science, vol 19., in: von Gleich, A., Ayres, R.U., Gößling-Reisemann, S. (Eds.), Sustainable Metals Management. Springer, Dordrecht, The Netherlands.

Ayres, R.U., Kneese, A., 1969. Production, Consumption, and Externalities. Am. Econ. Rev. 59, $282-297$.

Böhringer, C., Rutherford, T.F., 2008. Combining bottom-up and top-down. Energy Econ. 30, 574-596.

Börjeson, L., Höjer, M., Dreborg, K.-H., Ekvall, T., Finnveden, G., 2006. Scenario types and techniques: Towards a user's guide. Futures 38, 723-739.

Brunner, P.H., Rechberger, H., 2016. Practical Handbook of Material Flow Analysis. 2nd edition. CRC Press.

Cao, Z., Liu, G., Zhong, S., Dai, H., Pauliuk, S., 2018. Integrating Dynamic Material Flow Analysis and Computable General Equilibrium Models for Both Mass and Monetary Balances in Prospective Modeling : A Case for the Chinese Building Sector. Environ. Sci. Technol. 53, 224-233.

Cooper, S.J.G., Giesekam, J., Hammond, G.P., Norman, J.B., Owen, A., Rogers, J.G., Scott, K., 2017. Thermodynamic insights and assessment of the "circular economy." J. Clean. Prod. 162, 1356-1367.

Deetman, S., Marinova, S., Voet, E. Van Der, Vuuren, D.P. Van, Edelenbosch, O., Heijungs, R., 2019. Modelling global material stocks and flows for residential and service sector buildings towards 2050. J. Clean. Prod. 118658.

Deetman, S., Pauliuk, S., Van Vuuren, D.P., Van Der Voet, E., Tukker, A., 2018. Scenarios for Demand Growth of Metals in Electricity Generation Technologies, Cars, and Electronic Appliances. Environ. Sci. Technol. 52.

Elshkaki, A., Graedel, T.E., 2013. Dynamic analysis of the global metals flows and stocks in electricity generation technologies. J. Clean. Prod. 59, 260-273.

Elshkaki, A., Graedel, T.E., Ciacci, L., Reck, B.K., 2016. Copper demand, supply, and associated energy use to 2050. Glob. Environ. Chang. 39, 305-315.

Elshkaki, A., Graedel, T.E., Ciacci, L., Reck, B.K., 2018. Resource Demand Scenarios for the Major Metals. Environ. Sci. Technol.

Enkvist, P.-A., Klevnäs, P., 2018. The Circular Economy a Powerful Force for Climate Mitigation Transformative - innovation for prosperous and low-carbon industry. Stockholm.

Fischer-Kowalski, M., Weisz, H., 1999. Society as Hybrid between Material and Symbolic Realms: Toward a Theoretical Framework of Society-Nature Interaction. Adv. Hum. Ecol. 8, 215-251.

Gaustad, G., Olivetti, E., Kirchain, R., 2011. Toward Sustainable Material Usage : Evaluating the Importance of Market Motivated Agency in Modeling Material Flows. Environ. Sci. Technol. 45, 4110-4117.

Gielen, D.J., 1999. Materialising dematerialisation. Integrated energy and materials systems engineering for greenhouse gas emission mitigation. TU Delft.

Gielen, D.J., Gerlagh, T., Bos, A.J.M., 1998. MATTER 1.0 - A MARKAL Energy and Materials System Model Characterisation. Petten, The Netherlands.

Glöser, S., Soulier, M., Tercero Espinoza, L. a, 2013. Dynamic analysis of global copper flows. Global stocks, postconsumer material flows, recycling indicators, and uncertainty evaluation. Environ. Sci. Technol. 47, 6564-72.

Groenendaal, B.J., Gielen, D.J., 1999. The future of the petrochemical industry: A MARKAL-MATTER analysis. ECN, Energy Research Centre of the Netherlands, Petten, The Netherlands.

Grubler, A., Wilson, C., Bento, N., Boza-Kiss, B., Krey, V., McCollum, D.L., Rao, N.D., Riahi, K., Rogelj, J., De Stercke, S., Cullen, J., Frank, S., Fricko, O., Guo, F., Gidden, M., Havlík, P., Huppmann, D., Kiesewetter, G., Rafaj, P., Schoepp, W., Valin, $\mathrm{H}$., 2018. A low energy demand scenario for meeting the $1.5^{\circ} \mathrm{C}$ target and sustainable development goals without negative emission technologies. Nat. Energy 3, 515-527.

Guest, G., Cherubini, F., Strømman, A.H., 2013. Global Warming Potential of Carbon Dioxide Emissions from Biomass Stored in the Anthroposphere and Used for Bioenergy at End of Life. J. Ind. Ecol. 17, 20-30.

Gutowski, T.G., Branham, M.S., Dahmus, J.B., Jones, A.J., Thiriez, A., Sekulic, D.P., 2009. Thermodynamic Analysis of Resources Used in Manufacturing Processes. Environ. Sci. Technol. 43, 1584-1590.

Haberl, H., Wiedenhofer, D., Erb, K.H., Görg, C., Krausmann, F., 2017. The material stock-flow-service nexus: A new approach for tackling the decoupling conundrum. Sustain. 9.

Hatayama, H., Daigo, I., Matsuno, Y., Adachi, Y., 2010. Outlook of the world steel cycle based on the stock and flow dynamics. Environ. Sci. Technol. 44, 6457-63.

Hatfield-Dodds, S., Obersteiner, M., Schandl, H., 2017a. UNEP-IRP (International Resource Panel): Terms of Reference. Developing and demonstrating scenario modelling of integrated resource management. International Resource Panel.

Hatfield-Dodds, S., Schandl, H., Adams, P.D., Baynes, T.M., Brinsmead, T.S., Bryan, B. a, Chiew, F.H.S., Graham, P.W., Grundy, M., Harwood, T., McCallum, R., McCrea, R., McKellar, L.E., Newth, D., Nolan, M., Prosser, I., Wonhas, A., 2015. Australia is 'free to choose' economic growth and falling environmental pressures. Nature 527, 49-53.

Hatfield-Dodds, S., Schandl, H., Newth, D., Obersteiner, M., Cai, Y., Baynes, T., West, J., Havlik, P., 2017b. Assessing global resource use and greenhouse emissions to 2050 , with ambitious resource efficiency and climate mitigation policies. J. 
Clean. Prod. 144, 403-414.

Hawkins, T.R., Singh, B., Majeau-Bettez, G., Strømman, A.H., 2013. Comparative Environmental Life Cycle Assessment of Conventional and Electric Vehicles. J. Ind. Ecol. 17, 53-64.

Heeren, N., Fishman, T., Tu, Q., Wolfram, P., Berrill, P., Pauliuk, S., Hertwich, E.G., 2019. Annex C of the UN-IRP report "Resource Efficiency and Climate Change - Material Efficiency Strategies for a Low-Carbon Future" Supplementary material for the in-depth industrial ecology assessment. Nairobi, Kenya.

Hertwich, E.G., 2005. Consumption and the Rebound Effect: An Industrial Ecology Perspective. J. Ind. Ecol. 9, 85-98.

Hertwich, E.G., Ali, S., Ciacci, L., Fishman, T., Heeren, N., Masanet, E., 2019. Material efficiency strategies to reducing greenhouse gas emissions associated with buildings, vehicles, and electronics-a review. Environ. Res. Lett. 14, 043004.

Hertwich, E.G., Ali, S., Heeren, N., Pauliuk, S., 2017. Resource Efficiency For Greenhouse Gas Abatement: A Request from the Group of 7. --, New Haven, CT.

Hertwich, E.G., Gibon, T., Bouman, E.A., Arvesen, A., Suh, S., Heath, G. a., Bergesen, J.D., Ramirez, A., Vega, M.I., Shi, L., 2015a. Integrated life-cycle assessment of electricity-supply scenarios confirms global environmental benefit of lowcarbon technologies. Proc. Natl. Acad. Sci. 112, 6277-6282.

Hertwich, E.G., Gibon, T., Bouman, E.A., Arvesen, A., Suh, S., Heath, G.A., Bergesen, J.D., Ramirez, A., Vega, M.I., Shi, L., 2015b. Integrated life-cycle assessment of electricity-supply scenarios confirms global environmental benefit of lowcarbon technologies. Proc. Natl. Acad. Sci. 112, 6277-6282.

IEA, 2015a. Energy Technology Perspectives. International Energy Agency, Paris, France.

IEA, 2015b. World Energy Outlook 2015. Paris.

Kalt, G., Wiedenhofer, D., Görg, C., Haberl, H., 2019. Energy Research \& Social Science Conceptualizing energy services : A review of energy and well-being along the Energy Service Cascade. Energy Res. Soc. Sci. 53, 47-58.

KC, S., Lutz, W., 2014. The human core of the shared socioeconomic pathways: Population scenarios by age, sex and level of education for all countries to 2100. Glob. Environ. Chang. 42, 181-192.

Kim, H.C., Wallington, T.J., 2013. Life-cycle energy and greenhouse gas emission benefits of lightweighting in automobiles: review and harmonization. Environ. Sci. Technol. 47, 6089-97.

Kondo, Y., Nakamura, S., 2005. Waste input-output linear programming model with its application to eco-efficiency analysis. Econ. Syst. Res. 17, 393-408.

Kram, T., Gielen, D.J., Bos, A.J.M., de Feber, M.A.P.C., Groenendaal, B.J., Moll, H.C., Bouwman, M.E., Daniels, D.W., Worrell, E., 2001. The MATTER project: Integrated energy and materials systems engineering for GHG emission mitigation. ECN, Energy Research Centre of the Netherlands, Petten, The Netherlands.

Laner, D., Rechberger, H., Astrup, T., 2014. Systematic Evaluation of Uncertainty in Material Flow Analysis. J. Ind. Ecol. 00, n/a-n/a.

Lennox, J.A., Turner, G., Hoffman, R., Mcinnis, B., 2005. Modeling Basic Industries in the Australian Stocks and Flows Framework. J. Ind. Ecol. 8, 101-120.

Levasseur, A., Lesage, P., Margni, M., Deschenes, L., Samson, R., 2010. Considering Time in LCA : Dynamic LCA and Its Application to Global Warming Impact Assessments. Environ. Sci. Technol. 44, 3169-3174.

Levasseur, A., Lesage, P., Margni, M., Samson, R., 2013. Biogenic Carbon and Temporary Storage Addressed with Dynamic Life Cycle Assessment. J. Ind. Ecol. 17, 117-128.

Liu, G., Bangs, C.E., Müller, D.B., 2012. Stock dynamics and emission pathways of the global aluminium cycle. Nat. Clim. Chang. 2, 338-342.

Liu, J., Mooney, H., Hull, V., Davis, S.J., Gaskell, J., Hertel, T., Lubchenco, J., Seto, K.C., Gleick, P., Kremen, C., Li, S., 2015. Systems integration for global sustainability. Science (80-. ). 347, 12588321-12588329.

Løvik, A.N., Modaresi, R., Müller, D.B., 2014. Long-Term Strategies for Increased Recycling of Automotive Aluminum and Its Alloying Elements. Environ. Sci. Technol. 48, 4257-4265.

Marcellus-Zamora, K.A., Gallagher, P.M., Spatari, S., Tanikawa, H., 2016. Estimating Materials Stocked by Land-Use Type in Historic Urban Buildings Using Spatio-Temporal Analytical Tools. J. Ind. Ecol. 20, 1025-1037.

McCarthy, A., Dellink, R., Bibas, R., 2018. The Macroeconomics of the Circular Economy Transition: A Critical Review of Modelling Approaches OECD Environment Working Papers, No. 130. Paris, France.

Milford, R.L., Pauliuk, S., Allwood, J.M., Müller, D.B., 2013. The Roles of Energy and Material Efficiency in Meeting Steel Industry CO2 Targets. Environ. Sci. Technol. 47, 3455-3462.

Modaresi, R., Pauliuk, S., Løvik, A.N., Müller, D.B., 2014. Global carbon benefits of material substitution in passenger cars until 2050 and the impact on the steel and aluminum industries. Environ. Sci. Technol. 48, 10776-10784.

Mudd, G.M., Jowitt, S., Weng, Z., 2013. A detailed assessment of global Cu reserveand resource trends and worldwide Cu endowments. Econ. Geol. 108, 1163-1183.

Müller, D.B., 2006. Stock dynamics for forecasting material flows - Case study for housing in The Netherlands. Ecol. Econ. 59, 142-156.

Nakamura, S., Kondo, Y., Nakajima, K., Ohno, H., Pauliuk, S., 2017. MaTrace-alloy : tracing the fate of Cr and Ni in steel preliminary draft for internal discussion 1-28.

Norgate, T.E., Haque, N., 2010. Energy and greenhouse gas impacts of mining and mineral processing operations. J. Clean. Prod. 18, 266-274.

Northey, S.A., Mohr, S., Mudd, G.M., Weng, Z., Giurco, D., 2014a. Modelling future copper ore grade decline based on a detailed assessment of copper resources and mining. Resour. Conserv. Recycl. 83, 190-201.

Northey, S.A., Mohr, S., Mudd, G.M., Weng, Z., Giurco, D., 2014b. Modelling future copper ore grade decline based on a detailed assessment of copper resources and mining. Resour. Conserv. Recycl. 83, 190-201. 
Northey, S.A., Mudd, G.M., Werner, T.T., Jowitt, S.M., Haque, N., Yellishetty, M., Weng, Z., 2017. The exposure of global base metal resources to water criticality, scarcity and climate change. Glob. Environ. Chang. 44, 109-124.

O’Neill, B.C., Kriegler, E., Riahi, K., Ebi, K.L., Hallegatte, S., Carter, T.R., Mathur, R., van Vuuren, D.P., 2014. A new scenario framework for climate change research: the concept of shared socioeconomic pathways. Clim. Change 122, 387-400.

OECD/IEA, 2010a. Energy Technology Perspectives 2010. IEA, Paris, France.

OECD/IEA, 2010b. Energy Technology Perspectives : Scenarios and Strategies to 2050. Paris, France.

OECD/IEA, 2017. Energy Technology Perspectives. Paris, France.

OECD, 2019. Global Material Resources Outlook to 2060 - Economic drivers and environmental consequences. Paris, France.

Pauliuk, S., Arvesen, A., Stadler, K., Hertwich, E.G., 2017a. Industrial ecology in integrated assessment models. Nat. Clim. Chang. 7, 13-20.

Pauliuk, S., Heeren, N., 2019. ODYM - An Open Software Framework for Studying Dynamic Material Systems - Principles, Implementation, and Data Structures. J. Ind. Ecol. in press.

Pauliuk, S., Heeren, N., Hasan, M.M., Müller, D.B., 2019. A general data model for socioeconomic metabolism and its implementation in an industrial ecology data commons prototype. J. Ind. Ecol. 23, 1016-1027.

Pauliuk, S., Hertwich, E.G., 2016. Prospective models of society's future metabolism - What industrial ecology has to contribute, in: Clift, R., Duckmann, A. (Eds.), Taking Stock of Industrial Ecology. Springer, Netherlands., Dordrecht, The Netherlands., pp. 21-43.

Pauliuk, S., Kondo, Y., Nakamura, S., Nakajima, K., 2017b. Regional distribution and losses of end-of-life steel throughout multiple product life cycles-Insights from the global multiregional MaTrace model. Resour. Conserv. Recycl. 116, 84-93.

Pauliuk, S., Milford, R.L., Müller, D.B., Allwood, J.M., 2013. The Steel Scrap Age. Environ. Sci. Technol. 47, 3448-3454.

Pehl, M., Arvesen, A., Humpenöder, F., Popp, A., Hertwich, E.G., Luderer, G., 2017. Understanding future emissions from low-carbon power systems by integration of life-cycle assessment and integrated energy modelling. Nat. Energy 2 , 939-945.

Reck, B.K., Graedel, T.E., 2012. Challenges in metal recycling. Science 337, 690-5.

Reyna, J.L., Chester, M. V., 2014. The Growth of Urban Building Stock. J. Ind. Ecol. 00, n/a-n/a.

Riahi, K., van Vuuren, D.P., Kriegler, E., Edmonds, J., O’Neill, B., Fujimori, S., Bauer, N., Calvin, K., Dellink, R., Fricko, O., Lutz, W., Popp, A., Crespo Cuaresma, J., Samir, K., Leimback, M., Jiang, L., Kram, T., Rao, S., Emmerling, J., Ebi, K., Hasegawa, T., Havlik, P., Humpenöder, F., Da Silva, L.A., Smith, S., Stehfest, E., Bosetti, V., Eom, J., Gernaat, D., Masui, T., Rogelj, J., Strefler, J., Drouet, L., Krey, V., Luderer, G., Harmsen, M., Takahashi, K., Baumstark, L., Doelman, J., Kainuma, M., Klimont, Z., Marangoni, G., Lotze-Campen, H., Obersteiner, M., Tabeau, A., Tavoni, M., 2017a. The shared socioeconomic pathways and their energy, land use, and greenhouse gas emissions implications: An overview. Glob. Environ. Chang. in press.

Riahi, K., Vuuren, D.P. Van, Kriegler, E., Edmonds, J., Neill, B.C.O., Fujimori, S., Bauer, N., Calvin, K., Dellink, R., Fricko, O., Lutz, W., Popp, A., Crespo, J., Kc, S., Leimbach, M., Jiang, L., Kram, T., Rao, S., Emmerling, J., Ebi, K., Hasegawa, T., Havlik, P., Humpenöder, F., Aleluia, L., Silva, D., Smith, S., Stehfest, E., Bosetti, V., Eom, J., Gernaat, D., Masui, T., Rogelj, J., Stre, J., Drouet, L., Krey, V., Luderer, G., Harmsen, M., Takahashi, K., Baumstark, L., Doelman, J.C., Kainuma, M., Klimont, Z., Marangoni, G., Lotze-campen, H., Obersteiner, M., Tabeau, A., Tavoni, M., 2017b. The Shared Socioeconomic Pathways and their energy, land use, and greenhouse gas emissions implications : An overview. Glob. Environ. Chang. 42, 153-168.

Schandl, H., Hatfield-Dodds, S., Wiedmann, T.O., Geschke, A., Cai, Y., West, J., Newth, D., Baynes, T., Lenzen, M., Owen, A., 2016. Decoupling global environmental pressure and economic growth: scenarios for energy use, materials use and carbon emissions. J. Clean. Prod. 132, 45-56.

Schipper, B.W., Lin, H., Meloni, M.A., Wansleeben, K., Heijungs, R., Voet, E. Van Der, 2018. Resources , Conservation \& Recycling Estimating global copper demand until 2100 with regression and stock dynamics. Resour. Conserv. Recycl. $132,28-36$

Schumacher, K., Sands, R.D., 2006. Where Are the Industrial Technologies in Energy-Economy Models ? - An Innovative CGE Approach for Steel Production in Germany. DIW Discussion paper 605. Berlin.

Shanks, W., Dunant, C.F., Drewniok, M.P., Lupton, R.C., Serrenho, A., Allwood, J.M., 2019. Resources, Conservation \& Recycling How much cement can we do without ? Lessons from cement material fl ows in the UK 141, 441-454.

Stehfest, E., van Vuuren, D.P., Kram, T., Bouwman, L., Alkemade, R., Bakkenes, M., Biemans, H., Bouwman, A., den Elzen, M., Janse, J., Lucas, P., van Minnen, J., Müller, C., Prins, A., 2014. Integrated Assessment of Global Environmental Change with IMAGE 3.0 - Model description and policy applications.

UNEP-IRP, 2019. Global Resources Outlook 2019: Natural Resources for the Future We Want. Nairobi, Kenya.

van der Voet, E., Kleijn, R., Huele, R., Ishikawa, M., Verkuijlen, E., 2002. Predicting future emissions based on characteristics of stocks. Ecol. Econ. 41, 223-234.

van der Voet, E., van Oers, L., Verboon, M., Kuipers, K., 2018. Environmental Implications of Future Demand Scenarios for Metals Methodology and Application to the Case of Seven Major Metals. J. Ind. Ecol. 00.

van Ruijven, B.J., van Vuuren, D.P., Boskaljon, W., Neelis, M.L., Saygin, D., Patel, M.K., 2016. Long-term model-based projections of energy use and $\mathrm{CO} 2$ emissions from the global steel and cement industries. Resour. Conserv. Recycl. $112,15-36$.

van Vuuren, D.P., Riahi, K., Calvin, K., Dellink, R., Emmerling, J., Fujimori, S., KC, S., Kriegler, E., O’Neill, B.C., 2017. The Shared Socio-economic Pathways: Trajectories for human development and global environmental change. Glob. Environ. Chang. 42, 148-152. 
Watari, T., Mclellan, B.C., Giurco, D., Dominish, E., Yamasue, E., Nansai, K., 2019. Resources, Conservation \& Recycling Total material requirement for the global energy transition to 2050 : A focus on transport and electricity. Resour. Conserv. Recycl. 148, 91-103.

Wernet, G., Bauer, C., Steubing, B., Reinhard, J., Moreno-Ruiz, E., Weidema, B., 2016. The ecoinvent database version 3 (part I): overview and methodology. Int. J. Life Cycle Assess. 21, 1218-1230.

Winning, M., Calzadilla, A., Bleischwitz, R., Nechifor, V., 2017. Towards a circular economy : insights based on the development of the global ENGAGE-materials model and evidence for the iron and steel industry. Int Econ Econ Policy.

Wolfram, P., Tu, Q., Hertwich, E.G., Pauliuk, S., 2019. Documentation of the transport-sector model v1.0 within the RECC model framework. New Haven.

Worrell, E., Allwood, J.M., Gutowski, T., 2016. The Role of Material Efficiency in Environmental Stewardship. Annu. Rev. Environ. Resour. 41, 575-598.

Wu, J., Wang, R., Pu, G., Qi, H., 2016. Integrated assessment of exergy, energy and carbon dioxide emissions in an iron and steel industrial network. Appl. Energy 183, 430-444.

Zink, T., Geyer, R., 2017. Circular Economy Rebound. J. Ind. Ecol. 21, 593-602. 